


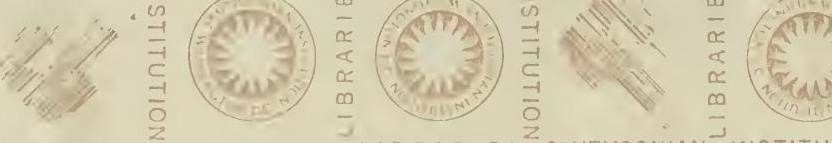

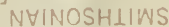
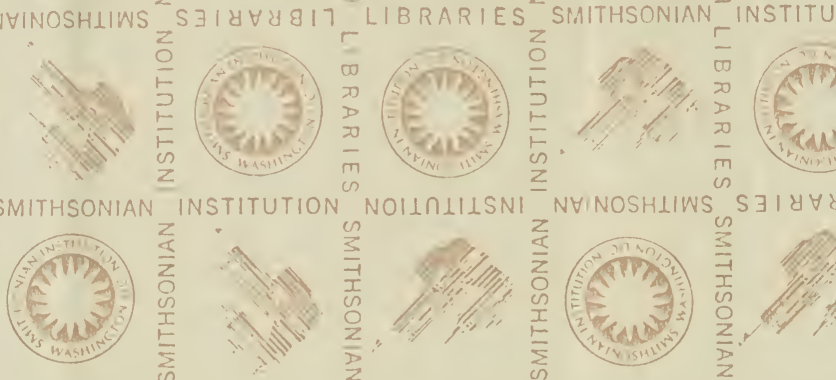

NVINOSHIIWS

S $\exists I \forall \forall<$
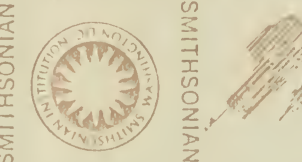

NYINOSHIIWS
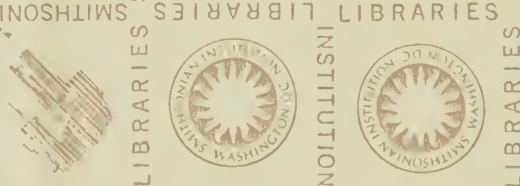

SMITHSONIAN

INSTITU

SMITHSONIAN INSTITUTION
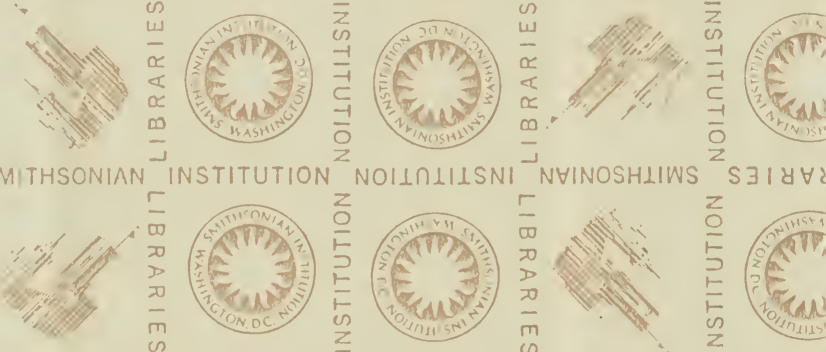

NHINOSH1IWS

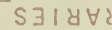

NVINOSHLIWS
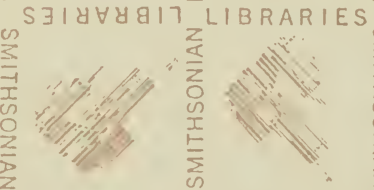

en
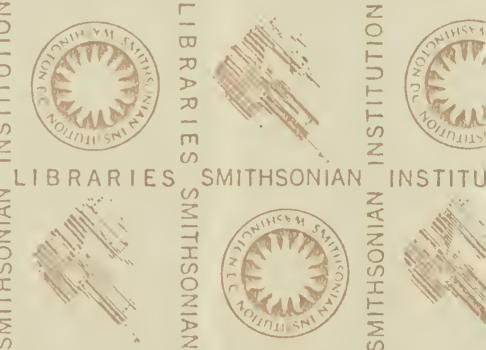

INSTITU

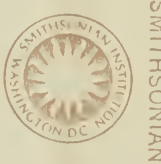

SMITHSONIAN
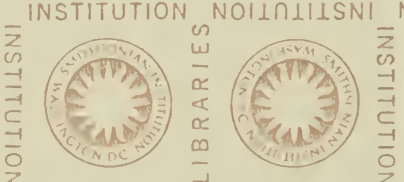

NHINOSHIIWS

S $\exists 18 \forall$

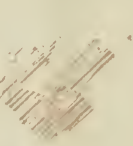

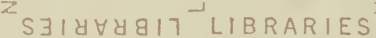
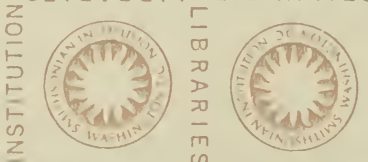

$z$
$\frac{1}{1}$
$\frac{1}{1}$
$\frac{1}{2}$
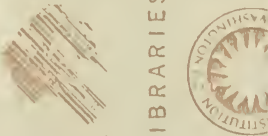

SMITHSONIAN

INSTITU
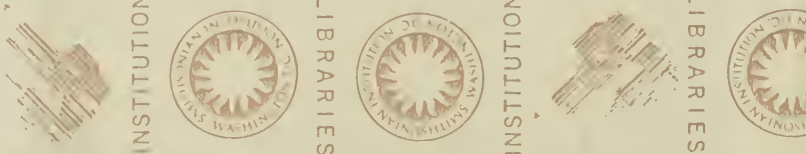

SMITHSONIAN INSTITUTION NOILOLIISNI

NYINOSHLIWS S $\exists I Y \forall$

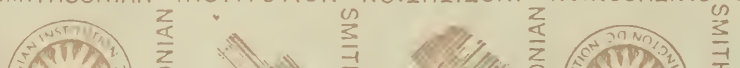






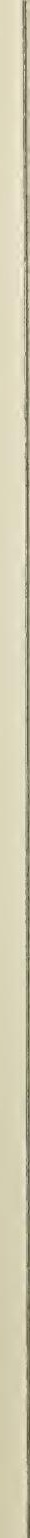




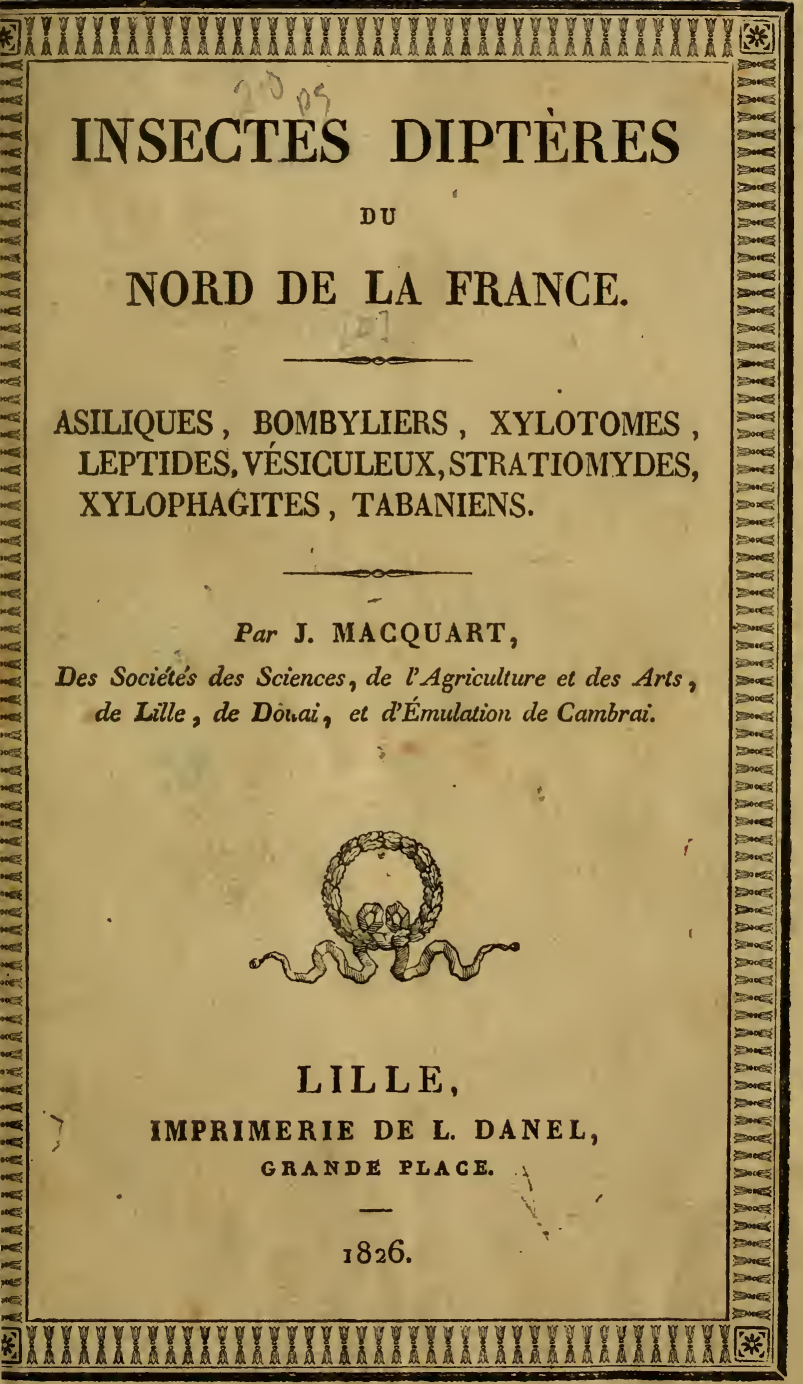




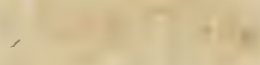

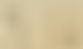

v.

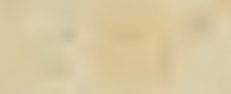

(1)

.

(1)

+

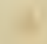

$\checkmark$

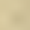

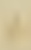

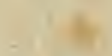




\section{INSECTES DIPTĖRES}

D U

\section{NORD DE LA FRANCE.}

ASILIQUES , BOMBYLIERS, XYLOTOMES , LEPTIDES, VÉSICULEUX,STRATIOMYDES, XYLOPHAGITES, TABANIENS. 


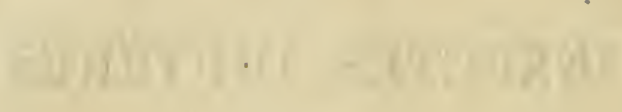

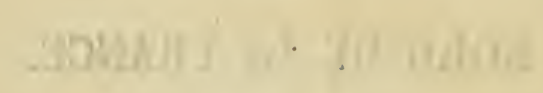

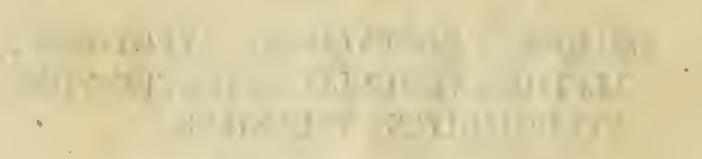




\section{INSECTES DIPTĖRES}

Do

\section{NORD DE LA FRANCE.}

ASILIQUES , BOMBYLIERS , XYLOTOMES , LEPTIDES, VÉSICULEUX, STRATIOMYDES, XYLOPHAGITES, TABANIENS.

\section{Par J. MACQUART,}

Des Sociétés des Sciences, de l'Agriculture et des Arts, de Lille, de Douai, et d'émulation de Cambrai.

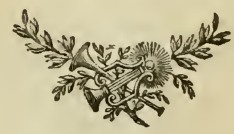

\section{I L L E,}

IMPRIMERIE DE L. DANEL,

GRANDE PLACE. 
Pothaty

Mหna

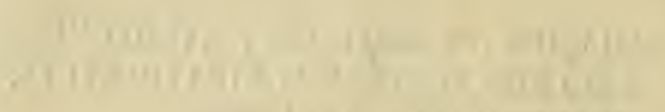

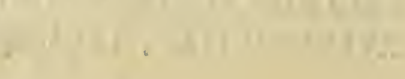

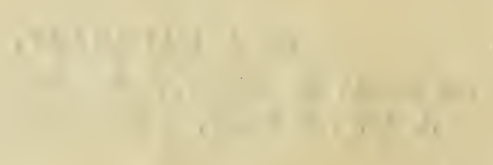




\section{N S E C T E S D I P T Ė R E S}

DU NORD DE LA FRANGE.

Asiliques,bombyliers, xylotomes, leptides, stratiomydes xylophagites et tabaniens.

Dans un premier essai sur les insectes diptères du nord de la France, nous avons décrit les Tipulaires, cette grande tribu qui offre les traits principaux de la race entière, mais dont l'éloignent des caractères secondaires fort importans, et une organisation généralement plus composée. Dans une première suite à ce travail, nous allons faire connaître les familles qui semblent se rapprocher des Tipulaires, soit par des rapports spéciaux dans quelques organes, soit par l'ensemble d'une organisation plus forte que dans le reste de l'ordre. En considérant les Diptères comme formant une seule série d'insectes dont lẹs organes sont plus ou moins composés, et qui se divisent en deux grandes sections; l'une caractérisée par des antennes de trois articles, l'autre à antennes multiarticulées; et en adoptant, comme plus philosophique, l'ordre ascendant, ainsi que nous l'avons fait pour les Tipulaires, ces dernières doivent être précédées immédiatement par les Diptères de l'autre section les plus fortement organisés; et par une cö̈ncidence remarquable, ces mêmes insectes offrent un caractère singulier qui lie les deux sections d'une manière plus sensible. Leurs antennes semblent 
composées de trois articles comme dans la première; mais le troisième, dont la forme est d'ailleurs fort ordinaire, est subdivisé en plusieurs segmens, de sorte que ces insectes appartiennent aux Diptères triarticulés par la figure de leurs antennes et aux multiarticulés ou Tipulaires par la composition de cet organe. Sous tous les autres rapports ils sont étroitement liés aux premiers.

Nous avons vu que la série formée par les Tipulaires, et considérée comme une simple famille, se divise en plusieurs sections. Cette série, à la vérité, est d'un ordre supérieur à une famille naturelle, et doit être regardée comme une des deux grandes divisions de l'ordre; cependant les sections dont elle est composée ne sont pas susceptibles d'être élevées au rang de familles; elles ont généralement trop de ressemblance entr'elles. Quant à la série dont nous allons nous occuper, elle se divise en familles très-distinctes et conformes aux principes de la classification naturelle. Ainsi que l'autre, elle offre divers degrés du simple au composé, depuis les Phthiromyies jusqu'aux Tabaniens.

ASILIQUES; Asilici, Latreille, Meigen.

Caractère essentiel : antennes de trois articles; troisième sans division. Hypostome à moustache. Front enfoncé. Trompe courte, horizontale. Ailes couchées sur le corps.

Corps allongé, étroit. Tête transversale, beaucoup plus large que longue, munie d'un cou, et séparée du thorax par un êtranglement considérable. Front ordinairement large dans les deux sexes, enfoncé supérieurement, muni d'une élévation sur le vertex portant les yeux lisses; hypostome large, couvert de petits poils soyeux, muni inférieurement d'une moustache ou touffe de longs poils dirigés en avant et placés sur une élévation. Dessous et 
côtés de la tête plus ou moins velus. Trompe coriacée, avancée horizontalement, ordinairement de la longueur de la tête, sans lèvres terminales distinctes; lèvre supérieure beaucoup plus courte que la trompe, obtuse ou tronquée; langue de la longueur de la trompe, aplatie, étroite, pointue, munie au-delà de la moitié de la longneur et du côté extérieur, de pointes tournées en dedans; deux soies (mâchoires) moins longues que la trompe, sétiformes, semi-tubuleuses, obliquement acuminées à l'extrémité. Palpes incérés à la base de la trompe, épais, courts, filiformes, velus, élevés, ordinairement de deux articles; le dernier plus alongé, arrondi à l'extrémité. Antennes très-rapprochées à la base, ordinairement de la longueur de la tête, de trois articles; le premier cylindrique; le deuxième ordinairement court; le troisième comprimé, ovalo-cylindrique ou ovalo-conique, ordinairement terminé par un style biarticulé. Yeux ovales, ordinairement verds (dans l'état de vie). Trois yeux lisses en triangle.

Thorax sans suture, grand, élevé, ovale; segment antérieur ( prothorax) bas, mais distinct; écusson petit. Abdomen long, subcylindrique, ou conique allongé, souvent terminé en pointe dans les femelles; organes sexuels des mâles souvent saillans. Pieds robustes, allongés, velus ou épineux; tarses ordinairement munis de deux ongles, de deux pelottes et d'une petite pointe intermédiaire. Balanciers découverts. Ailes couchées, horizontales; une cellule médiastine; point de stigmatique; une marginale ; deux sous-marginales; trois discoïdales ; cinq postérieures; une anale. ( $P l .1$, fig. $1-6$.)

Les Asiliques semblent au premier abord n'avoir rien qui les distingue bien nettement de beaucoup d'autres insectes diptères. On croirait qu'ils ne forment qu'une de ces 
familles artificielles, produit de l'art d'un ingénieux méthodiste, mais désavouées par la nature. Par la forme générale du corps, ils diffèrent peu des Leptides et des Xylotomes; ils ont la trompe effilée, les antennes des Bombyliers et des Empidies; les ailes réticulées comme celles des Rhagionides et des Tabaniens. Cependant, en les considérant avec quelqu'attention, on découvre un grand nombre de caractères qui leur sont propres, et l'on reste convaincu qu'ils forment une des familles les plus naturelles de leur ordre. La tête, qui est très-déprimée, a le vertex enfoncé, mais muni d'une élévation au haut de laquelle les trois yeux lisses se trouvent au niveau des yeux à facettes. Une autre saillie au bas du front porte une espèce de moustache en demi-cercle de poils longs, roides, dirigés en avant et courbés en bas, qui protègent la bouche. Celle-ci est caractérisée par une trompe dénuée de lèvres terminales, par une lèvre supérieure fort courte, obtuse ou tronquée, et par une langue garnie dans sa partie postérieure de petites pointes tournées en dedans. Enfin les pieds se distinguent par les poils et les épines dont ils sont plus ou moins couverts, et les tarses, par une petite pointe située entre les ongles.

Quoique la famille des Asiliques soit fort nombreuse, l'organisation de ces insectes est peu diversifiée, et ils ne forment que cinq genres établis par M. Latreille, et dont les caractères n'offrent pas même beaucoup d'imporlance. Les différences que présentent les parties de la bouche, consistent principalement dans la forme tantôt obtuse, tantôt tronquée de la lèvre supérieure. Les palpes, ordinairement de deux articles, semblent n'en avoir qu'un dans le genre Leptogastre. Les antennes, toujours l'organe le plus riche en modifications, varient particulièrement quant an style qui les termine. Ce singulier 


\section{(7)}

appendice, dont la destination paraît être de suppléer à la briéveté des antennes dans les insectes où il est le plus simple, comme dans les Diptères triarticulés et les Cicadaires, prend souvent dans les Asiliques l'apparence d'un article terminal, et semble devenir une première transition vers les Diptères dont les antennes ont un plus grand nombre d'articles. Il a encore la forme d'une soie allongée dans le genre Asile; il est conique dans les Dasypogons; cylindrique et velu dans les Leptogastres; court et obtus dans les Dioctries; il manque entièrement dans les Laphries. Les pieds des Asiliques sont modifiés en ce que les tarses sont dénués de pelottes dans les leptogastres, et que les jambes sont arquées dans les laphries. Les nervures des ailes enfin ont tantôt la quatrième cellule du bord postérieur ouverte, et tantôt fermée et plus ou moins pétiolée. En considérant les différens degrés d'organisation des Diptères, on reconnaît que dans la progression ascendante, les Asiliques offrent les premiers cinq cellules du bord postérieur par la subdivision de la quatrième, et ce nombre se soutient, excepté dans les Bombyliers, jusqu'aux Tipulaires qui forment une nouvelle série parcourant les mêmes degrés.

Les modifications spécifiques, très-nombreuses en les comparant aux génériques, sont en même temps trèslégères. Il n'a fallu rien moins que le génie éminemment germanique de M. Meigen, secondé par les Wiedemann, les Megerle, les Hoffmansegg, les Baumhauer, pour reconnaître en Europe plus de cent soixante espèces qui offrent tant d'uniformité dans la conformation, et dont les différences ne consistent très-souvent que dans la disposition de bandes ordinairenent peu distinctes sur le thorax et l'abdomen, et dans les couleurs du front et des pieds. 
Les Asiliques vivent de la chasse qu'ils font aux autres insectes, et il n'y a pas de familles de Diptères où l'appétit carnassier soit aussi général. Ils s'élancent sur leur proie en volant avec rapidité, et ils la saisissent avec leurs pieds antérieurs, comme les Empidies. Ils peuvent encore la retenir, lorsqu'ils ont enfoncé leur trompe dans, le corps de leur victime, par l'effet des pointes tournées en dedans dont leur langue est armée. Les grandes espèces ont un autre moyen de subsistance : ils se jettent, comme Jes taons, sur les bestiaux, les tourmentent, et se repaissent de sang, ce qui leur a valu l'honneur d'être nonımés par Virgile (1).

Nous devons à Degeer la seule découverte qui ait été faite sur le premier état des Asiliques. Elle ne concerne qu'une seule espèce, l'Asile cendré de ce célèbre observateur, Asilus forcipatus de M. Meigen. La Larve vit dans la terre; elle est sans pieds, à tête cornée, allongée, cylindrique, légèrement déprimée, glabre; la tête, un peu velue, est armée de deux crochcts. Les premier et pénultième segmens du corps offrent chacun deux stigmates dont les postérieurs sont tubuleux. M. Duméril dit qu'elle se nourrit d'insectes comme dans l'état adulte. La Nymphe, qui ne change pas d'habitation, quitte entièrement l'enveloppe de larve, sans se construire dẹ coque. Elle est glabre, cylindrique dans sa partie antérieure, conique postérieurement. La tête est munie en avant d'une pointe bifide, et de chaque côté en-dessous, d'une pointe trifide. Le thorax porte de chaque côté, vers la tête, un tubercule qui paraît terminé par un

(1) Est lucos silari circa illicibusque virentem

Plurimus Alburnum volitans, cni nomen asilo

Homanum est, æstron Graii vertère rocantes. (Georg.) 
stigmate. L'abdomen a le bord des segmens muni de spinules, et l'extrémité est armée de quatre pointes.

Les Asiliques sous ces deux formes diffèrent peu des autres Diptères qui se développent dans la terre, excepté des Syrphies et des Muscides dont les larves ont la tête membraneuse, et les Nymphes le corps enfermé dans'une coque. La dernière transformation s'opère à la surface de la terre où la Nymphe parvient par les contractions de son corps, et au moyen des pointes dont il est pourvu.

Cette famille de Diptères est peu considérable dans cette partie de la France, et généralement dans le nord de, l'Europe. Le genre Dioctrie est le seul qui appartienne à peu près exclusivement aux pays septentrionaux. Le genre Asyle se partage entre le nord et le midi; les autres préfêrent les climats méridionaux, et nous en voyons fort peu. Les Asiliques ne fréquentent guères qu'une partie de notre territoire. lls sont fort rares, par exemple, dans la forêt de Nieppe et dans tous les cantons dont la terre est humide ou d'une argile compacte. Leur existence souterraine dans l'état de larves leur fait sans doute préférer un sol facile à pénétrer. Nous ne les voyons donc fréquemment que dans les bois sablonneux et secs, et dans les fortifications de nos villes de guerre. Les diverses espèces se trouvent dans les mêmes lieux.

Tableau synoptique des genres.

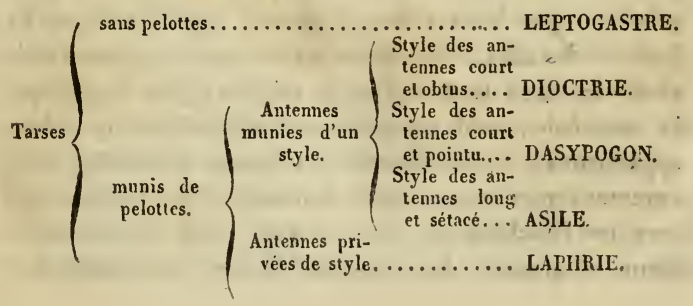


I. Pieds sans peloties.

\section{LEPTOGASTRE; LEPTOGASTER.}

Leptogaster, Meigen. Gonypes, Latreille. Dasypogon, Fabricius, systema antliatorum. Asilus, Fab., entomologia systematica, Degeer, Geoffroy, Fallèn, Schellenberg, Sch ranck.

Corps fort allongé. Tête hémisphérique, déprimée. Front étroit dans les mâles; hypostome à élévation peu saillante; moustache légère. Dessous et côtés de la tête presque nus. Trompe obtuse, légèrement renflée vers le milieu; lévre supérieure légèrement arquée et terminée en pointe mousse. Palpes en massue, garnis de quelques poils à l'extrémité, d'un seul article distinct. Antennes aux deux premiers articles courts, presque cylindriques; le troisième ovale, allongé, pointu, cornprimé; style allongé, velu (au microscope).

Abdomen long, menu. Pieds peu velus, sans pelottes; cuisses et jambes postérieures allongées. Ailes courtes; bord postérieur frangé; deuxième cellule sous-marginale allongce et droite; deuxième postérieure plus longue que la troisième; quatrième très-ouverte à l'extrémité ; anale entr'ouverte. ( $\mathbf{P l}$. I, fig. 1.)

Les Leptogastres sont les asiliques les plus faciles à distinguer des autres par les caractères qui leur sont propres. Ils s'écartent de tous par leurs tarses sans pelottes, par leurs palpes d'un seul article distinct. La briéveté des ailes, la deuxième cellule sous-marginale droite et allongée; et la deuxième postérieure plus longue que la troisième, sont encore des modifications qui leur appartiennent exclusivement. D'autres caractères leur sont communs avec une partie de la famille et particulièrement avec les Dioctries. Ils ont, comme ceux-ci, l'abdomen menu et alongé, la moustache légèrc, les pieds peu 


\section{(II)}

velus, les ailes à la quatrième cellule du bord postérieur ouverte.

M. Meigen ne décrit que trois Leptogastres, dont deux se trouvent dans ce pays. J'y joins une nouvelle espèce que j'ai observée dans les bois. Ils sont tous trois assez rares. Le nom de ces insectes rappelle la forme menue de leur abdomen.

1. Leptogastre cylindrique; L. cylindricus, Meig.

Grisâtre. Abdomen à bande obscure. Ailes plus courtes que l'abdomen.

Gonypes cylindricus, Lat. gen. crust. et ins., t. 4, p. 3ог. Dasypogon tipuloides, Fab. Syst. Antl. 172,37 . Asibus tipuloides, Fab. Ent. Syst. 385.

- 13, 1, Fallen, Dipt. Suec.

- cylindricus, Deg. 6, 99, 10.

Asile à pattes fauves allongées, Geoff. 2, 474, 17.

Schellenberg. g. de m. Tab. 3o, f. I.

Schranck, Faun. Boic. 3, 2556.

Long. $4-6.1$.

Trompe et yeux noirs. Front et hypostome jaunes; moustache blanchâtre. Deuxième article des antennes roux; les autres noirs. Thorax d'un gris roussâtre mat ; trois bandes obscures dont l'intermédiaire est divisée par une ligne. Abdomen cendré à bande dorsale noirâtre; une ligne transversale de puints enfoncés, vers la base de chaque segment; dernier segment muni de pinces épaisses dans les mâles, tronqué obliquement dans les femelles. Pieds antérieurs et intermédiaires jaunes; cuisses et jambes intermédiaires et jambes antérieures marquées d'une ligne longitudinale noire dı côté antérieur ; tarses noirs, à l'exception de la base du premier article; cuisses postérieures en massue, jaunes et marquées d'une bande noire longitudinale du côté intérieur, moins marquées à l'exté- 


\section{(12)}

rieur ; jambes renflées vers l'extrémité, jaunes à extrémité noire; tarses noirs à premier article jaune. Ailes hyalines. ( $\mathrm{Pl} .1$, fig. 1.)

Très-commun dans quelques prairies basses, au mois de juin.

2. Leptogastre obscur ; L. fuscus, Meig.

Cendré. Abdomen obscur. Ailes de la longueur de l'abdomen.

\section{Long. 41.}

L'abdomen entièrement obscur et la longueur des ailes sont les seules différences qui distinguent cette espèce de la précédente.

3. Leptogastre luisant; L. Nitidus, Nob.

D'un noir luisant. Segmens de l'abdomen à bord postérieur fauve.

\section{Long $4 \div 1$.}

D'un noir luisant. Hypostome, trompe, antennes et yeux noirs; moustache d'un blanc jaunâtre. Thorax et abdomen d'un noir fort luisant; bord postérieur des segmens de l'abdomen fauve; bord antérieur des troisième, quatrième, cinquième et sixième segmens marqué d'une tache fauve de chaque côté. Pieds jaunes; tarses antérieurs et intermédiaires à premier et second articles jaunes, terminés de noir ; cuisses et jambes postérieures marquées d'une ligne longitudinale noire; jambes terminées de noir ; tarses à premier article jaune. Ailes de la longueur de l'abdomen qui est moins long que dans les espèces précédentes.

Je ne l'ai trouvé qu'une fois, à Lestrem.

II. Pieds munis de deux pelottes. DIOCTRIE, Dioctria.

Dioctria, Meig. , Illiger , Lat. , Fab. Syst. antl. Fallèn. - Asilus, Linn., Gmelin , Geoff., Schr., 
Deg., Oliv., Vill., Ross., Walckenaer, Herbst, Fab.

Ent. syst.

Tête fort déprimée. Hypostome à élévation presque nulle; moustache légère. Trompe à pointe mousse et munie à l'extrémité supérieure d'une touffe de poils jaunes. Lèvre supérieure très-courte et conique. Soies presqu'aussi longues que la trompe; palpes cylindriques, velus; les deux articles peu distincts l'un de l'autre, Antennes plus longues que la tête, insérées sur une élévation; premier article allongé, velu en dessous; deuxième assez court, plus menu à sa base, presque nu ; troisième long, comprimé, nu, terminé par deux petits articles obtus.

Thorax presque nu, souvent marqué de bandes sur le dos, et de raies argentées ou dorées sur les côtés. Abdomen nu, presque cylindrique; premier segment un peu plus large et plus élevé que les autres. Pieds peu velus; cuisses et jambes postérieures légèrement frangées du côté antérieur; tarses postérieurs plus ou moins ŕenflés. Ailes grandes; deuxième cellule postérieure à base ordinairement assez large; quatrième terminale et imparfaite ; anale presque fermée. ( $P l$. I, $f g .2,3$.)

Il me semble que M. Meigen a méconnu les rapports que présente l'organisation des Dioctries avec celle des Leptogastres, en plaçant ces genres aux deux extrémités de la famille. Nous croyons, en les rapprochant, rétablir l'ordre naturel et former une série graduelle entre tous les Asiliques. En effet, les Dioctries lient parfaitement le genre précédent avec les suivans, et l'on s'aperçoit qu'elles ont les traits caractéristiques de la famille encore peu prononcés. Elles tiennent aux Leptogastres par l'abdomen allongé, la moustache légère, les pieds peu velus et les ailes à quatrième cellule du bord postérieur 


\section{(14)}

ouverte. Par le reste de l'organisation, elles avoisinent particulièrement les Dasypogons. Cependant les antennes offrent une conformation qui n'appartient qu'à elles. Outre qu'elles sont plus longues que dans les autres genres, et insérées sur un tubeŕcule plus saillant, le style paraît sous la forme de deux petits articles obtus. Vus au microscope, ce style et le troisième article sont couverts de petits poils fort serrés. Les pieds se distinguent aussi en ce que les postérieurs sont velus du côté antérieur seulement.

Quoique le genre Dioctrie soit nombreux, il se modifie peu sous le rapport de la conformation. Quelques espèces ont le premier article des tarses postérieurs dilaté; une autre a les antennes fort allongées. La base de la deuxième cellule postérieure des ailes varie de largeur, et elle est quelquefois légèrement pétiolée. Les couleurs offrent les autres moyens de reconnaître les espèces. L'hypostome, ordinairement argenté on doré, est parfois noir. Les ailes sont rembrunies dans quelques-unes. Enfin l'abdomen et les pieds sont aussi diversement colorés.

Les Dioctries sont proprement les Asiliques de nos climats septentrionaux. Nous les voyons nombreuses en espèces et en individus pendant les mois de mai, juin et juillet, voler rapidement dans les bois et les prairies, et poursuivre sans cesse leur proie. C'est cette espèce de persécution qu'elles exercent contre les autres insectes, qui leur a fait donner, par M. Meigen, le nom grec de Dioctries.

I. Hypostome d'un jaune cuivreux, ou d'un blanc argenté.

I. Dioctrie œlandique; D. celandica, Meig., Lat., Fab. Syst. antl., Fallèn.

Noir. Hypostome d'un blanc jaunâtre. Pieds fauves. Ailes fuligneuses. 


\section{( 15$)$}

Asilus óclandicus, Linn. , Fab. Ent. syst., Herbst,

Schranck.

Asile N. ${ }^{\circ}$ 8. Geoff. 2. 470.

Long. 71.

D'un noir luisant. Hypostome d'un blanc jaunâtre ; milieu noir; moustache jaunâtre. Thorax à deux lignes blanchâtres souvent effacées; côtés à deux bandes formées de petits poils jaunâtres. Pieds d'un fauve vif; hanches, extrémité des jambes et tarses noirs. Balanciers jaunes. Ailes d'un brun noirâtre violet; extrémité moins obscure entre les nervures.

Rare.

2. Dioctrie rufipède; $\boldsymbol{D}$. rufipes, Meig.

Noire. Hypostome d'un jaune cuivreux. Pieds fauves; postérieurs obscurs. Ailes hyalines.

Dioctria frontalis, Meig., Klassif.

favipes, var. 1, Fall. Dipt. suec. 72:

Asilus rufipes, Deg. T. $6,97,6$.

$$
\text { Long. } 5,61 \text {. }
$$

D'un noir luisant. Hypostome d'un jaune cuivreux; moustache jaunâtre. Dos et côtés du thorax à deux lignes formées de petits poils jaunâtres. Pieds antérieurs et intermédiaires fauves; hanches, extrémité des jambes et tarses noirs; base du premier article des tarses fauve; pieds postérieurs noirs; base des cuisses et des jambes fauve. Balanciers jaunes. Ailes hyalines à base jaunâtre. ( $P l .1$, fig. 2.)

Commune.

3. Dioctrie flavipède; $D$. Alavipes, Fall., Meig.

Noire. Hypotosme d'un jaune cuivreux. Thorax gris à lignes noires. Pieds jaunes; jambes postérieures et tarses obscurs. Ailes hyalines.

Long. 5,61 . 
Hypostome d'un jaune cuivreux pâle à deux trails noirs sous les antennes; moustache blanche. Thorax gris à deux bandes noires; côtés à bandes et taches d'un blanc argenté ; écusson noir. Abdomen noir ; bord postérieur des segmens légèrement blanchâtre. Pieds fauves; cuisses antérieures à point obscur peu distinct, à l'extrémité, en-dessus; postérieures à ligne noire au milieu, en dessus; jambes et tarses brunâtres. Balanciers jaunes. Ailes hyalines.

Rare, à Lille.

4. Dioctrie varipède; $D$. varipes, Meig.

Noire. Hypostome blanc. Thorax gris à lignes noires. Pieds fauves; jambes postérieures et tarses noirs.

\section{Long. 51.}

Hypostome d'un blanc de neige; une petite tache noire, bifide, sous les antennes; moustache blanche. Thorax gris à bandes noires; côtés noirs à bandes et taches blanches. Pieds fauves; antérieur's à extrémité des jambes et tarses noirs; base du premier article fauve ; cuisses postérieures à bande noire en-dessus, qui s'élargit au milieu; jambes et tarses postérieurs noirâtres; base des premières fauve. Ailes hyalines à bord extérieur jaunâtre.

5. Dioctrie de baumhauer; $\boldsymbol{D}$. baumhaueri, Meig.

Noire. Hypostome d'un blanc argenté. Thorax gris rayé de noir. Pieds antérieurs variés de fauve et de noir; postérieurs noirs.

\section{Long. 5 I.}

Hypostome d'un blanc quelquefois jaune; sous les antennes, une petite tache noire échancrée en-dessous; moustache blanchâtre. Thorax couvert de petits poils d'un gris roussâtre, avec trois bandes noires, lisses; côtés marqués de taches formées de petits poils blanchâtres. Pieds antérieurs et intermédiaires fauves; cuisses à ligne 


\section{( 17 )}

longitudinale noire du côté supérieur; bas des jambes et tarses noirâtres; pieds postérieurs noirs à articulations des cuisses et des jambes fauves; extrémités des jambes et premier article des tarses renflés. Ailes légèrement obscures.

Assez commune dans les fortifications de Lille.

6. Dioctrie frontale; D. frontalis, Meig., Lat., Fab. Syst. antl.

Noire. Hypostome d'un blanc argenté. Torax grisâtre. Pieds fauves; derniers articles des tarses postérieurs obscurs. Ailes hyalines.

Asilus frontalis, Fab. Ent. syst.

\section{Long. 41 .}

D'un noir luisant. Hypostome et moustache d'un blanc argenté. Thorax d'un gris luisant au milieu; côtés à bandes argentées. Pieds fauves; extrémités des jambes et des tarses obscures. Ailes hyalines; nervures costales jaunes.

Peu commune.

7. Dioctrie anomale; D. anomala, Nob.

Noire. Hypostome d'un blanc argenté. Thorax grisâtre. Pieds roux; derniers articles des tarses postérieurs obscurs. Ailes hyaiines; première cellule sous-marginale divisée vers l'extrémité par une nervure transversale.

$$
\text { Long. } 41 .
$$

Cette Dioctrie ressemble entièrement à la Frontale, à l'exception de la nervure transversale qui divise la première cellule sous-marginale; la deuxième cellule sousmarginale n'a pas sa base en pointe, mais tronquée; enfin la deuxième du bord postérieur est plus étroite que dans l'espèce précédente. ( $P l$. 1 , flg. 3.)

Je ne l'ai trouvée qu'une fois.

8. Droctrie de Reinhard; D. Reinhard, Meig., Wiedem. Noire. Hypostome noir en-dessus, d'un jaune pâle en- 
dessous. Base des cuisses et des jambes rousse. Ailes roussâtres.

\section{Long. 5,61 .}

D'un noir luisant. Hypostome noir dans sa partie supérieure, d'un jaune blanchâtre en-dessous ; moustache blanchâtre et assez touffue. Thorax marqué d'un trait jaunâtre en avant de l'insertion des ailes. Base et tiers de la longueur des cuisses et base des jambes d'un jaune pâle; ongles des tarses jaunes à pointe noire. Ailes légèrement roussâtres.

Cette espèce, que M. Meigen n'a trouvée qu'une fois, mais qui paraît assez commune en Autriche, n'est pas rare dans nos bois et nos prairies.

9. Dioctrie grèle; $D$. gracilis, Meig.

Noire. Hypostome d'un jaune cuivreux. Pieds fauves ; jambes postérieures et tarses d'un brun noirâtre. Thorax noir.

Long. $4 \frac{x}{2} 1$.

Grèle, d'un noir luisant. Hypostome d'un jaune cuivireux fort pâle; moustache blanchâtre. Thorax d'un noir Iuisant, sans bandes. Segmens de l'abdomen bordés postérieurement d'une ligne blanchâtre. Picds fauves; tarses noirâtres ; extrémité des jambes antérieures noirâtre ; partie inférieure des jambes postérieures noirâtre ; premier article des tarses postérieurs dilaté. Balanciers jaunes. Ailes légèrement obscures.

Peu commune, à Lille. 10. Dioctrie latérale; D. lateralis, Meig.

Noire. Hypostome d'un jaune cuivreux. Pieds antérieurs fauves; postérieurs à cuisses fauves avec un anneau noir avant l'extrémité ; jambes et tarses obscurs. Ailes hyalines. Long. 31.

D'un noir luisant. Hypostome d'un jaune cuivreux pâle; 


\section{(19)}

moustache blanche. Côtés du thorax à bandes argentées. Pieds antérieurs fauves; cuisses postérieures à anneau noir vers l'extrémité ; jambes et tarses obscurs. I I. Dioctrie longicorne; $\boldsymbol{D}$. longicornis, Meig. Noire. Hypostome d'un jaune cuivreux. Antennes une fois plus longues que la tête. Pieds fauves; postérieurs noirs.

\section{Long. 31 .}

D'un noir luisant. Hypostome d'un jaune cuivreux; moustache d'un jaune pâle. Troisième article des antennes fort alongé. Côtés du thorax marqués antérieurement d'une ligne argentée. Pieds antérieurs fauves; les quatre derniers articles des tarses noiratres; pieds postérieurs noirs'à genoux fauves; extrémité des jambes et premier article des tarses dilatés. Balanciers d'un jaune pâle. Ailes assez obscures; base de la deuxième cellule postérieure en pointe, et quelquefois légèrement pétioléé.

M. Meigen dit qu'elle a les aîles hyalines; toutes celles que j'ai observées les avaient assez obscures.

Peu commune, dans les fortifications de Lille.

12. Dioctrie hœmorrhoïdale; $\mathbf{D}$. hoemorrhoüdalis, $\mathbf{F a b}$. Syst. antl., Meig.

Noire. Hypostome d'un jaune cuivreux. Segmens de l'abdomen postérieurement fauves. Pieds fauvés; jambes postérieures noires dans le mâle.

Asilus hoemorrhoüdalis, Fab. Ent. syst., Meig. Klas.

\section{Long. 3.1.}

Hypostome d'un jaune cuivreux; moustache blanche. Côtés du thorax à bandes argentées. Troisième et quátrième segmens de l'abdomen à largé bord postérieur fauive; les suivans légèrement bordés ; le dernier entièrement fauve. Pieds fauvès; cuisses postérieures à anneau obscuit près de l'extrémité, quelquefois peu distinet; jámbes renflées 
à l'extrémité, noires à base fauve dans le inâle, fauves à extrémité obscure dans la femelle; tarses d'un fauve obscur; premier article renflé. Ailes' hyalines.

ı3. Dioctrie annulée; $\boldsymbol{D}$. annulata, Meig.

Noire. Hypostome d'un jaune cuivreux. Abdomen à deux bandes jaunes. Pieds roux ; jambes et tarses postérieurs obscurs. Premier article très-épais. Ailes hyalines.

\section{Long. $4: \frac{x}{2}, 1$.}

Noire. Hypostome d'un jaune pâle. Moustache blanche. Thorax avec les bandes ordinaires. Premier et deuxième segmens de l'abdomen marqués d'une tache jaune şur les côtés; les troisième et quatrième, d'une bande jaune à leur base. Pieds fauves; tarses antérieurs et intermédiaires obscurs; ; cuisses postérieures marquées d'une ligne noire; jambes légèrement renflées à l'extrémité, jaunes à la base; tarses noirâtres ; premier article très-dilaté et ovale.

Assez rare.

14. Droctrie à deux ceintures; $D$. bicincta, Meig:

Noire. Hypostome d'un jaune cuivreux. Abdomen à deux anneaux jaunes. Pieds roux; jambes et tarses postérieurs obscurs., Ailes fuligineuses.

\section{Long. $4 \div 1$.}

D'un noir luisant. Hypostome d'un jaune très-pâle; moustache blanche; premier et deuxième segmens de l'abdomen à tache jaune sur les côtés; deuxième et troisième marqués d'un anneau fauve formé du bord antérieur et postérieur des segmẹns; quatrième bordé postérieurement de jaune; les suivans entièrement noirs. Pieds fauves; antérieurs et intermédiaires à tarses obscurs; postérieurs à cuisses marquées d'une bande longitudinale obscure ; jambes noirâtres à base fauve et renflées à l’extrémité $\hat{\imath}_{1}$; tarses noirâtres ; premier article très-dilaté. Balanciers d'un jaune citron. Ailes obscures, presque hyalines vers l'extrénité. 
Cette description diffère de celle de $M$. Meigen, en ce que les bandes de l'abdomen sont fauves au lieu d'être d'un jaune citron.

Assez rares, dans les fortifications de Lille.

1,1., Hypostome noir.

15. Dioctrie à poils noirs; $D$. atricapilla, Meig., Fall.

Noire. Yeux violets. Ailes noirâtres.

$$
\text { (1) Long. } 4 \div 1 \text {. }
$$

Entièrement noire. Balanciers jaunes. Ailes d'un brun noirâtre, qui s'éclaircit vers l'extrémité; des lịgnes claires ạu milieu des cellules discoïdales.

Assez commune.

DASYPOGON; DASYPOGON.

Dasypogon, Meig., Ill. , Lat., Fab. - Asilus, Linn., Geoff., Schœef., Schr., Oliv., Vill. , Roosss., Panz., Walck. - Erax, Scopoli.

Tête hémisphérique déprimée. Hypostame à élévation peu saillante; moustache épaisse; trompe à pointe jmousse; dessous et extrémité velus; lèvre supérieure trè̀-courte, conique; langue légèrement renflée vers l'extrémité; palpes à premier article ordinairement plus court que le deuxième, quelquefois beaucoup plus long et plus gros. Ántennes aux deux premiers articles à-peu-près égaux, velus , un pẹu plus nuenus à la base; troisième allongé, légèrement fusiforme; style court, menu et conique.

Abdomen des mâles cylindrique, à crochẹts renfermés; celui des femelles également cylindrique; dernier segment muni d'un rang de petites dents; jambes antérieures quelquefois munies d'une pointe à l'extrémité, Ailes assez largess ; quatrième cellule postérieure ordinairement fermée; anale souvent fermée. ( $\mathrm{Pl} .1$, fig. 4.)

L'habitus propre aux Asiliques, plus ou moins imparfait dans les Leptogastres et less Dioctries, se montre pleinement 


\section{(22)}

dans les Dasypogons, les Asiles et les Laphries. Le premier de ces trois genres se rapproche cependant encore des Dioctries dans quelques espèces qui ont la quatrième cellule postérieure des ailes ouverte. Une autre, le Dasypogon minutus, a de plus les jambes postérieures garnies de poils du côté intérieur seulement (1), comme lés Dioctries, et elle devrait peut-être figurer dans ce genre.

Les caractères des Dasypogons consistent proprement dans la forme conique du style des antennes; la trompe est velue à l'extrémité; l'abdomen des femelles a le dernier. segment de la même largeur que les autres, et muni de petites dentelures à l'extrémité.

Les organes des Dasypogons présentent plusieurs légères modifications. Outre celles que l'on observe dans les nervurés des ailes, et dont nous venons de parler, il y en a dans la forme des palpes dont le premier article est quelquefois très-épais; dans celles des antennes qui ont le troisième article plus ou moins grèle; dans les jambes antérieures, tantôt armées, tantôt dénuées d'une pointe à l'extrémité.

Quoiqu'il y ait plus de quarante espèces de Dasypogons connues en Europe, nous en avóns observé peu dans le nord de la France. Ces insectes appartiennent particulièrement au midi. Leur nom rappelle la roideur des poils dont le front est hérissé.

1. Jambes antérieures terminées par une pointe.

I. Dasyrogon teuton; D. teutonus, Fab. Syst. antf. Meig.

Noir. Hypostome doré. Antennes fauves. Taches des flanç dorées: Abdomen à points latéraux blancs. Pieds fauves.

(t) Voyè Meig. , tome 2, tabl. 20, fig. 13. 


\section{( 23 )}

Asilus teutonus, Linn., Gmel., Fab., Lal., Panz., Schr.,

Schoeff: Icon., tab. 8, f. 13 .

Asile N. ${ }^{\circ} 7$, Geoff. 2, 469.

\section{Long. 8, 9 l.}

Palpes très - velus. Hypostome et moustache dorés. Antennes fauves; base du premier article obscure et style du troisième noir. Thorax noirâtre; deux lignes dorsales grisâtres ; une bande dorée s'étendant depuis lẹ cou jusqu'au-dessus de la base des aîles; côtés à taches dorées. Abdomen luisant ; tous les segmens, excepté le premier et le dernier, marqués d'un point blanc, luisant, de chaque côté du bord postérieur ; ventre à bord postérieur des segmens d'un jaune luisant. Pieds fauves; hanches noires, dorées en-dessus; jambes antérieures munies d'un duvet doré au cốté intérieur ; tarses noirâtres à pelottes blanchâtres. Balanciers fauves. Ailes brunâtres, plus obscures à l'extrémité ; côté extérieur jaunâtre jusque vers l'extrémité.

Rare.

2. DasYrogon ponctué ; $\boldsymbol{D}$. punctatus, Meig.

Noir. Abdomen à points latéraux blancs; mâle : ailes fuligineuses. Pieds noirs. Femelle : abdomen à bande testacée. Pieds d'un fauve ferrugineux. Ailes presque hyalines.

Dasypogon diadema, Fab. Syst. ant1. Asilus diadema, Gmel., Panz., Fab.

Long. 101.

Mâle : d'un noir violâtre peu luisant. Hypostome d'un blanc argenté un peu jaunâtre, couvert de poils noirs au milieu; le bas noir, ainsi que la moustache; thorax à ligne arquée d'un blanc changeant, s'étendant du cou jusqu'au-dessus de la base des ailes; devant cette base, une tache de la même couleur. Abdomen à taches latérales 


\section{(24)}

d'un blanc changeant, depuis le deuxième jusqu'au cinquième segment. Pelottes des tarses rousses. Balanciers fauves. Ailes d'un brun noirâtre à reflets violets; les bords des nervures plus obscurs."

- Femelle :' hypostome et moustache blanchâtres. Front gris à sommet noir. Deuxième ârticle des antennes et base du troisième testacés. Thorax noirâtre, changeant en gris blanchâtre avec deux lignes noires ; côtés à taches 'd'un blanc changeant ; quatrième et cinquième segmens de l'abdomen testacés; points latéraux comme dans le mâle Pìeds testàcés ; "hanches blanchâtres antérieurement' et velues ; tarses' à extrémitê noirâtre. Balanciers jaunes. Ailes légèrement brunâtres.

"Rare. Les points latéraux de l'abdomen sont sorivent peu'distincts dans l'état de mort: J'en possède un individu dont la première cellule postérieure de l'aile droite est divisée en deux par une nervure transversale qui forme une petite cellule carrée. A l'aile gauche, elle est divisée par une nervure oblique qui ne forme qu'une très-petite cellule triangulaire.

3. Dasýpogon fascié; $D$. fasciatus, Meig.

- Noir. Abdomen à bande testacée et points latéraux blancs. Pieds noirs. Ailes fuligineuses.

\section{Long. 61.}

Hypostome et moustache blancs. Front antérieürement blanchâtre à poils blancs, et sommet noir. Antennes noires. Thorax à ligne arquée d'un blanc changeant, s'étendánt du cou jusqu'au-dessus de la base des aîles; devant cette base, une tachè de la même couleur. Quatrième et cinquième segmens de l'abdomen testacés, pointś latéraiix blancs. Pieds noirs. Balanciers jaunes. Ailes fuligineuses. Rare.

4. Dasypogon cylindrique; D.cylindricus, Fàb., Meig. 
Noir. Abdomen à trois segmens fauves. Pieds fauves. Asilus cylindricus, Fab. Ent. syst., Meig., Klass.?

\section{Long. $6 \frac{3}{4} 1$.}

Hypostome et moustache blanchâtres. Base du troisième article des antennes testacé. Thorax à ligne-d'un cendré changeant depuis le cou jusqu'au dessus de la base des ailes; saillie des épanles testacée. Troisième, quatrième et cinquième segmens de l'abdomen fauves. Pieds fauves, quelquefois obscurs. Balanciers d'un blane 'jaunâtre. Ailes jaunâtres; nervures brunes, bordées de jaune obscur.

Rare.

11. Jambes antérieures sans pointe à l'extrémité.

5. Dasypogon velu; D. hirtellus, Fall., Meig.

Noir. Thorax gris; trois lignes obscures. Abdomen noir à poils blanchâtres; bord postérieur des segmens blanchâtre.

Dasypogon marginatus, Megerle.

\section{Long. 3, 41 .}

Hypostome noir changeant en blanchâtre; moustache noire. Côtés de la tête blancs. Thorax gris à trois lignes obscures; l'intermédiaire droite, peu distincte; les latérales courbées antérieurement. Abdomen d'un noir luisant à poils blanchâtres, bord postérieur des segmens blanchâtre, plus large sur les côtés. Pieds noirs, velus. Balanciers d'un jaune pâle. Ailes légèrement grisâtres.

Rare.

6. Dasypogon brévirostre; $D$. brevirostris, Meig.

Noir. Thorax postérieurement gris et velu. Jambes postérieures à base fauve.

Dasypogon longitarsis, Mas., Fal. Dipt. suec. 13, 4. Armillatus, fem., ibid. $12,4$.

Dioctria brevirostris, Meig., Klass. Tab. 13, f. $16,17$.

\section{Long. $4 \mathrm{l}$.}

Mâle : d'un noir luisant. Hypostome et moustache noirs. 
Bord intérieur des yeux blanc; poils des côtés et du derrière de la tête blancs. Thorax couvert antérieurement de petits poils noirs, postérieurement de longs poils blanchâtres. Abdomen conique; poils blancs sur les côtés. Pieds noirs; postérieurs à cuisses légèrement renflées; jambes échancrées à la base du côté intérieur et trèsvelues de ce côté ; premier article des tarses très-long, aplati; obliquement sillonné ; les autres très-courts, atteignant à peine ensemble le sixième de la longueur. du premier ; cuisses à poils blancs en avant, moins noirs en arrière; jambes à base testacée. Balanciers jaunes. Ailes hyalines légèrement obscures à l'extrémité.

Femelle : thorax couvert postérieurement de poils roux. Abdomen cylindrique, à quatre taches latérales d'un blanc changeant. Pieds de forme ordinaire ; jambes postérieures légèrement renfées à l'extrémité. Aịles à base et partie du bord extérieur d'un blanc jaunâtre. Rare.

7. Dasyrogon menu; $D$. minutus, Meig.

Noir. Moustache fauve. Abdomen cendré à l'extrémité. Ailes obscures à base blanche (mâle). Abdomen noir, Ailes légèrement obscures (femelle).

Dasypogon iris, Meig. , Klass.

Dioctria minuta, Fab. Syst. antl., Mejg., Klass.

\section{Long. 3 l.}

Mâle : hypostome d'un noir cuivreux; moustache fauve à quelques poils noirs. Front d'un jaune clair; tache noire, allongée sur le sommet. Thorax élevé, d'un noir luisant, gris antérieurement, \& bande noire. Aldomen. à poils noirs vers la base; premier et deuxième segmeus luisans ; troisième à bande grise échancrée au bord antérieur; les trois suivans gris à bord postérieur noir; septième noir. Pieds noirs; jambes et premier article Áps tarses postérieurs en massue. 
Femelle : hypostome noir à reflets blancs; mouslache noire. Abdomen entièrement noir. Ailes légèrement obscures.

Rare.

ASILE ; AsILus.

Asilus, Liun., Gmel. , Geoff. , Schœff., Scop., Schr.,

Fab., Deg., Lat., Oliv., Vill., Ross., Cuy., Lam.,

Panz., Walck., Ill., Schellenb., Herbst, Fall., Meig:

- Erax, Scop.

Tête hémisphérique, déprimée. Hypostome, à élévation fort saillante; moustache épaisse. Trompe à extrémité acuminée, bifide et velue; deụx petites élévations velues vers l'extrémité; lèvre supérieure une fois plus courte que la trompe, tronquée obliquement à l'extrémité, Antennes à $\mathrm{r}^{\text {er }}$ article cylindrique, velu en dessous; 2. ${ }^{\text {e }}$ eyathiforme, légèrement velu; $3 .^{\mathrm{c}}$ long, subulé, nu, comprimé; style sétacé, quelquefois renflé à l'extrémité.

Thorax ordinairement marqué d'une bande noirâtre souvent divisée, et d'une autre de chaque côté, raccourcie antérieurement et obliquement tronquée postérieurement. Abdomen des mâles terminé par deux appendices alongés, relevés obliquement, tantôt pointus, tantôt obtus; tarière des femelles luisante. $2 .^{e}$ cellule sous-marginale des ailes élargie vers la base; $4 .^{\mathrm{e}}$ postérieure parfaite, et pétiolée à l'extrémité; anale parfaite. $(P l .1, f i g .5$.

Le genre Asile est le plus considérable de la famille, tant sous le rapport du nombre des espèces connues que sous celui de la grandeur qu'elles atteignent assez souvent. Il se distingue des autres par le style sétacé des antennes, par la forme tronquée de la lèvre supérieure, et par deux petits tubercules arrondis et couverts de poils, que l'on observe vers l'extrémițé de la trompe. Il ressemble fort, d'ailleurs, aux genres Dasypogon et Laphrie.

L'organisation se modifie très-peu dans les Asiles malgré 
le. grand nombre des espèces. Le style des antennes est cependant renflé à l'extrémité dans l'Asilus pictus - de la Hongrie. La base de la deuxième cellule sous-marginale est quelquefois coupée carrément, et la quatrième du bord postérieur n'est pas toujours triangulaire ; mais elle s'arrondit dans quelques espèces. La couleur du corps est toujours cendrée ou ferrugineuse.

Quoique les Asiles soient répandus partout et qu'ils fréquentent également le nord et le midi, nous en avons observé peu d'espèces dans cette partie de la France, dont le sol souvent humide et argileux convient peu sans doute' à leur développement.

y I. Asile crabroniforme; $A$. crabroniformis, Linn., Fab., Lat., Meig.

Abdomen noir, postérieurement ferrugineux. Ailes jaunâtres à taches marginales obscures.

Aisle N.・ 3. Geoff. 2, 468.

Deg. $6,9^{8}, 7$.

Schr. (Faun. boic. 3, 2541.)

Herbs. 8, 118.

Schoeff. 8, 15 .

Schell. $29, i$.

Fall. Asil. 81.

\section{Long. 121.}

- Tête fauve. Trompe, troisième article des antennes et yeux noirs. Thorax noirâtre; deux larges bandes roussâtres sur le dos; une bande intermédiaire brune, séparée par une ligne roussâtre; métathorax noirâtre, à grande tache rougeâtre sur les côtés. Abdomen de la femelle incliné; les deux premiers segmens noirs; une' petite tâche blanchâtre de chaque côté du bord postérieur; les quatre suivans fauves; septième brun-et luisant dans la femelle. Pieds fauves; cuisses postérieures et intermédiaires 
brunes. Balanciers fauves à tête brune. Ailes roussâtres; milieu des cellules postérieures brun.

II n'est pas rare.

2. Asile chrysitis; $A$. chrysitis, Hoffm., Meig.

D'un jaune brunâtre. Hypostome blanchâtre; moustache noire en-dessus, blanchâtre en-dessous. Bandes du thorax et taches dorsales de l'abdomen obscures. Pieds ferrugineux; cuisses noirâtres.

\section{Long. $10,111$.}

Hypostome blanchâtre ;' moustache noire en-dessus et surr les côtés, blanchâtre en-dessous ; derrière de la tête à poils blanchâtres. Antennes noires' à poils blancs sous la base. Thorax d'un jaune grisâtre, à bandes obscures; côtés d'un gris noirâtre; écusson d'un jaune - brun. Abdomen d'un jaune brun à taches dorsales d'un brun changeant, triangulaires; d'autres taches latérales plus petites, de même couleur, dans les femelles. Pieds fauves; cuisses noirâtres à extrémité fauve; extrémité des tarses noirâtre ; pieds antérieurs à poils blancs. Balanciers jaunes. Ailes brunâtres.

"Rare. Cette espèce a été trouvée en Portugal, dans le midi de la France et à Paris.

3. Asile barbe rousse; $A$. Rufibarbis, Meig.

D'un cendré jaunâtre. Hypostome blanchâtre; moustache noire en-dessus, ferrugineuse en-dessous. Thorax à poils noirs et bandes obscures. Abdomen obscur, 'bord postérieur des segmens pâle. Pieds noirâtres.

\section{Long. 9 : 1 .}

Hypostome d'un blanc jaunâtre; möustache et poils derrière la tête ferrugineux. Thorax d'un gris jaunâtre, mêlé de ferrugineux; bandes obscures; côtés cendrés endessous; abdomen d'un brun obscur; bord postérieur des segmens pâle, changeant en gris brun; tarière de la 
femelle noire, large, tronquée obliquement. Pieds noirâtres ; hanches antérieures à poils jaunes, Balanciẹrs fauves. Ailes brunâtres à l'extrémité et au bord intérieur.

Rare.

4. AsIle albiceps; $A$. albiceps, Meig.

D'un cendré obscur. Hypostome et moustạche blancs. Thorax à poils noirs et bandes obscures. Abdomen obscur en-dessus; bord postérieur des segmens pâle. Pieds noirâtres.

\section{Long. 81.}

Cette espèce, qui ressemble à l'Asile barbe rousse, en diffère par l'hypostome entièrement blanc; moustache blanche, noire en-dessus. Abdomen changeant en gris brun à taches dorsales rondes et obscures; tarière de la femelle presque linéaire, obtuse. Pieds d'un brun grisâtre à pointes jaunes. Balanciers jaunes. Ailes légèrement obscures.'

Rare.

5. Așile à tenailles; A. forcipatus, Linn., Fab., Lat., Meig.

D'un gris roussâtre. Hypostome fauve; moustache noire en-dessus, fauve en-dessous. Abdomen d'un brun changeant. Pieds noirs.

Asilus cinercus, Deg. 6, 98, 8 .

Dasypogon forcipatus, Fab. Syst. antl. 167,17 :

Gmel. 5, 2889, 13.

Fall. Asil. 9, 3 .

Schr. Faun. boic. 3, 2547.

Long. 71 .

Trompe, antennes et yeux noirs. Hypostome d'un fauve clair; moustache noire en-dessus, fauve en-dessous; poils des côtés de la tête fauves. Front d'un gris noirâtre. Thorax d'un gris roussatre à poils jaunes; bande inter- 


\section{(3, )}

médiaire divisée; côtés cendrés. Abdomen d'un gris roussâtre;' bord postérieur 'des segmens fauve. Pieds d'un brun noirâtre à poils jaunâtres; hanches cendrées; jambès à poils noirs en dehors. Ailes grisâtres.

\section{Assez raire:}

6. Asıle opaque; $A$ : opacus, Gürtl., Meig.

Cendré. Hypostome blanc; moustache noire. Abdomen d'un brun changeant. Pieds antérieur's roussâtres; jambes et premier article des tarses postérieurs à duvet fauve du côté intérieur.

\section{Long. 7 1.}

Hypostome blanc; moustache noire; quelqués poils blancs en-dessous. Front 'gris ; derrière de la tête blanc. Thorax à bandes noires. Abdomen d'un brun noirâtre changeant en gris; bord postérieur des segmens d'un gris jaunâtre. Pieds antérieurs d'un fauve rougeâtre à poils noirs. Coté intérieur des cuisses nọir; jambes à extrémité noire; tarses obscurs à l'extrémité; pieds postérieurs noirâtres ; jambes et premier artiele des tarses d'un fauvè satiné du côté intérieur; extrémité des ailes légèrement obscure.

Rare; j'en-al un individu dont le côté supérieur des cuisses postérieures est fauve.

7. AsIle estival ; $A$. restivus; Schr,; Meig.

Cendré. Hypostome et moustache blanchâtres; pieds noirs; jambes fauves.

Asilus niger, Deg. 6, 99, 9 .

- tibialis, Fall. Asil. 9, 4 .

Gmel. 5, 2901,46 .

Long. 9 1. fem:

Fem. saillie de l'hypostome et moustache s'étendarít jusques près des antennes; bords de l'hypostome d'un blanc roussâtre; milieu noirâtre ; moústache d'un blane 
roussâtre; poils supérieurs noirs. Front noir ; derrière de la tête roussâtre. Bande intermédiaire dn thorax double. Abdomen noir à reflets roussâtres. Pieds noirs; jambes d'un fauve rougeâtre à extrémité noire; premier article des tarses et base des suivans fauves. Balanciers fauves. Ailes hyalines avec $_{\mathrm{e}}$ le, bord des nervures brunâtre.

1. Un individu mâle, qui paraît appartenir à cette espèce, n'a que 7 l. :Moustache ipresque noire. Extrémité de l'abdomen d'un noir bleuâtre. Tarses entièrement noirs.

Assez rare.

8. Asile cothurne; A. cothurnatus, Meig.

- Cendré. Hypostome blanchâtre ; moustache d'un jaune pâle. Thorax à bandes noires. Abdomen noir ; bord postérieur des segmens cendré. Pieds noirs; 'jambes fauves.

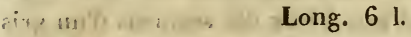

Cette espèce, qui ressemble à la précédente, en diffère par la moustache d'un jaune pâle avec quelques poils noirs en-dessus. Derrière de la tête à poils également jaunes. Bande intermédiaire du thorax simple. Abdomen du mâle

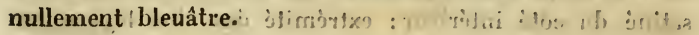
Rare.

9. Asıle germanique ; $A$. germanicus, Linn., Fab., Meig. Cendré. Hypostome et moustache fauves. Abdomen noir. Jambes et tarses fauves Ailes brunes à base hyaline (mâle), grisâtre, (fem:)

Asilus tibialis, Fab. Ent. syst. 383, 30.

Dasypogon germanicus, Fab. Syst. antl. 169, 21.

Gmel. 5, 2898, 12.

Fall. Asil. 8, 2.

Schœff, tab. 48 , f. 9:, 10 .

Panz: 107,19 .

Frisch. 3, tab. 7 .

Herbst. 8 , tab. 346 , f. 6 . 
Long. 8, 1 .

Hypostome et moustache fauves; poils supérieurs de cette dernière noirs. Derrière de la tête fauve. Bord antérieur des yeux blanchâtré: Thorax d'un gris jaunâtre. Bande -intermédiaire légèrement divisée ; côtés cendrés. Abdomen, d'un noir luisant à reflets bleus dans le mâle, bruns dans la femelle; premiers segmens à bord postérieur blanchâtre. Cuisses noires; jambes et tarses - fauves "l à articulations noires.: Balanciers blanchâtres. Ailes à nervures fauves à la base; moitié antérieure hyaline et la postérieure brune dans le mâle, d'un gris brunâtre dans la femelle.

Assez rare. "! 10. Asile, à ceinture ; $A$. cingulatus, Fab.; Meig.

Cendré. Moustache noire en-dessus, blanche en-dessous. Thorax à bandes obscures. Abdomen à ligne dorsale noire. Pieds fauves, annelés de noir.

Fall. Asil. ro, 6.

Schr. Faun. boic. 3, 2548.

$$
\text { Long. } 5,61 \text {. }
$$

Hypostome blanchâtre; moustache noire en-dessus, blanche en-dessous. Bande dorsale du thorax noirâtre, divisée par une ligne peu distincte; les bandes latérales interrompues, et figurant trois taches. Abdomen à ligne dorsale noire; bord postérieur des segmens changeant en blanchâtre. Pieds testacés; cuisses, noires en dehors, à extrémité testacée, d'un brun noirâtre en dedans, testacés vers. l'extrémité ; jambes à deux anneaux noirs; extrémité des tarses noire. Balanciers fauves. Ailes hyalines.

Rare.

11. Asue émule; A. cemulus, Hoffm., Meig.

Hypostome blanc; moustache noire., Thorax cendré à bande intermédjaire double. Abdomen noir ; bord pos- 
térieur des segmens et deux points à la base blancs. Pieds noirs.

Asilus fasciatus, Gïirtl., Megerle.

Long. 61.

Moustache noire atteignant à-peu-près la base des antennes. Derrière de la tête blanc. Thorax d'un gris clair à bandes brunes; l'intermédiaire double. Abdomen' d'un noir luisant; bord postérieur des segmens blanc; bord antérieur du deuxième à deux points allongés d'un gris blanchâtre changeant. Pieds noirs. Balanciers jaunes. Ailes légèrement obscures à l'extrémité.

Rare.

12. AsIle punctipenne; $A$. punctipenuis, Hoffm., Meig.

Cendré. Moustache blanche et noire. Thorax à bande obscure double. Abdomen caréné; des taches obscures changeantes. Ailes hyalines; nervures transversales et extrémité obscures.

Asilus punctatus, Meig. Klass.

$$
\text { Long. } 7,81 .
$$

Femelle : hypostome blanc; monstache épaisse s'étendant jusqu'aux antennes, mélangée de blanc et de noir. Front cendré. Poils blanchâtres derrière la tête. Antennes noirâtres. Thorax à bande noirâtre, double. Poils blancs à l'écusson. Abdomen caréné, à taches obscures changeantes ; tarière longue, d'un noir luisant. Pieds parsemés de pointes noires et converts de poils blanchâtres; hanches noirès; cuisses et jambes nóires du côté intérieur, d'un testacé obscur à l'extérieur ; jambes postérieures èt premier article des tarses à duvet fauve à l'intérieur; premier aiticle des autres tarses testacé, les autres noirs; pelottes fauves. Balanciers brúns. Ailes hyalines; extrémité et taché sur chaque nervure transversale obscures.

Ráre. 
13. Asıle bordé; A. marginatus, Megerle, Meig.

Cendré. Hypostome et moustache blancs. Pieds noirs; jambes et premier article des tarses à duvet fauve du côté intérieur.

$$
\text { Long. } 8 \text { 1. fem. }
$$

Fem. : hypostome blanc; moustache blanche; quelques poils noirs en-dessus; front et derrièrc de la tête d'un gris roussâtre clair. Thorax cendré; trois baudes noirâtres; l'intermédiaire divisée par une ligne cendrée. Abdomen cendré, noir en-dessous. Pieds noirs, couverts de longs poils blanchâtres; hanches cendrées ; côté intérieur des jambes et des tarses antérieurs et postérieurs couvert d'un duvet fauve très-dense, surtout au premier article des tarses; pelottes d'un roux clair. Balanciers jaunes. Ailes presqu'hyalines; bord des nervures trèslégèrement obscur.

Assez rare, dans les bois. 14. Asıle strié ; $A$. striatus, Meig.

Cendré. Hypostome et moustache blancs. Abdomen d'un cendré changeant; ligne dorsale noire. Jambes fauves.

\section{Long. 51.}

Hyposiome blanc; moustache à poils supérieurs noirs et inférieurs blancs. Front d'un gris roussâtre. Thorax à bande dorsale noire, double. Abdomen noirâtre changeant en cendré; bord postérieur des segmens' cendré. Pieds noirs; côté postérieur des cuisses et des jambes d'un rouge testacé ; premier article des tarses et base des suivans rouges. Balanciers d'un jaune pâle. Ailes; à bord postérieur obscur.

Suivant Meigen, les cuisses n'ont que l'extrémité testacée.

Assez commun dans les fortifications de Lille. 15. Asıle nigripède; $A$. nigripes, Nob.

Cendré. Hypostome blanc; moustache noire. Abdomen 
noirâtre. Pieds noirs; jambes et premier article des tarses postérieurs à duvet fauve du côté intérieur.

\section{Long. $5 \mathrm{l}$.}

Hypostome blanchâtre à saillie noire; moustache noire à quelques poils blanchâtres en-dessous. Front noir. Derrière de la tête d'un gris obscur. Thorax à bandes noires. Abdomen noirâtre changeant en cendré. Pieds noirs à longs poils jaunes ou noirs; postérieurs à jambes et premier article des tarses couverts, du côté intérieur, d'un duvet fauve. Balanciers jaunes. Ailes à extrémité légèrement obscure.

Rare.

16. Asile annelé; $A$. annulatus, Nob.

Cendré. Abdomen d'un cendré changeant. Jambes antérieures et intermédiaires annelées de noir et de rouge.

Long. $4 \frac{1}{2} 1$.

Hypostome blanchâtre; moustache à poils supérieurs noirs et inférieurs blancs. Front d'un gris roussâtre. Thorax à bande dorsale noirâtre, entière. Abdomen brun changeant en cendré ; borrl postérieur des segmens cendré. Pieds noirs ; cuisses d'un rougeâtre obscur du côté postérieur; jambes antérieures et intermédiaires à deux anneaux d'un rouge testacé, l'un à la base, l'autre avant l'extrémité; jambes postérieures à base rouge et côté postérieur couvert d'un duvet fauve; premier article des tarses fauve d̀ extrémité noire; les suivans noirs à base fauve. Balanciers d'un jaune pâle. Ailes à bords obscurs.

Rare; trouvé dans les fortifications d'Arras.

\section{LAPHRIE ; LAPHRIA.}

Laphria, Meig., Ill. , Lat., Fab. - Asilus, Linn., Geoff., Schœef., Schr., Fab., Deg., Oliv., Vill. , Ross., Panz., Walcken., Schell. - Erax, Scop.

Tête très-déprimée. Moustache épaisse. Trompe plus 
longue que la tête; lèvre supérieure conique. Palpes à articles d'égale longueur. Antennes insérées sur une élévation; premier article long, cylindrique, velu; deuxième petit, cyathiforme, peu velu ; troisième nu, en massue, comprimé; point de style. Cuisses renflées; jambes arquées. Deuxième cellule sous-marginale des ailes rétrécie vers la base ; quatrième postérieure parfaite et pétiolée à l'extrémité ; anale parfaite. ( $\left.P l .1, f_{g} .6.\right)$

Suivant M. Meigen, les Laphries se distinguent des autres Asiliques par des antennes privées de style; suivant M. Latreille, le troisième article est concave à son extrémité, et il renferme un style rudimentaire non saillant. Les espèces que j'ai observées m'en ont paru dénuées. $\mathrm{Au}$ surplus, l'absence de cette partie des antennes est un caractère assez rare parmi les Diptères. On ne l'observe guères que dans les Tipulaires où ces organes sont toujours composés de plus de trois articles, dans les familles des Xylophages et des Tabaniens, dont le troisième article se subdivise en plusieurs segmens, et dans le genre Bombyle où, de plus, les trois articles ressemblent entièrement à ceux des Laphries. Il semble que ce style ait été donné aux Diptères pour suppléer au peu de développement des antennes, et ces deux genres sont privés de cet avantage.

Les Laphries se distinguent encore des autres Asiliques par l'épaisseur des cuisses et la courbure des jambes qui font le crochet avec elles, conformation qui paraît donner à ces insectes plus de forcé et de facilité pour saisir leur proie. Le nom grec de Laphrie, qui signifie voleur, fait allusion à leur ardeur pour la chasse.

Ces Asiliques, communs au midi, sont rares dans nos campagnes.

I. Laphrie bossue ; L. gibbosa, Meig., Fab., Lat. Noire. Abdomen à extrémité blanche. 
Asilus gibbosus, Linn., Gmel., Fab. Ent. syst.

Asilus Bombylius, Deg. 6, 96, 1 .

Fall. Asil. 4 , 1.

Schoeff. Tab. 8, f. 1 I.

Wiedem. Zool. mag. 1, 2, 27. -

Schr. Faun. boic. 3, 2543.

\section{Long. 101.}

Moustache jaunâtre à reflet d'un brun fauve. Thorax noir à poils d'un brun fauve. Les trois premiers segmens de l'abdomen d'un noị luisant; les trois suivans à duvet d'un blanc jaunâtre; le septième noir; ventre et pieds noirs; pelottes fauves. Balauciers noirs; nervures des ailes bordées de brun jaunâtre.

Rare.

2. Laphrie jaune; L. flaia, Meig., Fab., Lat.

Noire. Extrémité du thorax et abdomen à poils fauves. Asilus flavus, Linn., Gmel., Fab. Ent. syst., Schr. Faun. boic. Fall. As. 4, 2.

Deg. $6,9^{6}, 3$.

Panz. Faun. germ. $39,23,24$.

Schoeff. Icon. tab. 5 ז, f. 2 .

Herbst, 8, 19 .

\section{Long. 101.}

Mâle : moustache grise. Derrière de la tête à poils noirs. Thorax noir à poils noirs en devant et d'un jaune brunâtre derrière. Abdomen couvert en-dessus d'un duvet fauve; organe sexuel grand, épais, d'un noir luisant. Pieds noirs à poils brunâtres. Balanciers jaunes. Nervures des ailes bordées de brun jaunâtre.

Femelle : moustache d'un brun noirâtre. Abdomen épais. Cuisses à poils noirs; jambes postérieures à poils d'un jaune blanchâtre à la base.

Rare. 


\section{( 39 )}

3. Laphrie dorsale; L. ephippium, Meig., Fab.

Noire. A poils noirs. Thorax postérieurement à poils fauves.

Asilus ephippium, Fab., Gmel., Lat.

- dorsalis, Deg. 6, 96, 2.

Fall. Asil. 4, 3.

$$
\text { Long. 9, I } 0.1 \text {. }
$$

Mâle : moustache d'un brun noirâtre, blanchâtre à l'extrémité. Derrière de la tête noir. Thorax noir; poils d'un jaune brunâtre. Abdomen d'un noir luisant à poils noirs; bord postérieur des segmens à petits poils fauves. Pieds noirs; cuisses antérieures à poils gris à la baśe en-dessous. Balanciers bruns. Ailes brunâtres au côté extérieur; base plus claire.

Femelle : tête noire; bord antérieur des yeux jaune. Abdomen entièrement noir. Pieds noirs; dessous des tarses brun.

Rare.

4. Laphrie bordée; L. marginata, Meig., Fab.

Noire. Hypostome doré ; moustache noire. Thorax à tache blanche humérale. Bord postérieur des segmens de l'abdomen à poils fauves.

'Asilus marginatus, Linn., Gmel., Fab.

Fall. Asil. 5, 5 .

Deg. 6, 97, 5 .

Schr. Faun. boic. 3, 2545.

Long. fem. 71 , mâle $5 \frac{1}{2} 1$.

Antennes noires. Hypostome couvert de poils jaunes; moustache noire. Front noir. Derrière de la tête noir. Bord postérieur des yeux blanc. Thorax noir à petits poils fauves; une tache blanche alongée aux épaules; côtés noirs changeant en gris. Abdomen d'un noir luisant, à poils fauves plus épais au bord postérieur des 
segmens. Pieds noirs à poils fauves. Balanciers fauves. Ailes brunâtres à base plus claire.

M. Meigen ne décrit que la femelle. Je n'ai observé qu'un mâle.

5. Laphrie fauve; L. fulva, Meig.

Noire. Hypostome blanc; moustache fauve mélée de noir. Abdomen à poils fauves et base blanche.

\section{Long. 61.}

Hypostome d'un blanc luisant; moustache fauve mêlée de poils: noirs en-dessus, et sur les côtés, à fond noir. Front noir. Antennes d'un brun noirâtre à poils jaunes à la base. Thorax noir à poils fauves; une tache allongée d'un blanc jaunâtre changeant aux épaules; une petite bande jaune s'étendant de la base des ailes jusqu'à l'écusson; côtés à duvet fauve, surtout devant la base des aîles. Abdomen noir ; premier segment couvert d'un duvet blanc changeant. Les autres à poils fauves plus épais au bord postérieur. Pieds noirs à poils fauves, excepté les tarses. Balanciers fauves. Ailes obscures, hyalines vers la: base.

Rare.

6. LAPHrie changeante; L. 'gilva, Meig., Fab., Lat., Fall.

Noire. Moustache noire. Abdomen d'un fauve luisant. Asilus gilvus, Linn., Gmel., Fab. Ent. syst.

- rufus, Deg. 6, 97, 4 .

Panz. Faun. germ. $107,18$.

Schœff. Tab. 78,6 .

Herbst. 8, 119 .

Schr. Faun. boic. 3, 2544.

$$
\text { Long. } 8,9 \mathrm{l} \text {. }
$$

Femelle : hypostome noir à bords blancs; moustacbe noire, parsemée de quelques poils blancs. Front noir. côtés et derrière de la tête à poils gris obscurs. Thorax 


\section{(41)}

noir; deux lignes grises peu distinctes. Abdomen noir; les deuxième, troisième, quatrième et cinquième segmens couverts en-dessous d'un duvet d'un roux fauve vineux très-brillant. Pieds noirs ; pelottes roussâtres. Balanciers bruns. Ailes à nervures bordées de brun noirâtre.

Rare; dans les forêts du Hainaut.

7. Laphrie fémorée; L. femorata, Meig.

Noire. Hypostome blanc; moustache noire. Cuisses postérieures renflées.

\section{Long. 41.}

Mâle : d'un noir luisant. Hypostome d'un blanc argenté; moustache noire. Bord postérieur des yeux blanc. Thorax marqué sur les côtés et aux épaules de quelques taches d'un blanchâtre changeant. Abdomen couvert de petits poils d'un fauve clair. Pieds noirs; cuisses brunes endessous; postérieures d'un rouge obscur en-dessous et fort renflées au milieu; jambes antérieures garnies du côté intérieur d'un duvet fauve clair. Balanciers jaunes. Ailes légèrement obscures.

Je l'ai trouvée à Hazebrouck.

8. Laphrie âtre; L. atra, Meig., Fab.

Noire. Moustache noire. Abdomen violet. Asilus ater, Linn., Gmel., Fab. Ent. syst. Schr. Aust. $99^{3}$.

$$
\text { Long. } 7,81 \text {. }
$$

D'un noir luisant. Moustache noire. Derrière de la tête d̀ poils blanchâtres. Thorax à deux lignes roussâtres peu distinctes. Abdomen noir à reflets violets. Ailes obscures. Rare. 


\section{BOMBYLIERS; Bombyliarir, Meig.}

Bombyliarii, Anthracii, Lat.

Caractère essentiel : antennes de trois articles; le troisième sans division. Style apical. Front plat. Trompe retirée dans la bouche, ou plus ou moins saillante. Abdomen déprimé. Ailes étendues, horizontales; ordiwairement quatre cellules du bord postérieur.

Corps élargi, velu. Tête sphérique ou hémisphérique. Trompe submembraneuse, siphunculiforme, horizontale, coudée prise de la base, tantôt courte, retirée dans la cavité de la bouche, tantôt aussi ou plus longue que la tête, terminée par deux lobes terminaux allongés, souvent peu distincts; lèvre supérieure pointue, canaliculée endessous, plus courte que la trompe; langue capillaire, un peu plus longue que la lèvre supérieure; deux soies (machoires) capillaires de da longuear de la lèvre supérieure; palpes petits d'un ou deux articles distincts. Antennes lantôt rapprochées, tantôt éloignées l'une de l'autre, de trois articles; premier ordinairement cylindrique; deuxième cyathiforme; troisième de diverses formes; un style terminal ordinairement très-petit. Yeux ovales ou réniformes; trois yeux lisses en triangle.

Thorax sans suture, grand, peu élevé; prọthorax nullement distinct. Abdoınen souvent déprimé; dernier segment fort petit. Pieds grêles; tarses munis de deux ongles et de deux pelottes très-petites et quelquefois nulles. Balanciers découverts, mais souvent cachés sous les poils de l'abdomen. Ailes grandes, écartées; ordinairement deux cellules sous-marginales terminales; trois discoïales; ordinairement quatre du bord postérieur; anale renfermant une fausse nervure le long de la nervure interno-médiaire; nervure axillaire à-peu-près nulle. ( Pl. 1, fig. 7, 8. - Pl. 2, fig. 1.) 
Cette famille dans laquelle je comprends, à l'exemple de M. Meigen, les Bombyliers et les Anthraciens de M. Latreille, est moins naturelle que la plupart de celles des autres insectes Diptères. Toüt leur habitus se compose de caractères qui leur sont communs avec l'une ou l'autre des familles voisines, et ils n'ont guères en propre que le port fort écarté de leurs ailes. Ils se rapprochent des Asiliques par l'organisation et la position horizontale de la trompe; de la même famille et des Leptides par lá conformation des antennes. Les principales différences quì les distinguent de ces Diptères consistent dans la forme déprimée de l'abdomen et dans les nervares des ailes dont le bord postérieur n'offre ordinairement que quatre cellules. Ils s'éloignent encore des Asiliques par la lèvre supérieure allongée, le front plat et sans moustache et les pieds grêles; des Xylotomes ét des Leptides par la conformation de la trompe; de ces dernières encore par le nombre des ongiles dont les tarses sont munis.

Si les nombreux rapports que cette famille a avec lés voisines la rendent peu naturelle, elle ne le paraît pas davantage, lorsque l'on considère le peu d'uniformité qui règne entre les différens genres qui la composent. Les uns ont la tête sphérique et à la hauteur du thorax, les autres l'ont hémisphérique et inclinée. La trompe, fort longue dans les uns, est à peine saillante dans d'autres. Les antennes varient également sous le rapport de la conformation du premier et du troisième article, et elles sont tantôt rapprochées, tantôt éloignées à leur base. Ce sont particulièrement les modifications de ce dernier organe qui ont déterminé M. Latreille à former deux familles de ces insectes, et qui lui en ont fourni les caractères. Dans les genres peu nombreux qu'il connaissait à l'époque où il a écrit son excellent genera, l'insertion des antennes 
s'accordait avec la forme du troisième article ; mais plusieurs de ceux qui ont été établis depuis ne présentent pas ce double rapport : les genres Stygie, Géron, Toxophore, ont lesantennes rapprochées comme les Bombyliers, et le troisième article conique comme dans les Anthraciens. Il ne paraît donc plus possible de conserver ces deux familles, et $M$. Meigen les a réunies. Ce défaut d'uniformité se manifeste également dans les nervures des ailes. Il y a ordinairement quatre cellules postérieures; mais les genres Géron et Usia, du midi de la France, n'en offrent que trois, et on en compte cinq dans les Fallenia et les Hirmoneura de l'Europe orientale, si l'on peut toutefois les reconnaître au milieu des modifications qui les rendent si remarquables et des étranges déplacemens qu'elles subissent, la moitié de la largeur des ailes étant occupée par les cellules marginales.

Les Bombyliers sont généralement des insectes remarquables par la beauté de leurs grandes ailes diversement mélangées de parties transparentes et noires. Nous aimons à les voir voler avec la plus grande rapidité, et s'arrêter en planant dans les airs ou près des fleurs, en allongeant leur trompe pour y puiser le suc des nectaires. Quand ils se posent, c'est presque toujours sur les troncs d'arbres ou sur la terre, rarement sur le feuillage. Ils paraissent rechercher surtout la chaleur, et ce n'est guères que lorsque le soleil brille de tout son éclat qu'ils prennent leur essor. Aussi, à l'exception d'un petit nombre d'espèces, ces Diptères sont-ils étrangers à ce pays, et propres seulement aux régions méridionales qui en comptent une grande quantité.

Nous ne connaissons, sur le premier état des Bombyliers, que les présomptions de quelques observateurs. Latreille soupçonne que les larves des Anthraciens sont 
parasytes; Meigen dit qu'elles vivent probablement dans le bois vermoulu ; Fallèn présume que celles des Bombyles se développent dans la terre en se nourrissant de racines de plantes. Cette dernière conjecture me paraît la plus vraisemblable par la raison que les larves des Diptères les plus voisins de cette famille, dont les transformations ont été observées, c'est-à-dire des Leptides, des Asiliques, et même des Tabaniens et des Xylotomes, vivent dans la terre ou dans le terreau. Celles de ces dernières seulement ont été trouvées aussi dans du bois vermoulu.

M. Latreille dit que les nymphes des Anthraciens'sont nues, incomplètes avec les segmens du corps munis de petites épines.

TABLEAU synoptique des genres.

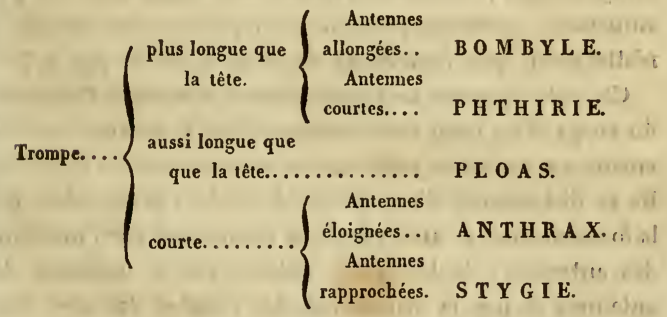

BOMBYLE; BoMbYLIUS.

Bombylius, Linn., Schœff., Scop., Schr., Gmel., Deg., Fab., Oliv., Vill., Ross., Cuv., Walck., Lam., Panz., Mikan, Schell., Meig., Ill., Fall., Herbst, Wiedem. Asilus, Geoff.

Corps très-velu. Tête hémisphérique, déprimée, plus basse que le thorax; hypostome très-velu. Trompe beaucoup plus longue que la tête, très-menue, un peu élargie vers la base, relevée à l'extrémité. Lèvre supérieure assez 
large, sillonnée en-dessus dans la partie antérieure de sa longueur ( 1 ). Palpes cylindriques, velus, obtus, légèrement arqués, insérés à la base supérieure de la trompe. Antennes rapprochées à la base, dirigées sur les côtés, presqu'aussi longues que la tête; premier article long, cylindrique, velu du côté extérieur; second très-court, cyathiforme, également velu ; troisième nu, comprimé, un peu plus long que le premier, renfé au milieu; style triarticulé ( vu au microscope) et terminé en pointe. Yeux elliptiques d'un vert foncé pendant la vie, noirâtres après la mort, contigus dans les mâles; séparés par un large front dans les femelles.

Abdomen large, déprimé. Pieds allongés, très-grêles; cuisses couvertes de longs poils en-dessous vers l'extrémité. Ailes longues, étroites; cellules sous-marginales un peu sinueuses; première postérieure ordinairement fermée et n'atteignant pas l'extrémité de l'aile. ( $P l .1, f i$. 7.)

Ces jolis insectes se reconnaissent d'abord à l'épaisseur du corps d'un beau noir velouté, dont le volume s'accroît encore par les longs poils jaunes ou fauves qui le couvrent. Ils se distinguent d'une partie des autres Bombyliers par la forme menue et allongée de la trompe, et par l'insertion des antennes; de la famille entière par la longueur des antennes et par la disposition des cellules des ailes dont la première du bord postérieur n'est pas terminale comme les autres, et représente une quatrième discoïdale; modification que l'on retrouve très-rarement dans les Diptères.

(I) M. Meigen, dans les caractères génériques des Bombyliers, dit que les deux autres soies sont plus courtes que la lèvre supérieure, et dans les figures, il les représente plus longues, ainsi que les décrit M. Latreille. Elles m'ont paru de la longueur de la lèvre supérieure. Cette différence peut provenir de ce que l'insecte peut les allonger. 
Ils ont aussi les pieds plus longs et plus grêles que les autres genres.

Nous ne voyons les Bombylęs que peu de jours, vers la fin du mois de mai. Ils ne volent-qu'aux rayons du soleil et pendant les heures les plus chaudes de la journée. Leur vol rapide et saccadé est accompagné d'un bourdonnement assez grave. On les voit toujours se poser sur la terre, ce qui semble indiquer qu'ils y déposent leurs œufs.

1. Bombyne majeur ; B. major, Linn., Gmel., Fab. ,

\section{Lat., Meig.}

Couvert de poils jaunes. Bord extérieur des ailes obscur, sinué.

Bombylius variegatus, Deg. Tab. 15 , f. 10.

Klassif. sinutus, Mik. Mon. 35, t. 2, f. 4 , Meig.,

Fall., Dipt. suec., Bomb. 9, 1.

Schceff. Icon, tab. $12 x$, f. 3 .

Schell. g. de m., Tab. 34, f. 2.

Schr. Aust. 1002.

Herbst Gemeinn. Nat. de Thierr. 8, t. 347 , f. $x$.

Wiedem. Zool., Mag. 1, 2, 20.

Asile Bichon, Geoff. 2, 466.

Long. 4, 61 .

Corps noir, tout couvert de poils jaunes. Tête à poils d'un jaune blanchâtre. Barbe blanchâtre. Antennes ả'un brun noir. Thorax à poils d'un jaune blanchâtre sur les côtés. Pieds jaunâtres à tarses obscurs. Balanciers d'un brun noir. Base et bord extérieur des ailes d'un brun ubscur sinué; le reste hyalin.

Assez commun, au printemps.

2. Bombyle moyen; B. medius, Linn., Gmel., Fab., Lat. , Meig. 
Poils fauves. Abdomen noir postérieurement et endessous. Ailes à points noirs.

Bombylius discolor, Mik., Meig., Klass.

Fall., Dipt. suec., Bomb. 10, 2.

Müller, Natur syst. 5, p. 1008.

Schr., Aust. 1003.

Faun., Boic. $3,{ }_{25} 58$.

\section{Long. 5, 6 l.}

Corps noir, couvert de poils fauves. Tête à poils d'un jaune brunâtre, noirs à la base des antennes. Thorax à poils fauves; deux lignes courtes, obliques au bord antérieur; une bande de poils noirs sur les côtés, atteignant la base des ailes. Abdomen à poils fauves sur la moitié antérieure, noirs sur la postérieure; ventre noir. Pieds d'un jaune brunâtre; hanches et grande partie des cuisses noires. Balanciers noirs. Base et bord extérieur des ailes jusqu'aux deux tiers de la longueur, d'un brun noirâtre; le reste hyalin à points bruns sur les nervures.

Commun, au printemps.

3. Bombyle croisé ; B. cruciatus, Fab., Meig.

Thorax à poils roussâtres. Base des ailes obscure. Abdomen noir antérieurement, blanc postérieurement (mâle); noir varié de blanc (femelle).

Bombylius leucopogon (mas), Meig. Klass., Lat. gen. crust. 4,314 .

\section{Long. 5 l.}

Mâle ! barbe blanche, d'un jaune brunâtre près de la bouche. Front fauve. Antennes noires. Thorax couvert de poils d'un jaune brunâtre; côtés blanchâtres. Abdomen à poils fauves depuis la base jusqu'aux deux tiers; côtés plus touffus et blanchâtres; le dernier tiers blanc; une ligne dorsale formée d'un duvet blauc s'avançant vers la base; extrémité noire; ventre à poils blancs. Pieds 
d'un brun noirâtre; cuisses et jambes jaunâtres. Balanciers bruns à bouton blanc. Ailes hyalines, brunes à la base et au bord extérieur ; nervure costale couverte d'un duvet blanc vers la base.

Femelle : Front à poils blanchâtres en avant, fauves en arrière. Thorax marqué au bord antérieur d'une petite tache noire allongée. Abdomen noir à poils fauves peu touffus, mêlés de noirs; premier et second segmens à poils blancs sur les côtés; second à ligne transversale blanche; troisième et suivans à tache triangulaire blanche, dorsale; quatrième et cinquième à poils blancs sur les côtés. Ailes moins obscures que dans le mâle.

Rare.

4. Bombyle postérieur; B. posticus, Fab., Meig.

Poils roux. Abdomen postérieurement à poils blancs. Bombylius micans, Meig. Klass.

-Wiedem., Zoolog., Mag., 1, 2, 22.

Long. $4 \div 1$.

Mâle : barbe d'un jaune pâle en-dessous, noir en-dessus. Front noir; un point blanc ùe chaque côté. Corps à poils fauves; extrémité de l'abdomen blanche. Pieds d'un jaune grisâtre luisant ; tarses d'un brun noirâtre; jambes antèrieures noirâtres du côté intérieur. Balanciers bruns. Ailes hyalines, brunes à la base; une petite tache d'un jaune pâle sur la nervure costale, à la base.

Femelle : le troisième article des antennes est un peu plus large que dans le mâle; l'extrémité de l'abdomen est moins couverte de poils blancs, et les ailes ont à peine la base et le bord extérieur jaunâtres.

Rare. Cette espèce est propre au midi.

5. Bombyle mineur; B. minor, Linn., Gmel. Fab., Lat., Meig.

Noir à poils jaunâtres. Barbe jaunâtre à bords noirs. 
Balanciers obscurs. Ailes subhyalines à base roussâtre.

Bombylius venosus, Mikan. Mon., Meig. KI.

Fall., Dipt. suec., Bomb. 10, 3.

Schœff., icon. tab. 112 , f. 6 .

Herbst gem. nat. 8 , tab. 347 , f. 3 .

Schr., aust. 1004 .

\section{Long. 41.}

Barbe jaunâtre à bord noirs. Front de la femelle à poils fauves. Corps d'un noir mat, à poils d'un fauve pâle. Pieds fauves; tarses obscurs. Balanciers d'un brun noir. Ailes légèrement grisâtres ; bases et bord extérieur légèrement fauves.

Rare.

6. Bombyle luisant ; B. niticlulus, Fab., Meig.

Obscur à poils pâles. Barbe blanche. Front noir. Balanciers obscurs. Ailes d'un brun pâle, pectinées à la base. Bombylius diadema, Meig. K1., 1, 182, 8 .

- cuudatus, ibid. $184,12$.

Long. $4 \frac{1}{2} 1$.

Barbe blanche. Front de la femelle plus large qu'à l'ordinaire, à poils noirs. Corps d'un brun noir à longs poils soyeux d'un blanc brunâtre, mêlés de quelques poils noirs sur l'abdomen. Pieds jaunâtres; tarses obscurs. Balanciers obscurs. Ailes d'un brun rougeâtre pâle, plus foncé à la base et au bord extérieur; une tache blanche sur la nervure costale, et des soies disposées en forme de peigne, près de la base; cellule discoïdale postérieure plus allongée que dans les autres espèces.

Rare.

7. Bombyle sulphuré; B. sulphureus, Fab., Meig.

Noir, à poils d'un jaune doré. Barbe noiree (mâle), jaune mêlée de noir (femelle). Balanciers blancs. Bombylius flavus, Meig. Klass.

Long. 31. 


\section{(5ı)}

Mâle : barbe noire. Front à deux points blancs. Corps noir à poils d'un jaune doré; poitrine à poils noirs. Pieds jaunâtres; tarses obscurs. Balanciers jaunes à tête blanche: Ailes à base et partie du bord extérieur d'un brun jaunâtre; première cellule postérieure ouverte à l'extrémité.

Femelle : barbe jaune. Front large, à poils jaunes mêlés de noirs. Ailes à bord extérieur d'un jaunâtre,pâlẹ.

Rare.

8. Bombyle étincelant; $\boldsymbol{B}$. favillaceus, Meig.

Poils cendrés. Barbe grise. Balanciers obscurs. Ailes à base obscure.

Bombylius cinerascens, Meig. $\mathbf{K I}$.

\section{Long. 41.}

Corps entièrement couvert de poils cendrés, soyeux, mêlés de bruns en-dessous. Pieds bruns; jambes jaunâtres. Balanciers obscurs. Ailes brunes à la base et au bord extérieur; moins dans la femelle.

Rare.

9. Bombyle anguleux; $B$. angulatus, Nob.

Poils d'un gris roussâtre. Ailes à base obscure; nervure séparant Ics deux cellules sous-marginales, anguleuse.

\section{Lon $\mathrm{g} 3 \mathrm{l}$.}

Femelle : corps entièrement couvert de poils d'un gris roussâtre. Pieds bruns; jambes jaunâtres, Balanciers obscurs. Ailes hyalines à base légèrement obscure; nervure séparant les deux cellules sous-marginales, anguleuse près de sa base.

Je ne l'ai observé qu'une fois.

Phthirie, Phthiria.

Phthiria, Meig., Fab. - Bombylius, Mick. - Volucella, Fab., Fall.

Corps petit. Tête sphérique ; front proéminent. Trompe 
heaucoup plus longive que la tête, très-menue, un peu élargie vers la hase. Lèvre supérieure sillonnée en-dessus dans sa partie antérieure. Langue un peu plus courte que la lèvre supérieure; palpes en massue, couchés dans la cavité de la bouche. Antennes un peu plus courtes que la tête, insérées sur la proéminence du front, trèsrapprochées à la base, dírigées sur les côtés; premier article court, quelques poils du côté extérieur ; deuxième cyathiforme, légèrement velu ; troisième fusifurme, comprimé, une fois plus long que les deux premiers ensemble, quelques poils du côté intériẹr. L'extrémité paraît munie d'un style très-petit, bifide.

Abdomen obtusément conique (1). Ailes de grandeur médiocre ; cellules sous-marginales presque droites ; première postérieure ouverte; deuxiène plus longue que large ; anale fermée à l'extrémité et légèrement pétiolée. (Pl. 1, f. 8.)

Les principaux rapports que les Phthiries ont avec les Bombyles consistent dans la longueur de la trompe, dans le rapprochement des antennes à leur base et dans la forme du troisième article; mais des différences plus considérables leur donnent $m$ habitus particulier, et font facilement méconnaître leur affinité. La figure sphérique de la tête, la forme conique de l'abdomen', la briéveté du premier article des antennes, enfin le système réticulaire des ailes les en éloignent plus ou moins. Par ce dernier caractère, les Phthiries s'écartent encore de la plus grande partie de la famille. Les nervures ne sont pas sinuenses comme dans les Anthrax, les Mulions; la première cellule du bord postérieur n'est pas fermée

(1) M. Meigen dit que l'abdomen de la femelle est aplati; je l'ai trouvé conique comme dans le mâle. 


\section{(53)}

comme celle des Bombyles; l'anale au contraire est close à son extrémité, comme dans les Usies, les Gérons, les Cyllénies. Enfin ses ailes prennent une grande ressemblance avec celles des Empidies.

M. Meigen, qui a détaché ces petits insectes du genre Usie de Latreille (Volucella de Fab.), en décrit sept espèces, dont deux paraissent quelquefois dans le nord de la France, et les cinq autres dans le midi. Il ne dit rien de leurs nœurs.

1. Phthirie fauve; P. fulva, Lat., Meig.

Fauve, pubescente. Écusson jaune. Balanciers blancs. Ailes brunâtres.

\section{Long. 21.}

Hypostome blanchâtre à poils noirs. Front large, noirâtre; un point blanc de chaque côté, en avant des antennes. Thorax noirâtre à poils jaunes; une ligne oblique d'un jaune clair sur les côtés; deux points de la même couleur sur les côtés de la poitrine; écusson d'un jaune de soufre. Abdomen noirâtre, à poils d'un jaune doré. Pieds noirs ; cuisses jaunâtres. Balanciers blancs. Ailes légèrement obscures.

Rare.

2. Phthirie pulicaire; $P$. pulicaria, Meig.

Noir. Écusson à point jaune apical. Balanciers blancs ( femelle). Ailes subhyalines.

Phthiria nigra, Meig. Kl.

pygmoea, Lat. Gen. crust.

Volucella pygmoea, Fab. Syst. antl. 115, 5. campestris, Fall. Dipt. suec. Bomb. Ir, I.

Bombylius pulicarius, Mik. mon. $58,14$.

\section{Long. $1 \div 1$.}

Mâle : d'un noir mat. Hypostome gris à poils blancs. Front noir. Abdomen à poils blanchâtres, plus ou moins 
effacés. Pieds noirs. Balanciers obscurs. Ailes subhyalines; stigmate brun.

Femelle : noirâtre. Hypostome blanc. Front large, brun, à deux points blancs. Tour des yeux blanc. Thorax à bande latérale blanchâtre ; côtés de la poitrine grisâtres; deux points blancs; écusson noir ; un point jaune pâle à l'extrémité. Balanciers blancs. Ailes hyalines.

M. Judas l'a trouvée à Amiens.

PLOAS ; PLOAS.

Ploas, Lat., Fab., Meig. - Conophorus, Meig. Klass. -

Bombylius, Fab. ent. syst., Gmel., Mikan, Oliv.

Tête sphérique. Trompe peu allongée; lobes terminaux allongés, charnus; lèvre supérieure à-peu-près de la longueur de la trompe, obtuse; langue de la longueur de la trompe, très-pointue; soies capillaires un peu plus courtes que la langue. Palpes avancés, cylindriques, terminés par une petite pointe aiguë. Antennes très-rapprochées à la base, divergentes, de la longueur de la tête; premier article très-épais, très-velu, assez allongé, en cône tronqué; deuxième, court, velu; troisième, menu, nu, fusiforme, légèrement comprimé ; style court, biarticulé, conique. Yeux contigus dans les mâles, séparés par un large front dans les femelles. Trois yeux lisses sur le vertex.

Thorax ovale, bombé. Ecusson petit. Abdomen elliptique, déprimé. Pieds grêles. Ailes demi-ouvertes; trois cellules sous-narginales; première postérieure ouverte (à-peu-près comme celles du g. Phthirie, pl. I, f. 8 , à l'exception de la troisième cellule sous-marginale formée par une nervure qui divise en deux la première vers son extrémité ).

Ce genre, institué par M. Latreille, est caractérisé par l'épaisseur du premier article des antennes. Il présente le port des Bombyles, mais sa trompe plus courte, et les trois 
cellules sous-marginales des ailes le rapprochent davantage des Cyllénies et des Mulions, Diptères du midi. Meigen a observé qu'au lieu de sucer les fleurs en volant, les Ploas le font en se posant sur les corolles. La briéveté de la trompe détermine sans doute cette habitude.

Les cinq espèces décrites par ce célèbre naturaliste appartiennent au midi. Une seule d'entr'elles paraît quelquefois à Paris et dans le nord de la France.

PlOAS verdâtre; $P$. virescens, Fab., Lat., Meig.

D'un verdâtre obscur, à poils gris. Écusson nu, d'un noir luisant.

Ploas hirticornis, Lat. Hist. nat. des Cr., 14, 300, S.'-

Farg. et Serv, encyc.

Conophorus maurus, Meig. Klass.

Bombylius virescens, Oliv. ent., Fab. ent. syst., Gmel., Meig. Klass.

Bombylius maurus, Mikan. mon.

$$
\text { Long. 3, } 41 .
$$

Hypostome noirâtre à poils gris. Front blanchâtre dans le mâle, noirâtre à poils fauves dans la femelle. Les deux premiers articles des antennes d'un gris brunâtre à longs poils noirs; troisième noir. Thorax noirâtre à poils fauves ; côtés à poils blanchâtres; écusson d'un noir luisant, nu. Abdomen d'un vert noirâtre à poils fauves; côtés à longs poils blancs et noirs par touffes dans le mâle. Cuisses grises; jambes jaunâtres; tarses obscurs. Balanciers pâles à tête obscure. Ailes légèrement grisâtres à base brunâtre.

Rare.

ANThraX, Anthrax.

Anthrax, Scop., Fab., Cuv., Lam., Panz., Walck., Meig., Ill., Schell., Fall. - Bibio, Fab. spec. ins,, Schr. - Nemotetus, Deg. - Musca, Linn., Gmel., Geoff. 
Tête sphérique, un peu aplatie postérieurement et au niveau du thorax. Hypostome couvert de poils courts. Trompe ordinairement cachée dans la cavité de la bouche ; lobes terminaux ovalo-allongés; lèvre supérieure étroite. Palpes courts, cylindriques, velus, insérés sur la première partie (Stipes, Lat.) de la trompe, avant la base de la seconde (Caulis). Antennes éloignées à la base, dirigées sur les côtés, courtes; premier article cylindrique; deuxième cyathiforme; troisième ordinairement pyriforme, arrondi à la base, subitement atténué et allongé, terminé tantôt par un style simple, tantôt par une touffe de poils. Yeux réniformes.

Pieds postérieurs ordinairement plus longs que les autres; pelottes des tarses fort petiles, quelquefois nulles. Ailes longues et ětroites; cellules sous-niarginales sinueuses, quelquefois au nombre de trois, dont les deux postérieures petites et terminales. ( $P l .2, f$. 1.)

Ce genre, type de la famille des Anthraciens de Latreille, diffère des Bombyles par la forme sphérique de la tête et par sa position à la hauteur du thorax; par les antennes éloignées, ét par la forme conique du troisième article; par la briéveté ordinaire de la trompe, et par la conformation des petites lèvres qui la terminent; par l'insertion des palpes qui paraissent labiaux plutôt que maxilaires ; par la forme échancrée des yeux; enfin par les cellules des ailes dont la première du bord postérieur n'est jamais fermée. Dans cette énumération des caractères différenciels, le plus remarquable est l'insertion des palpes qui se trouve sur la base de la trompe assez éloignée du point où ils prennent naissance ordinairement. Ce n'est guères que dans les Stratiomydes et dans les Muscides que l'on rencontre cette disposition qui prouve incontestablement que les palpes des Diplères sont labiaux et nullement maxillaires. 


\section{( 57 )}

Les Anthrax, qui forment un genre très-nombreux (l'Europe seule en comptant près de soixante espèces), présentent plusieurs modifications dans leurs organes. La trompe, ordinairement courte et cachée dans la cavité de la bouche, est quelquefois assez longue et saillante comme celle des Bombyles. Le troisième article des antennes a tantôt la forme allongée d'un radis et tantôt celle d'une rave, ou plutôt d'une cornue de chimiste. Le style qui le termine est simple dans les uns, biarticulé dans d'autres, composé de petites pointes disposées en couronne dans quelques-uns. Les tarses sont quelquefois munis de pelottes, et quelquefois ils en manquent totalement. Les ailes sont diversifiées d'abord sous le rapport des nervures. Dans plusieurs espèces méridionales, on compte trois cellules sous-marginales, toutes les autres n'en ont que deux, plus ou moins sinueuses, ainsi que la discoïdale postérieure. Ces grandes ailes offrent bien plus de diversité encore dans la manière dont elles sont généralement colorées. Le noir et le diaphane s'y combinent pour produire les effets les plus singuliers. Tantôt sur un fond rembruni on ne voit briller que quelques légères clartés; d'autres fois c'est le contraire; ici le sombre et le gai sont nettement divisés; là ils dominent inégalement tour à tour. Ces ailes sont l'image de la vie humaine, avec ses jours sereins et ses noirs orages.

Nous ne connaissons qu'un petit nombre de ces jolis insectes dans la France septentrionale. Ils ont le vol trèsrapide et ils planent comme les Bombyles. Ils vivent comme ceux-ci du suc des fleurs; ils paraissent également au printemps, à l'exception des deux premières espèces que l'on voit au mois d'août dans les sols les plus argileux, et se posant souvent à terre.

1. Anthrax jaune; $A$. flava, Hoffm., Meig. 
Anthrax holtentotta, Lat. gen. crust. inst. 4, 310, Meig., Klassif 1, 199 , 1 .

Noir, couvert de poils fauves. Ailes hyalines; bord extérieur brun; base pectinée de noir.

\section{Long. 61.}

Les deux premiers articles des antennes couverts de longs poils noirs. Hypostome à poils jaunes; front à poils noirs entremêlés de quelques jaunes. Thorax et abdomen couverts de longs poils jaunes et soyeux. (Sous ces poils il y en a d'autres noirs très-courts.) Trois touffes noires à l'extrémité de l'abdomen. Tarses sans pelottes. Balanciers bruns à tête jaune. Ailes hyalines; bord extérieur d'un brun clair; base bordée extérieurement de poils noirs.

Meigen dit que lorsqu'on enlève les poils de l'abdomen, on voit des bandes transversales et alternatives jaunes et noires. Tout ce que j'ai vu à cet égard, c'est que les poils du bord postérieur des segmens se détachent moins souvent que les autres, et qu'ils forment alors des bandes.

Très-commun au moins d'aoùt dans certains endroits argileux.

2. Anthrax bordée; $A$. circundala, Hoffm., Meig. Anthrax hottentotta, Fab. Syst. antl. Fall., Meig. Klassif. Bibio hoitentotta, Fab. Spec. ins., Schr.

Nemotelus holtentottus, Deg.

Musca hotlentolta, Linn., Gmel.

Schœff. icon. tab. 12, f. 10, 12, tab. 76, f. 7 .

Noir, couvert de poils fauves. Ailes presqu'hyalines; bord extérieur brun. Tache blanche à la base (mâle).

\section{Long. 61.}

Semblable au précédent, excepté le bord postérieur des yeux entouré de blanc; les ailes légèrement roussâtres, avec une tache blanche à la base dans le mâle.

Il se trouve avec le précédent.

3. Anthrax semi-atre; $A$. scmiatra, Meig. 


\section{( 59 )}

Noir. Còtés à poils fauves. Ailes demi-noires. Anthrax morio, Lat., Meig. Kl., Panz., Fall. Bibio morio, Schr. Faun. boic. 3, 2,368. Musca morio, Linn., Schr. Aust.

\section{Long. 3,61 .}

Thorax à poils fauves à la base et sur les côtes. Abdomen à poils jaunes à la base, noirs sur les côtés. Pieds noirs ; jambes quelquefois jaunes. Balanciers noirs à tête blanche. Ailes à demi-noires vers la base; bord de la partie noire oblique et à plusieurs enfoncemens, l'autre moitié hyaline.

Rare.

4. Anthrax sinué ; $A$. sinuata, Meig., Fall.

Noir. Abdomen à bandes blanches. Balanciers obscurs. Ailes d'un brun noir à extrémité hyaline.

Anthrax morio, Lat., Fab.

Bibio morio, Fab. Spec. ins. 2, 414, 11 .

- anthrax, Schr. Faun. boic. 3, 2367.

Nemotelus morio, Deg., 6, 78, 14 .

Musca morio, Limn., Gmel.

anthrax, Schr. Aust. 893.

Geoff. $2,49^{3}, 2$.

$$
\text { Long. } 3 \frac{1}{2}, 61 \text {. }
$$

Antennes terminées par un rang de pointes. Abdomen à poils blancs sur les côtés de la base; troisième segment et les suivans à ligne transversale blanche. Pieds et balanciers d'un brun noir. Ailes d'un brun olsscur. Cette couleur s'affaiblit au bord intérieur, qui est sinué ; extrémités à-peu-près hyalines; nervures bordées de brun:

Commun.

5. Anthrax velouté ; $A$. velutina, Meig.

Noir. Base du thorax à poils fauves. Abdomen à bande et extrémité blanches. Balanciers obscurs à tête blanche. Ailes à demi-noires; un enfoncement et un point avant l'extrémité. 


\section{(6o)}

Anthrax holosericeus, Meig. K1.

Schell., g. de m. tab. 32 , f. 3 .

$$
\text { Long. } 3 \frac{1}{2}, 61 \text {. }
$$

Tête légèrement saupoudrée de jaune, à poils noirs. Antennes terminées par un rang de pointes. Thorax à poils fauves au cou et sur les côtés. Abdomen à poils fauves sur les côtés de la base ; une bande blanche sur le quatrième segment; les suivans à points blancs latéraux; anus blanchâtre. Pieds noirs; cuisses et jambes saupoudrées de jaune. Balanciers obscurs à tête blanche. Ailes d'un brun noirâtre; côté intérieur et extrémité hyalins; bord de la partie noire onduleux; un enfoncement considérable près du bord extérieur ; nervures transversales de la partie colorée, bordées de roussâtre clair.

Rare. Cette espèce, propre au midi, parât quelquefois à Paris et dans le nord.

6. Anthrax varié; $A$. varia, Fab., Meig.

Noir. Abdomen postérieurement argenté, tacheté de noir. Ailes à trois bandes interrompues et points obscurs.

$$
\text { Lorg. } 2 \frac{1}{2}, 4 \frac{1}{2} 1 \text {. }
$$

Hypostome et devant du front saupoudrés de jaune. Antennes terminées par des soies. Thorax à poils d'un gris blanchâtre mêlés de noirs au cou et sur les côtés. Base de l'abdomen munie sur les côtés d'une touffe de poils blanchâtres; bord postérieur des trois premiers segmens à poils blancs; les trois derniers segmens d'un blanc argenté à tache triangulaire noire. Pieds noirs ; jambes saupoudrées de jaune. Balanciers obscurs à tête blanche. Ailes hyalines; bord extérieur d'un brun jaunâtre et à trois demi-bandes transversales; des points obscurs à la jonction des nervures.

Rare. 
7. Anthrax à fenêtre; $A$. fenestrata, Fall., Meig.

Noir. Thorax à poils fauves. Abdomen à deux bandes blanches rapprochées. Ailes à demi-obscures et taches hyalines.

Antlirax mrura, Meig. Klass. nigrita, Fab. Mus.

Musca Maura, Herbst, Gem. nat. 8, 104. Asilus morio, Linn. Faun. suec. 1917.

$$
\text { Long. } 5,6 \text { I. }
$$

Hypostome d'un rouge brun, saupoudré de fauve. Front noirâtre saupoudré de fauve, à poils noirs. Bord extérieur des yeux blanc. Thorax d'un brun noir à poils fauves; bande blanche sur les côtés; écusson testacé. Troisième et quatrième segmens de l'abdomen à bande blanche interrompue; anus à poils blancs; côtés à poils blancs à la base et aux deux bandes, et noirs dans le reste. Ventre d'un gris llanc en devant, noirâtre postérieurement. Pieds d'un brun noir. Balanciers obscurs à extrémité de la tête blanche. Ailes hyalines; moitié antérieure brune à taches plus claires.

8. Anthrax Pandore; $A$. Pandora, Fab., Meig.

Noir. Abdomen à bandes interrompues argentées. Ailes d'un brun noir à taches hyalines; extrémité et bord intérieur hyalins et profondément sinués.

$$
\text { Long. } 3 \text {, } 4 \text { I. }
$$

Noir à poils bruns, cuivrés et dorés. Front noir à poils fauves en devant. Thorax à poils noirs sur les côtés; une touffe de poils noirs et blancs devant les balanciers. Abdomen à poils d'un rouge cuivreux; premier segment à deux points, deuxième à bande interrompue au milieu, troisième à deux points, quatrième à bande interrompue, cinquième et sixième à bande ordinairement entière. Pieds noirs légèrement rougeâtres. Balanciers noirs. Ailes d'un 


\section{(62)}

brun noir; à extrémité et bord intérieur hyalins; partie colorée, profondément sinuée sur le bord et marquée de taches pâles.

Cette espèce du midi paraît quelquefois à Paris et dans le nord.

STYGIE ; Stygia.

Stygia, Meig. - Anthrax, Fab., Panz.

Tête sphérique, un peu aplatie postérieurement. Trompe peu saillante, assez menue; tubes terminaux allongés et velus. Lèvre supérieure voûtée, légèrement comprimée en avant, pointue; langue plus longue et soies capillaires plus courtes que la lèvre supérieure; palpes courts, légèrement renflés vers l'extrémité. Antennes très-rapprochées à la base, divergentes, courtes; premier article court, épais, velu, élargi en-dessus et obliquement obtus ; deuxième plus court, cyathiforme ; troisième allongé, conique, nu, terminé par un très-petit style. Yeux réniformes dans les mâles; trois yeux lisses sur le vertex.

Thorax ovale. Abdomen elliptique allongé, légèrement convexe. Pieds menus; postérieurs un peu allongés. Ailes demi-ouvertes; cellules comme dans les anthrax ( $p l .2$, .. I ), mais moins sinueuses.

Ce genre, que M. Meigen a détaché des Anthrax, en diffère particulièrement par la conformation et l'insertion des antenues, par la forme plus menue de la trompe, par la disposition moins sinueuse des nervures des ailes. De plus, le corps, moins velı, est toujours d'un noir luisant qui a donné lieu au nom de Stygie, et à celui de. Belzebul que porte l'une des espèces.

Ces insectes sont propres au midi; cependant l'espèce que nous allons décrire se rencontre quelquefois en Allemagne et dans le nord de la France.

1. Strgie latérale; $S$. lateralis, Meig. 
D'un noir luisant. Thorax à poils fauves. Segmens de l'abdomen bordés de jaune; ventre fauve. Anthrax Belzebul, Panz. Faun. Germ. 45, 16.

\section{Long. 3,41 .}

Hypostomé et partie antérieure du front à poils blancs. Vertex d'un noir luisant. Thorax à poils fauves en-dessus et blancs sur les côtés. Segmens de l'abdomen bordés postérieurement de jaune; premier à poils latéraux fauves; une tache latérale d'un jaune orangé aux deuxième et troisième, dans la femelle; ventre fauve à extrémité noire; segmens bordés postérieurement de jaune pâle. Pieds noirs. Balanciers jaunes à tête blanche. Ailes hyalines; bande d'un brun clair au bord extérieur, depuis la base jusqu'à la moitié de la longueur, dans le mâle; au-delà de cette moitié et s'affaiblissant jusqu'à l'extrémité de l'aile, dans la femelle.

XYLOTONES ; Xгцотомж. Meig.

Caractère essentiel: antennes de trois articles; troisième sans division; style apical. Trompe cachée. Tarses munis de deux pelottes. Ailes à demi-ouvertes; cinq cellules du bord postérieur.

THÉREVE ; THEREVA.

Thereva, Lat., Meig. - Bilio, Fab., Fall., Meig. Klassif.

- Nemotelus, Deg. - Musca, Linn., Gmel. - Tabanus, Geoff.

Corps oblong. Tête hémisphérique dans les mâles, sphérique dans les femelles. Front nu; hypostome velu. Trompe entièrement retirée dans la bouche, charnue, convexe en-dessous, creusée en gouttière en-dessus, labiules épaisses, velues et finement rayées en dehors. Lèvre supérieure petite, plate, canaliculée en-dessous; langue capillaire; deux soies (machoires) capillaires, un peu plus courtes que la lèvre supérieure; palpes d'un seul 
article, un peu plus long que la lèvre supérieure, cylindrique, velu du côté extérieur et terminé par un bouton arrondi et nu. Antennes de la longueur de la tête, trèsrapprochées à leur base, ensuite inclinées vers les côtés, de trois articles; premier cylindrique, légèrement velu et assez allongé ; deuxième cyathiforme, très-court, velu; troisième conique, nu, un peu plus long que le premier; style terminal fort court, de deux articles. Yeux ovales, contigus dans les mâles; trois yeux lisses en triangle.

Thorax ovale, sans suture; écusson en demi-cercle. Abdomen légèrement velu, conique. Pieds assez grêles, garnis de petites épines; jambes terminées par de petites pointes; tarses munis de deux pelottes. Balanciers découverts. Ailes à demi-ouvertes. Deux cellules sous-marginales terminales, peu sinueuses; trois discoïdales; cinq postérieures; quatrième tantôt ouverte, tantôt fermée à l'extrémité ; nervure axillaire ne s'étendant pas jusqu'au bord de l'aile. ( $P l .2$, fig. 2.)

Les Thérèves qui forment seules la famille des Xylotomes, offrent, comme les Bombyliers, un assemblage de caractères qui leur sont communs avec les familles voisines, et qui les ont fait comprendre, tantôt dans les unes, tantôt dans les autres, tandis que d'autres caractères les en éloignaient, et ont fini par les isoler entièrement. Latreille, qui en a fondé le genre en les séparant des Bibions de fabricius/qui sont nos Anthrax, et des Taons de Geoffroy avec lesquels elles étaient confondues, les a d'abord comprises dans la famille des Tabaniens; ensuite, dans son genera, il les a placées dans celle des Mydasiens. En dernier lieu, Meigen, trouvant cette association peu naturelle, les a entièrement isolées en instituant pour elles la nouvelle famille Xylotome.

Les caractères qui ont occasionné cette fluctuation dans 
la classification des Thérèves, consistent dans l'organisation de la trompe et dans la forme des antennes qui les rapprochent des Anthrax; dans le port et les nervures des ailes disposées comme dans les Tabaniens. Elles ont des rapports encore plus grands avec les Leptides, surtout par la forme du corps. Les caractères qui distinguent les Thérèves de ces trois familles et qui ont déterminé Meigen à les considérer comme une famille particulière, se trouvent dans l'organisation des palpes formés d'un seul article et terminé par un petit renflement sphérique; dans la position de la trompe entièrement retirée dans la bouche, et dans la forme de la tête, sphérique chez les mâles, hémisphérique chez les femelles. Elles sont les derniers Diptères à antennes triarticulées dont les tarses ne sont munis que de deux pelottes.

Ces insectes habitent les bois et les prairies, et quoique leur nom indique qu'ils font la chasse aux animaux, ils paraissent vivre beaucoup plus du suc des fleurs. Les femelles déposent leurs œufs dans la terre humide ou dans le vieux bois décomposé. Frisch a observé la larve de la Thérève plébéienne, et Meigen celle de la noble. Elles sont vermiformes, très-allongées; la tête est cornée, petite, noire; le corps, composé de vingt segmens, est muni à son extrémité de deux tubes aërifères. La larve observée par Meigen s'est transformée, au mois de mai, en nymphe allongée, et l'insecte parfait en est sorti en juin.

A l'exception de la Thérève plébéienne, qui est commune partont, et de l'Anilis qui fréquente le Hainaut, celles que je décris sont rares dans le nord de la France. MM. Serville et Carcel les ont trouvées dans les environs de Paris.

1. Thérève noble; T'. nobilitata, Lat., Fab., Meig. 
Poils fauves. Abdomen ferrugineux; base des segmens noire; ventre obscur à bandes jaunes.

Bibio nobililata, Fab., Meig. Klass.

Bibio plebeia, Fall. Dipt. suec. Anth. 4, 1.

Nemotelus hirtus, Deg. ins. 6, 76,9 .

Musca nobilis, Gmel. Syst. nat. 5, 2829, 13 I.

Long. 5, 61 .

Mâle : hypostome d'un gris noirâtre, à poils fauves qui forment un cercle autour des antennes. Antennes obscures. Bord antérieur des yeux blanchâtre. Thorax brun, quelquefois noir, couvert de poils fauves. Abdomen ferrugineux à longs poils fauves; segmens noirs à la base; bord postérieur (excepté le premier) d'un jaune doré. Cuisses obscures; jambes et tarses testacés. Balanciers d'un jaune brunâtre. Ailes légèrement brunâtres; stigmate à peine distinct.

Femelle : moins velue que le màle. Hypostome et front fauves; ce dernier à saillie cordiforme d'un noir luisant. Thorax à trois bandes d'un brun grisâtre. Tarière d'un noir luisant. Balanciers jaunâtres.

Assez commune dans le Hainaut.

2. ThÉrève ceinte; $T$. cincta, Meig.

Abdomen noir à poils fauves et bruns; bord des segmens jaune; ventre noir.

\section{Long. 51.}

Elle diffère peu de la précédente : abdomen noir à poils alternativement fauves et d'un brun noirâtre sur les côtés; ventre noir; bord postérieur des segmens jaune. Ailes brunâtres à stigmate d'un brun jaunâtre.

Rare.

3. Thérk̀ve plébéienne; $T$. plebeia, Lat., Fab., Meig.

Mâle : noirâtre. Abdomen à poils noirs; bord des segmens jaune. Femelle: Thorax pâle à bandes obscures. 


\section{(67)}

Abdomen ardoisé à bandes noires; bord des segmens pâle.

Bibio plebeia, Fab.

- rustica, Fall. Dipt. suec. Anth. 4, 2.

-_ fasciata, Meig. Kl. 1, $214,3$.

- strigata (mas), Fab. Ent. syst., syst. antl.

Nemotelus fascialus, Deg. ins. $6,76,8$.

Tabanus, $N^{\circ} 6$, Geoff. $2,462$.

Musca plebeia, Linn., Gmel.

Friscl, ins. 1, 34, tab. 9 .

Schcll. g. de m., tab. 33 , f. r.

\section{Long. 5, 61 .}

Mâle : hypostome à poils bruns; une tache arquée de poils noirâtres. Antennes d'un brun noirâtre.' Thorax à poils d'un brun noirâtre, d'un brun grisâtre en-dessus, à trois bandes obscures. Abdomen à poils noirâtres; bord postérieur des segmens, excepté le premier, d'un jaune clair; taches latérales fauves. Cuisses brunes; jambes et tarses d'un testacé obscur à extrémité noirâtre. Balanciers bruns. Ailes légèrement brunatres; nervures d'un brun rougeâtre; stigmate d'un brun obscur.

Femelle : hypostome à poils blancs, légèrement jaunâtre vers le haut. Front d'un jaune brunàtre à deux saillies d'un noir luisant, contiguës. Antennes d'un brun noirâtre; premier article gris. Thorax d'un jaune brunâtre en-dessus, à trois bandes d'un brun obscur ; côtés cendrés. Abdomen à premier segment d'un gris brunatre; deuxième et suivans à bande antérieure d'un noir luisant, plus large au milieu, ensuite d'un gris ardoisé; bord postérieur d'un blanc jaunâtre; septième segment entièrement d'un noir luisant ; ventre ardoisé ; bord postérieur des segmens jaunâtre.

Fort commune. 
4. Thérìve albipenne; T. albipennis, Meig.

Thorax cendré. Trois bandes obscures. Abdomen arḍoisé à poils blanchâtres et bandes noires. Ailes blanchâtres.

\section{Long. $3 \frac{1}{2}, 4 \frac{2}{2} 1$.}

Mâle : hypostome d'un blanc grisâtre à poils de la même couleur qui forment un arc vers le haut. Antennes brunes. Thorax blanchâtre à soies noires et trois bandes d'un gris obscur; côtés ardoisés. Deuxième segment de l'abdomen et suivans à bande noire élargie au milieu, et bord postérieur d'un jaune blanchâtre; septième noir; ventre ardoisé; bord postérieur des segmens d'un jaune blanchâtre. Pieds bruns; jambes d'un jaune brunâtre. Balanciers bruns. Ailes blanchâtres à nervures et bord extérieur noirâtres.

Femelle : hypostome blanc. Front jaune à deux saillies séparées, d'un noir luisant.

Rare.

5. ThérÈve biponctuée; T. bijunctata, Meig.

Noirâtre. Front de la femelle à deux points noirs. Thorax à bandes obscures. Abdomen à bandes obscures; segmens à bord jaune.

\section{Long. $4 \mathrm{l}$.}

Femelle : hypostome à poils d'un blanc grisâtre. Front d'un jaune brunâtre à deux points d'un noir luisant, l'un près de l'autre. Antennes brunes; les deux premiers articles grisâtres. Thorax d'un gris brunâtre, à trois bandes obscures. Abdomen d'un gris brunâtre; segmens à bandes obscures et bord postérieur jaune; ventre d'un gris brun; bord postérieur des segmens jaune. Pieds d'un jaune brunâtre; cuisses d'un gris noirâtre. Balanciers d'un brun noirâtre. Ailes d'un gris pâle; bord extérieur jaunâtre.

Rare. 


\section{( 69 )}

6. ThÉRÈve Aavilabre; T. flavilabris, Meg., Meig.

Tête jaune. Abdomen fauve; bord des segmens noir (femelle). Balanciers jaunes.

\section{Long. $4 \frac{2}{3} \cdot 1$.}

Mâle : hypostome à poils d'un jaune blanchâtre. Front de même, à bord des yeux muni de soies noires; une ligne enfoncée au milieu. Les deux premicrs articles des antennes d'un gris brun. Thorax noirâtre à poils fauves ; côtés et poitrine cendrés; écusson d'un jaune brunâtre. Abdomen fauve; côtés des segmens à ligne brune et blanche. Ventre d'un gris brun. Cuisses brunes; jambes d'un jaune obscur; tarses bruns. Balanciers d'un jaune clair. Ailes légèrement grisâtres à nervures costales d'un brun jaunâtre.

Femelle : hypostome et front d'un jaune pâle; ce dernier à tache cordiforme d'un noir luisant qui s'étend jusqu'aux yeux lisses; derrière de la tête gris. Thorax d'un gris jaunâtre pâle en-dessus, à trois handẹs grises; Cótés et poitrine d'un gris clair; écusson d'un gris clair à tache noire. Abdomen fauve; deuxième segment à bord postérieur d'un jaune clair qui est peu distinct dans les suivans; troisième, quatrième et cinquième à bord antérieur noir; tarière noire; ventre d'un gris brun; bord postérieur des segmens pâle.

7. THÉRÈVE argentée; T. anilis, Meig.

Antennes à poils obscurs. Thorax roussâtre. Abdomen d'un blanc argenté (mâle), gris (femelle). Pieds fauves. Bibio anilis, Fall., Panz. (Mas.), Meig. Kı.

- flavipes, Fab., Meig. KI. (var. 216, c.)

- - sordida, Panz., Fem.

Musca anilis, Linn. Faun. Suec., Gmel.

Long. $5 \frac{1}{2} 1$.

Male : hypostome et front d'un gris brun; ce dernier 
à soies noires et ligne enfoncée. Derrière de la tête à poils fauves, premier article des antennes épais, d'un jaune brun, couvert de soies noirâtres; thorax d'un brun noirâtre à poils fauves et deux lignes plus claires. Abdomen à poils d'un blanc argenté ; bord postérieur des segmens blanc. Pieds fauves à articulations noirâtres; cuisses quelquefois noirâtres. Balanciers bruns à tête blanchâtre. Ailes légèrement brunâtres à nervures brunes; la plupart des nervures transversales plus obscures.

Femelle : front gris, quelquefois d'un jaune brunâtre, à tâches brunes, peu distinctes. Thorax d'un gris jaunâtre à trois bandes obscures. Abdomen d'un cendré brunâtre, soyeux; bord postérieur des segmens plus clair; tarière d'un noir luisant. Pieds d'un jaune brunâtre.

Assez commune dans le Hainaut.

8. ThÉrève annelée; T. annulata, Meig.

D'un gris blanchâtre. Antennes à poils blancs. Thorax à bandes cendrées, abdomen (femelle) à bandes noires. Thereva anilis, Lat. gen. crust. , 4, 296.

Bibio anilis, Fab., Schr. faun. boic., Meig. Kl.

- annulata, Fab. Syst. antl., 68, 11 , Fall. D. Suec. Anth., 5, 4 .

$$
\text { Long. } 4 \frac{i}{i}, 5 \text { l. }
$$

Mâle : hypostome et front à poils blancs; ce dernier à ligne enfoncée. Les deux premiers articles des antennes d'un gris clair à poils blancs; troisième d'un brun noirâtre. Derrière de la tête d'un gris clair ; bord des yeux blanc. Thorax à poils blancs et bandes d'un gris pâle. Abdonnen d'un gris blane ardoisé, à poils blanes; bord postérieur des segmens blanc. Cuisses grises; jambes et premier article des tarses testacés; les autres articles bruns. Balanciers brunâtres à tête blanche. Ailes hyalines à nervures brunes; bord extérieur d'un brun clair.

Femelle : Front d'un blanc argenté en-dessous, testacé 


\section{( 71 )}

en-dessus. Deuxième segment de l'abdomen et suivans bande demi - sphérique noire, pâle aux cinquième et sixième; tarière noire.

Rare.

9. Thérève voisine; $T$. confinis, Meig.

Thorax blanchâtre, à bandes obscures. Abdomen argenté (mâle); d'un brun noirâtre à taches latérales blanches (femelle).

Bibio confinis, Fall., Dipt. suec. platyp., 12.

-_ rustica (fem.), Panz. Faun., Germ., 90, 21, Lat.

-_plebeius (fem.), Sch., Faun, Boic., 3, 2370.

$$
\text { Long. } 5 \frac{1}{2} \text {. }
$$

Mâle : hypostome et front d'un blanc luisant. Thorax d'un gris clair à bandes plus obscures. Abdomen à poils d'un blanc argenté, luisant, à reflets bleuâtres; bord postérieur des segmens blancs; anus fauve en-dessous. Cuisses grises; jambes et tarses fauves à articulations noirâtres. Balanciers d'un jaune pâle. Ailes hyalines.

Femelle : hypostome et partie antérieure du front d'un blanc luisant; vertex noirâtre. Abdomen d'un brun noirâtre en-dessus; segmens à taches latérales blanches et bord postérieur jaunâtre; ventre d'un gris noirâtre, à bord postérieur des segmens jaunâtre.

Rare.

\section{LEPTIDES ; Leptides, Meig.}

Rhagionides, Lat.

Caractère essentiel : antennes de trois articles; troisième sans divisions. Trompe saillante. Tarses munis de trois pelottes. Ailes à cinq cellules du bord postérieur.

Corps allongé. Tête hémisphérique très-déprimée, de la largeur du Thorax, et un peu plus basse. Front souvent nu. Hypostome nu, court, marqué de deux lignes enfoncées et divergentes. Trompe saillante, charnue, épaisse, 


\section{$\left(7^{2}\right)$}

creusée en gouttière en-dessus; ; labiules épaisses, allongées, légèrement velues en-dessous, marquées d'une ligné enfoncée, oblique, du côté extérieur. Lèvre supérieure tantôt tronquée obliquement, tantôt pointue ; langue capillaire ; deux soies ( mâchoires ) cápillaires. Palpes fort velus, de deux articles; premier court, cylindrique; deuxième allongé, tantôt conique, incliné sur la tròme, tantôt cylindrique et relevé. Antennes rápprochées l'une de l'autre, insérées à la partie inférieure de la tếte, près de la trompe; de trois articles; premier ordinairement court et cylindrique ; second cyathiforme; troisième conique ou ovale, muni d'un style capillaire, tantôt apical et velu, tantôt dorsal et nu. Yeux ronds ; trois yeux lisses.

Thorax souvent muni d'un tubercule sur les épaules ; suture interrompue; poitrine souvent saillante en-dessous. Abdomen long, conique, obtus dans les mâles, pointu dans les femélles, quelquefois déprimé. Pieds assez longs, grêles, finement velus; jambes postérieures et intermédiaires terminées par deux pointes; tarses munis de trois pelottes. Balanciers découverts. Ailes à deux cellules sousmarginales terminales, trois discoïdales, cinq postérieures ; anale ordinairement ouverte, quelquefois fermée et pétiolée ; nervure axillaire nulle. ( $\mathrm{Pl} .2, \mathrm{f} .3,5$.

La place qu'occupe la famille des Leptides dans l'ordre naturel me paraît mieux déterminée qu'aucune autre. Elles sont, avec les vésiculeux, les seuls Diptères qui aient à la fois le troisième article des antennes simple, c'est-àdire, sans subdivisions, et les tarses munis de trois pelottes; de sorte qu'ils forment une transition entre les deux grandes séries des Diptères à antennes triarticulées. Toutes les familles qu'il nous reste à décrire jusqu'aux Tipulaires nous offriront le troisième article des anteines 


\section{$\left(7^{3}\right)$}

plus ou moins subdivisé, et les tarses pourvus de trois pelottes. Ce dernier caractère peut paraitre, par son peu d'importance physiologique, un lien bien faible pour unir ces deux tribus; mais le reste de l'organisation montre qu'il n'est pas arbitraire, et les Leptides les lient encore entrelles par les parties de la bouche et par les nervures des ailes.

Plusieurs autres organes ont une disposition qui distingue plus ou moins les Leptides des autres Diptères. Les antennes sont insérées au bas de la tête et bien près de la trompe. Le thorax a souvent de chaque côté du bord antérieur un tubercule comme dans les Conopsaires. La poitrine est fort proéminente en-dessous, et les hanches antérieures qui s'appliquent contre elle, sont allongés dans la même proportion. Enfin les jambes postérieures et intermédiaires sont terminées par deux pointes, tandis que les antérieures n'en ont pas.

Cette petite famille présente plusieurs modifications assez importantes dans les organes. La lèvre supérieure est tronquée obliquement dans les uns et pointue dans les autres. Les palpes sont tantôt couchés sur la trompe, et tantôt relevés verticalement. Les antennes ont le troisième article conique et à style terminal dans le genre Leptis, ovale et à style dorsal dans les Athérix. Enfin il $\mathbf{y}$ a une légère variation dans la cellule anale des ailes, qui est ouverte ou fermée.

Les Leptides sont communs partout. Ils se tiennent sur les herbes et sur le tronc des arbres. On ne sait pas quelle est leur nourriture. Je ne les ai jamais vus sur les fleurs où tant de Diptères puisent des sucs nourriciers, et je ne les ai jamais trouvés occupés, comme tant d'autres, à faire la guerre aux autres insectes.

Nous connaissons mieux le développement des Leptides. 


\section{( 94 )}

Degeer a le premier observé les larves des Leptis scolopacea et annulata. Elles habitent la terre, le sable, le terreau des vieux saules. Elles sont apodes, allongées, à-peu-près cylindriques, rétrécies antérieurement, munies de deux stigmates à l'extrémité, couronnées de papilles ou de tubercules. Elles ont le corps composé de onze ou douze segmens qni sont souvent entourés d'un anneau élevé. La tête est petite, cornée, munie d'antennes. Les nymphes sont nues, cylindriques, pourvues d'épines fort petites au bord des segmens, et plus grandes à l'extrémité. Ces larves et ces nymphes, fort semblables à celles des autres Diptères, vivent cachées dans la terre, et se nourrissent apparemment de substances végétales.

Degeer a observé dans le midi de la France une autre larve de Leptide différente de celle-ci par quelques parties de l'organisation, et surtout par les habitudes qui nous présentent un des faits les plus singuliers de l'histoire des insectes. Tandis que les larves des Diptères ont généralement l'instinct le plus obtus, celle du Vermilion nous fait admirer une industrie presqu'égale à celle du Fourmilion, si bien décrite dans les Mémoires de Réaumur. Cette larve a la tête petite, molle (1), conique, armée de deux crochets; le corps est muni ça et là de poils roides dirigés en avant et insérés sur de petits mamelons. Le dernier, segment est plus long que les autres, plat, courbé et élevé, et il se termine par quatre tentacules charnus, pourvus de quelques poils assez épaịs. Sur les côtés du cinquième segment, on voit aussi une petite saillie de l'extrémité de laquelle sort une pointe rétractile, cornée, brune, conique. Aussi vive que les autres larves

(v) Latréille dit que cette larve a la tête de forme variable if ei Meigren, qu'elle $\mathrm{T}$ a cornce. 


\section{( 75 )}

sont lentes, celle-ci se fait dans le sable de petits enfoncemens en forme d'entonnoirs semblables à ceux du Fourmilion. Degeer n'a pas vu si elle se sert du même procédé pour les creuser ; si elle y parvient en jetant le sable de la même manière et en faisant les mêmes circonvolutions; mais comme elle est différemment conformée, et que, u'ayant pas de pieds, elle ne peut que ramper, il est très-probable qu'elle se borne à lancer le sable du centre de l'excavation au moyen d'un mouvement de tête qui lui est propre. Quoiqu'il en soit, elle se tient de même à demi-cachée au fond de son embuscade, et attend que quelque petit insecte y trébuche. Elle le saisit alors en le serrant dans les replis de son corps, et sans doute avec les pointes du cinquième segment, elle le tue, en hume toute la substance, et finit par en jeter fort adroitement la dépouille hors de l'entonnoir avec la tête. Lorsqu'elle a atteint le terme de son développement, elle se transforme en nymphe sans se faire de coque et sans conserver l'enveloppe de la larve, mais en se couvrant de sable qui s'attache au corps.

La classification des Leptides a éprouvé de grandes variations. Confondus dans le genre mouche par Linnée, comprises parmi les Némotèles de Degeer, Fabricius institua pour elles le genre Rhagion dans ses premiers ouvrages, mais en y colloquant, par une assimilation bien peu naturelle, les Rhyphes et même les simulies et les Sciares. Latreille en ofa tout ce qui y était étranger, et il fonda la famille des Rhagionides, en y comprenant les Dolichopes dout il fit depuis une famille particulière. Meigen, dans son ouvrage sur la classification des Diptères, sépara des Rhagions le genre Athérix, caractérisé par le style dorsal des antennes. Pẹu après, Fabricius, dans le Systema antlia- 
torum, adopta le nom de ce nouveau genre; mais, prenant pour caractère la disposition des palpes, il y introduisit d'autres Rhagions. Il substitua aussi à ce dernier nom celui de Leptis pour éviter qu'on ne le confondît avec celui de Rhagium donné à un genre de Coléoptères. Enfin Meigen, dans sa description des Diptères d'Europe, conserva cette nouvelle dénomination ; mais, rendant au genre Athérix les caractères qu'il lui avait donnés, il replaça parmi les Leptis les espèces dont Fabricius avait fait des Athérix. Tel est l'état actuel de cette famille, auquel je crois devoir proposer encore un changement. Meigen en caractérisant le genre Leptis par les antennes à style apical, l'a divisé en deux sections d'après la direction et la conformation des palpes; l'une composée des espèces qui ont ces organes couchés sur la trompe; l'autre, de celles où ils sont relevés, et dont Fabricius a formé le genre Athérix. Comme cette dernière section me paraît offrir, outre ce caractère important, d'autres différences dans la plupart des organes, j'y trouve tout ce qui constitue un genre très-naturel, et j'en propose la formation sous le nom de Chrysopile, celui d'Athérix appartenant de droit aux Leptides à style dorsal, auxquelles Meigen l'a primitivement donné.

\section{Tableau synoptique des genres.}

Troisième article des antennes à style apical.

$$
\begin{cases}\text { Palpes couchés..... } & \text { LEPTIS. } \\ \text { Palpes relevés...... } & \text { CHRYSOPILE. }\end{cases}
$$

Troisième article des antennes à style dorsal...... ATHÉRIX.

LEPTIS, LEPTIS.

Leptis, Fab. Syst. antl., Fallèn, Meigen.

Rhagio, Fab. Spec. ins., Ent. syst., Rossi, Cuvier, 


\section{( 77 )}

Panzer, Latreille, Walckenaer, Illiger, Schranck , Schellenberg, Meig. Klassif. - Nemotelus, Degeer. Musca, Iinnée, Gmelin, Schranck, Villiers.

Cor'ps lisse. Têtè assez petite. Trompe cylindrique; lèvre supérieure tronquée obliquement. Palpes couchés; deuxième article conique. Troisième article des antennes à style apical.

Thorax muni d'un tubercule de chaque côté ; poitrine fort saillante en-dessous. Hanches antérieures allongées. Cellule anale des ailes ouverte. ( $\mathrm{Pl} .2, f$. 3.)

Ce genre que je réduis, à l'exemple de Fabricius, aux Leptides dont les palpes sont couchées sur la trompe, forme la première section des Leptis de Meigen. Toutes les espèces que j'ai observées ont les caractères qui leur sont attribués. Cependant plusieurs autres, décrites par cet observateur, ne les réunissent peut-être pas tous, et peuvent se rapprocher du genre suivant.

Ces insectes sont assez agréables par les taches noires qui ornent le fond jaune de leur abdomen. Ils ne se tiennent guères que sur le tronc des arbres. Lorsqu'ils se posent, leur unique mouvement est ordinairement de se placer le corps dirigé vers la terre, et ils y restent long-temps immobiles. Ils se réunissent souvent en grand nombre, le soir pendant l'été, sur le côté de l'arbre exposé aux derniers rayons du soleil.

1. Leptis striée ; L. strigosa, Meig.

Fauve. Antennes jaunes. Thorax à trois bandes noires (mâle), à ligne dorsale noire (femelle). Abdomen à taches dorsales antérieures et à bandes noires postérieures. Rhagio strigosus, Meig. Klass. I , 299, 3.

Long. 51.

Mâle : hypostome, front, palpes et antennes ferrugineux. Derrière de la tête cendré. Thorax à trois bandes 
noires; intermédiaire divisée ; côté d'un jaune clair à trois taches ardoisées à la base des hanches; écusson jaune à tache noire à la base. Abdomen fauve; segmens à tache dorsale noire; cinquième et suivans à bande noire. Pieds fauves; deuxième article des hanches à point noir à l'extrémité ; les quatre derniers articles des tarses obscurs. Balanciers jaunes. Aîles légèrement brunâtres ; extrémité et bord intérieur bruns ; nervures transversales bordées de brun; stigmate noirâtre.

Femelle : front jaunâtre à ligne brune. Thorax d'un jaune brunâtre luisant, à ligne dorsale noire. Les trois premiers segmens du ventre jaunes, les autres noirs.

Rare. Baumhauer l'a trouvée près de Paris.

2. Lepris bécasse; L. scolopacea, Meig., Fab. Syst. antl., Fall.

Thorax cendré à bandes obscures. Abdomen fauve à trois rangs de taches noires. Pieds jaunes; cuisses postérieures à anneau noir. Ailes tachées de noirâtre. Rhagio Scolopacca, Fab., Lat., Panz. , Schell., Schr. Faun. boic., Meig. Klass.

Nemotelus scolopaceus, Deg. 6, 68, $\mathbf{x}$. Musca scolopacea, Linn., Gmel., Schr. aust.

\section{Long. $6,7 \mathrm{l}$.}

Hypostome et front d'un gris clair. Palpes jaunes à poils blancs. Les deux premiers articles des antennes d'un brun grisâtre; le troisième roussâtre. Thorax ardoisé à bandes brunâtres; l'intermédiaire divisée antérieurement; écusson gris. Abdomen fauve, transparent; segmens à tache dorsale et bande latérale noires; dernier noir; ventre jaune dans le mâle, avec les deux derniers segmens noirs, souvent entièrement noir dans la femelle. Pieds jaunes; tarses bruns; cuisses postérieures à anneau d'un brùn noirâtre vers l'extrémité. Balanciers jaunes. Ailes 


\section{( 79 )}

blanchâtres; une bande brune et en zig-zag sur les nervures transversales à la base et à l'extrémité des cellules discoïdales; bords postérieur et intérieur bruns ; stigmate noir, allongé.

\section{Commune.}

3. Leptis distinguée; $\boldsymbol{L}$. conspicua, Meig.

Thorax ardoisé à bandes obscures. Abdomen fauve à trois rangs de taches noires. Pieds jaunes; cuisses et jambes postérieures noires à l'extrémité. Ailes à ligne marginale d'un brun noirâtre.

Rhagio conspicuus, Lat. gen. crust., Meig. Klass.

\section{Long. 8, $9 \mathrm{l}$.}

Mâle : hypostome et front d'un gris clair, changeant en blanc. Palpes jaunes. Antennes d'un brun noirâtre; premier article gris. Thorax ardoisé à bandes obsçures. Abdomen fauve; segmens à tache dorsale et bande latérale noires; le dernier noir; ventre fauve; les trois derniers segmens noirs. Pieds jaunes; premier article des hanches ardoisé ; deuxième noir; cuisses et jambes postérieures noires à la moitié inférieure; articulations jaunes; tarses d'un brun noirâtre. Ailes d'un brun jaunâtre pâle; bord extérieur fauve à ligne costale noire.

Femelle : front d'un gris brunâtre. Ventre noirâtre; bord postérieur des segmens jaunes.

Rare, dans les bois.

4. Leptis chevalier; L. tringaria, Meig., Fab., Fall.

Fauve. Abdomen à trois rangs de taches noires. Ailes sans taches.

Leptis vanellus, Fab. Syst. antl., Fall. Rhagio tringarius, Fab. , Lat., Schr., Meig. Rhagio vanellus, Fab. Ent. syst. 272, 3. Nemotelus scolopaceus, Var., Deg. 6, 69, I. Musca tringaria, Linn., Gmel. 


\section{( 80 ) \\ Long. 5,6 I.}

Mâle: hypostome et front d'un gris blanchâtre. Antennes d'un gris jaunâtre. Thorax à bandes d'un gris brunâtre. Abdomen fauve; segmens à tache dorsale et bande latérale noires; les trois derniers noirs. Pieds jaunes; tarses bruns; extrémité des jambes obscure. Balanciers jaunes. Ailes d'un jaune brunâtre pâle; bord extérieur fauve.

La femelle a l'abdomen noir dès le quatrième segment.

Commun. J'en ai trouvé une femelle qui n'a que $3 \div 1$.

5. LEPTIS vitripenne; L. vitripennis, Meig.

Troisième article des antennes fauve. Thorax cendré à quatre bandes obscures. Abdomen à trois rangs de taches noires. Ailes hyalines à ligne marginale obscure. Pieds jaunes.

Rhagio tringarius, Panz. Faun. Germ. 9, 14, 20.

Long. 4,5 1 .

Mâle : Trompe noire. Palpes jaunes. Hypostome gris. Les deux premiers articles des antennes noirs; le troisième fauve à style noir. Thorax cendré à bandes obscures; intermédiaire plns ou moins divisée; écusson jaunâtre à l'extrémité. Abdomen fauve; segmens à tache dorsale arrondie et bande latérale noire ; cinquième noir à large bord postérieur jaune; les deux derniers noirs; ventre noir; bord postérieur des segmens jaunes. Pieds jaunes ; tarses obscurs. Balanciers jaunes. Ailes légèrement jaunâtres au bord extérieur; bords postérieur et intérieur très-légèrement obscurs, ainsi que le bord des nervures; stigmate noirâtre.

Femelle : front d'un gris jaunâtre à grande tache noirâtre au milieu. Palpes noirâtres. Taches dorsalés de l'aldomen triangulaire

Plus commune que la L. bécasse. 
6. LEPTIS antennes jaunes; $L$. flavicornis, Nob.

Antennes jaunes. Thorax fauve à bandes obscures. Abdomen à trois rangs de taches noires. Ailes hyalines à ligne marginale noire; extrémité obscure.

\section{Long. $4 \mathrm{l}$.}

Semblable à l'espèce précédente, excepté : antennes jaunes à style noir. Thorax jaune sur les côtés; dos d'un fauve rougeâtre à ligne intermédiaire et deux bandes noirâtres. Ailes à bord postérieur obscur ; stigmate noir.

Assez rare.

7. LEPTIS sans tache; L. immaculata, Meig.

Fauve. Thorax à bandes obscures. Abdomen et aile sans taches.

Rhagio immaculatus, Meig. Klass. 1, 3ox, 8.

\section{Long. 51.}

Mâle : hypostome et front d'un blanc grisâtre. Trompe, palpes et antennes jaunes. Thorax à bandes obscures ; intermédiaire divisée. Ecusson fauve. Les deux derniers segmens de l'aldomen noirs. Pieds fauves; tarses obscurs. Balanciers fauves. Ailes d'un jaune brunâtre pâle ; stigmate brun.

Femelle : front d'un gris roussâtre. Stigmate jaune.

Assez rare. M. Meigen n'a observé que le mâle.

8. Lepris linéole; L. lineola, Meig., Fall.

Thorax noirâtre: côtés blancs. Abdomen fauve. Taches dorsales noires. Ailes hyalines; ligne marginale noirâtre. Rhagio lineola, Fab. Ent. syst. 4, 275, 17, Meig. KI.

albifrons, Meig. Klass. 1,307 (m. ).

Atherix lineola, Fab. Syst. antl. $74,6$.

Long. 3,41 .

Hypostome et front blancs. Palpes et antennes d'un brun noir. Thorax noirâtre à bandes plus obscures; côtés d'un blanc grisâtre; écusson jauue. Abdomen jaune à 


\section{( 82 )}

taches dorsales noires. Pieds jaunes ; tarses obscurs. Cuisses antérieures et postérieures à anneau ¿brun vers l'extrémité. Ailes hyalines; ligne marginale d'un brun noir.

Rare.

CHRYSOPILE ; Chrysopilus. Nob.

Leptis, Sect. B. Meig. , Fall. - Atherix, Fab. Syst. antl. Rhagio, Fab. Spec. ins., Ent. syst., Lat. , Meig. Klassif.Musca, Linn., Gmel., Geoff., Schr.

Corps velu. Tête assez grande. 'Trompe cylindrique; lèvre supérieure tronquée obliquement; palpes relevés; deuxième article cylindrique. Troisième article des antennes à style spécial.

Thorax sans tubercule; poitrine saillante en-dessous. Pieds très-grêles. Cellule anale des ailes fermée. ( $P l .2$, f. 4.)

Les caractères qui distinguent ce genre du précédent consistent dans le duvet soyeux qui couvre le corps; dans la grandeur de la tête; dans la forme et la direction des palpes; dans l'absence des tubercules du thorax; dans la conformation très-grêle des pieds, et enfin dans la disposition de la cellule anale des ailes. L'importance de tous ces caractères m'a paru réclamer, comme je l'ai déjà dit, la formation d'un nouveau genre pour séparer ces insectes des Leptis, parmi lesquelles Meigen les a rangés, et des Athérix avec lesquels Fabricius les a confondus sans faire aucune mention des différences qu les distinguent.

Les poils dorés qui couvrent le corps de ces Leptides, et d'où dérive leur nom, leur donne quelque ressemblance avec les Anthrax, et Panzer en a compris une espèce dans ce genre; mais ces poils ont si peu d'adhérence avec le corps, qu'il en est très-souvent dégarni quand on 


\section{(83)}

prend ces insectes; et c'est ainsi que la nomenclaluré s'est obscurcic par les différens noms que l'on a dennés aux nêmes espèces, suivant l'état dans lequal on lés á observées.

Les Chrysopyles vivent particulièrement dans lés prairics et ne se posent pas sur les trones d'arbres comme les Lepi-s.

1. Cirnysopile dorée; $C$. aurraita.

Noire, couverte de poils dorés (mâle), jaụncs pâles (femelle). Balanciers et stigmate des ailes bruns.

Leptis aurala, Meig. 2, 99.

- atrata, Fall. Dipt. Suec. 13, 8.

Atherix atrata, aurata ( femelle), tomentosa fem. Fab. Syst. antl.

Rhagio atratus (femelle), Fab. Spec., Ent, syst., "Lat., Meig. Klass.

Rhagio tomentosus, Fab. Ent. sysi. Meig. Klass.

Misca alrata, Gmel. Syst. nat. $5,2866,323: 9: i$. Musca , 2, 534, 79, Geoff.

$$
\text { Long. } 3,41 .
$$

ils $b$ sisol hit ins.

Nâle : hypostome d'un gris noirâtre. "Antrintes din brun noirâtre. Cuisses et tarses d'un brun noirâtre jainles testacées. Balanciers obscurs. Ailes légèrcnènt obscures ; stigmate d'un brun rongeâtre. (Le corps nu est d'un beau noir velouté.)

Femelle : hypostome et front d'un gris noiratice. Ailes presqu'hyalines. (Le thorax nu est d'un gris 'brun avec trois bandes noires; l'intermédiaire lincaire.)

Très-commun au mois de mai dans les fortifications des villes; assez rare ailleurs.

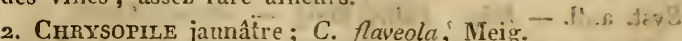

Couverte de poils d'un jaune pâle. Pieđs jąunes ; cuisseses olscures. Balanciers bruns. Ailes jaunâtres "stignnate pâle.

Anthrax genius, Panz. Faun. Cerm., $54,4$.

Long. $3 \div 1$. 
Corps d'un noir velouté à poils d'un jaune clair, luisans. I Palpes et antennes noirs. Hypostome d'un noir grisâtre. Côtés du thorax gris. Pieds jaunes; cuisses brunes à extrémité jaune; tarses à extrémité brune. Balanciers noirâtres. Ailes d'un jaune brunâtre pâle; stigmate pâle.

Rare.

3. Chrysopile diadème; $C$. diadema.

Noirâtre, à poils dorés. Trompe et pieds jaunes. Abdomen du mâle à bandes noires. Stigmate des ailes brun.

Leptis diadema, Meig. t. 2, $\mathbf{1 0}$.

Atherix diadema, Fab. Syst. ant. , 73, 2.

Rhagio diadema, Fab. Spec. ins., Ent. syst., Meig. Klass.

- aureus, Meig. Klass., x, 302, 9 .

Musea diadema, Gmel. Syst. nat., Schr. aust.

2, 535, 80, Geoff.

\section{Long. $2 \div 1$.}

Mâle : Trompe jaune. Palpes d'un brun noirâtre. Hypostome d'un gris blanchâtre. Antennes obscures. Pieds d'un jaune pâle ; extrémité des jambes obscure; tarses obscurs à base jaúne. Balanciers d'un jaune pâle à point obscur à l'extrénité. Ailes hyalines à tigmate brun. (Lorsque le corps est $n u$, le thorax est d'un gris hrun, et l'abdomen a les segmens gris à bord antérieur noir.

Femelle : Hypostome et front d'un gris clair. Corps. d'un gris brun à poils d'un jaune clair soyeux.

Assez commune.

ATHÉRIX ; ATHERIX.

Atherix, Meig., Lat., Fab. - Leplis, Fab. Syst. antI. - Rhagio, Fab. Ent. syst. - Anthrax, Fab. Ent. syst., Syst. antl. - Bibio, Fab., Meig. - Musca, Gmel.

Corps peu velu. Trompe convexe en-dessous. Lèvre supérieure pointue. Palpes relevés vers la base et courbés en-dessous vers l'extrémité. Troisième article des antenues ovale; style dorsal. 
Thorax muni d'un tubercule de chaque côté. Poitrine peu saillante en-dessous. Cellule anale des ailes souvent fermée. ( $P l .2, f .5$.)

Le caractère essentiel des Athérix est d'avoir le troisième article des antennes muni d'un style inséré vers la base ell-dessus. C'est une singularité, si l'on considère que dans toutes les familles voisines le style est terminal. Meigen attribue à ce genre un autre caractère plus singulier encore; ce sont des palpes de trois articles. Comme ce nombre ne se trouve que dans une seule famille de Diptères, celle des Stratiomydes, je n'ai pu me défendre d'un doute, et j'ai voulu m'assurer par mes propres observations de l'exactitude de cette assertion. J'ai examiné au microscope et avec beaucoup d'attention les palpes de l'Athérix sans tache, et je n'y ai distingué que deux articles; l'un fort court et servant de base au second qui est long. Je me persuade donc que Meigen s'en eșt rapporté à de fausses apparences. $\Lambda u$ surplus, dans la figure qu'il donne de ces palpes, et qu'il a dessinée lui-mệme, on ne voit distinctement que deux arlicles; et l'on n'y aperçoit d'indice du troisième que lorsque l'on connất la description.

Le genre Athérix est assez naturel. L'organisation des diverses espèces n'est modifiée que dans la forme de l'abdomen, qui est tantôt conique, tantôt déprimée. Cependant, comme, à l'exception de Meigen, aucun observateur n'a fait mention du caractère que fournit l'insertion du style des antennes, ces insectes ont été disséminés parmi les Anthrax, les Thérèves et les Leptis. 1. Athérix Ibis; $A$. Ibis, Meig.

Pieds fauves. Ailes tachetées de noir. Atherix maculdulu, Meig. Klass., Lat. Gen. crust. Leptis Ibis, Fab. Syst. antl., 70, 5. 
Rhagio Ibis, Fab. Ent. syst. supp., 556.

Anthrax titunus, Meig. Klass., Fab. Syst. Antl., Schoeff. icon. tab. 107, f. 5,6 .

\section{Long. 4,51 .}

Mâle : hypostome et front d'un gris clair. Thorax d'un brun jaunâtre, velu, à bandes étroites ardoisées ; écusson noir. Abdomen conique, premier segnent d'un brun noirâtre; les suivans fatives à bord postérieur d'un jaune clair, une tache dorsale et une de chaque côté noires, ces taches confondues dans les derniers segmens; ventré jaune. Pieds fauves; extrémité des tarses obscure. Balanciers jaunes à tête brune. Ailes hyalines à bandes transversales irrégulières d'un brun rougeâtre.

Femelle : front jaunâtre à ligne brunâtre, divisée antérieurement. Abdomen cendré ; segmens à bandes antérieurement noires, pointues sur les côtés; bord postérieur blanc; ventre cendré.

Rare, dans le Hainaut.

2. Athérix bordé; $A$. marginata, Meig.

Noir. Abdomen à bandes blanches.

Bibio marginata, Fab. Syst. antl., Ent. syst., Spec. ins., Meig. Klassif.

Musca marginata, Gmel. Syst. nat.

\section{Long. 41.}

Tête grise, velue. Front de la femelle nu sur les bòrds et au milieu. Trompe et antennes noires. Thorax du mâle noir avec les côtés gris; celui de la femelle d'un gris blanchâtre, marqué de trois bandes noirâtres qui n'atteignent pas le bord postérieur; tubercuies d'un gris roussâtre mat. Abdomen noir avec le bord postérieur des segmens blanchâtre; conique dans le mâle, déprimé dans la femelle; anus noir. Pieds testacés avec l'extrémité des tarses noire. Balanciers noirs à pédicule fanve. Ailes à 


\section{( 87 )}

trois bandes noirâtres, irrégulièrement en zig zag sur les nervures transversales; l'intermédiaire plus grande ; base de l'aile brune danş le mâle; cellule anale fermée et pédiculée.

La description de Meigen diffère de celle-ci par les pieds noirs. Celle de Fabricius en diffère encore par les tubercules du thorax luisans. Meigen dit que cet insecte est très-rare; Fabricius, qu'il est d'Ttalie. Je le trouve chaque année, au mois de mai, en naviguant sur la Lys. Il se pose sur les bateaux.

3. AthÉRIx nẻbuleux; $A$. nebulosa, Meig. , Fab. Syst. antl. Abdomen noir à bandes jaunes. Stigmate des ailes obscur.

Rhagio nebulosus, Fab. Ent. syst. supp., Meig. Klassif.

Long. 3 l. m., $2 \frac{1}{2}$ l. fem.

Noirâtre. Front de la femelle marqué d'un large sillon. Thorax d'un noir luisant; côtés et tubercules jaunes; une tache noire sous la base des ailes; poitrine noire. Abdomen cylindrico-conique, noir, avec une large bande jaune au bord postérieur des segmens; les trois derniers entièrement noirs dans le mâle. Pieds jaunes avec les tarses et une ligne noirâtre vers l'extrémité des cuisses postérieures en-dessus; premier article des tarses postérieurs légèrement renfé dans le mâle. Balanciers noirâtres avec le pédicule jaune. Ailes hyalines marquées d'une bande légèrement obscure sur les nervures transversales; bord postérieur également obscur; tache stygmatique noirâtre; cellule anale fermée et pédiculée.

La. description de Meigen diffère de celle-ci par l'hypostome ferrugineux et par l'écusson jaune. Il n'a vu que la femelle qui lui a été communiquée par Wiedemann. . Fabricius dit que cette espèce est d'Italie. J'ai trouvé ici un mâle et une femelle. 
4. Atuenrux sans tache; $A$. immaculata, Meig.; Fab. Syst. antl.

D'un gris obscur. Ailes sans tache. Balanciers testacés. Long. 21 . m. , 3 1. fem.

Front marqué d'un point blanc au-dessus des antennes. Thorax à trois bandes noires peu distinctes. Pieds noirs; genoux roussâtres. Ailes légèrement grisâtres; tache stigmatique peu distincte; cellule anale ouverte.

Très-commun au mois de mai sur les herbes des fortifications de Lille.

VÉSICULEUX ; inflate, Lat., Meig.

Caractère essentiel : antennes ordinairement de deux articles distincts; dernier sans divisions. Abdomen trèsépais. Tarses munis de trois pelottes.

Corps court, très-épais. Tête très-petite, subglobuleuse, déprimée antérieurement, beaucoup plus basse que le thorax. Trompe tantôt très-allongée, fléchie sous la poitrine et accompagnée de palpes très-petits et filiformes, tantôt paraissant nulle et sans palpes distincts. Antennes insérées tantôt entre les yeux, sur le vertex, tantôt sur le bord antérieur de la bonche, ordinairement de deux articles distincts, le dernier quelquefois terminé par un style. Yeux contigus, occupant presque toute la tête. Trois yeax lisses.

Thorax beancoup plus large que la tête, arrondi, fort élevé; côtés du premier segment se prolongeant souvent en épaulettes saillantes. Abdomen grand, paraissant vide, cylindrique, arrondi postérieurement, de cinq segmens distincts. Pieds sans pointes. Tarses munis de trois pelottes; premier artīcle allongẻ. Cuillerous très-grands, voùtés. Balanciers petits. Ailes écartées, inclinées aux côtés du corps; nervures diversement disposées; tantôt deux cel- 


\section{( 89 )}

lules sous-marginales, trois discoïdales, cinq postérieures, tantôt une ou deux discoïdales, trois on quatre postérieures peu distinctes (1).

Nous plaçons ici une famille embarrassante pour la classification, assez naturelle, si l'on considère la forme générale du corps, mais bien arbitraire et composée de deux familles distinctes, si l'on examine les divers organes en particulier; empruntant quelques traits de divers autres Diptères, mais ayant en propre une figure fort extraordinaire. En voyant le thorax et l'abdomen grands, larges, convexes, ce dernier ne semblant contenir que de l'air, accompagnés d'une tête si petite, insérée tellement au bas du thołax, qu'on ne l'aperçoit pas d'abord, on comprend comment le nom d'Acéphale a pu être donné à l'un de ces insectes, et il semble qu'une conformation si disproportionnée n'est due qu'à l'injection artificielle d'un fluide qui aurait élevé et étendu excessivement le corps sans la tête, et produit ainsi une espèce de monstre.

Les vésiculeux, outre cette conformation si anomale, ont une espèce d'épaulette au thorax, formée par la dilatation du premier segment; les cuillerons qui recouvrent les balanciers sont très-grands. Les ailes écartées et inclinées semblent rejetées sur les côtés du corps; enfin les pieds ne sont armés d'aucune pointe, et les tarses sont munis de trois pelottes. Maintenant, si l'on recherche les différences qui les distinguent entr'eux, on voit d'abord, dans les uns, une trompe longue, accómpagnée de palpes et semblable à celles des Bombyles, mais féchie sous la poitrine comme dans les insectes Hémiptères; dans les autres, elle semble nulle et sans palpes. Les premiers ont le système réticulaire des ailes très-complet et semblable

(1) Nous figurerous ces ailes daus le prochain fasciculc. 


\section{( 90 )}

à celui de Leptides; dans les seconds, il est trèsimparfait et se rapproche quelquefois de celui des Stratiomydes. Outre ces deux modifications qui, par. leur importance, pourraient autoriser la division de ces Diptères en deux familles, l'insertion, des antennes est diversifiée dans l'un de ces groupes, eì se trouve tantôt sur le vertex, tantôt sur le bord antérieur de la cavité de la bouche. It semble que la pețtesse de la tête et la grandeur relative des yeux n'aient laissé de place pour. cet organe qu'aux deux extrémités de la tête.

"On ne sait que peu de chose sur les mœurs de ces, petits Diptères, et rien sur leur mode de développement. Ceux qui ont la trompe allongée et les nervures des ailes nombreuses, voltigent en bourdonnant autour des fleurs (1), et y puisent leur nourriture, sans doute en volant comme les. Bombyles. Ils recherchent le soleil et les lieux un peu élevés. Ceux dont la trompe et les nervures alaires sont peu dévcloppées, n'ont pas de vivacité (2). On les trouve sur les herbes et sur les fleurs, souvent au bord des eaux. Les premiers sont propres au midi; ils s'étendent dans l'intérieur de la France, mais ne parviennent pas jus iu'à Paris. Les autres appartiennent à toute l'Europe, mais ils sont rares partout.

Cette petite famille, qui offre deux genres d'organisation si éloignés l'un de l'autre, ne peut pas se placer d'une manière naturelle. Instituée par M. Latreille, elle a été rangée par son fondateur, d'abord entre les Empides et les Siphonculés, ensuite entre les Bombyliers et les Syrphies. M. Meigen, Ia place entre les Empides et les Stratiomydes. Je crois devoir la mettre entre celles-ci et les Leptides, par la

(1) Voyez Latreille, Mistoire naturelle des Crust. et Ins. , t. 14 , p. 314.

(2) Voyez Neigen, iom. 3, p. 99 


\section{( $\left.9^{\mathrm{I}}\right)$}

considération des trois pelottes des tarses. Elle forme, comme je l'ai dit, avec cette dernière famille, une transition pour arriver aux Diptères dont le troisième article des antennes est divisé, et elle présente quelquefois des rapports directs avec les Stratiomydes parmi lesquels Fallèn a rangé l'un des genres dont elle se compose.

\section{TABLEAU DES GENRES.}

Trompe cachée.
Antennes insérées, $\left\{\begin{array}{l}\text { sur le vertex........ ACROCÈRE. } \\ \text { au bord de la bouche. OGCODE. }\end{array}\right.$ ACROCËRE; ACRocera.

Acrocera, Meig., Lat. - Hencps, Fall., Fab. Syst. antl.

- Ogcodes, Lat. Gen. crust: - Syrphus, Fab. Ent. syst., Panz.

Trompe et palpes en apparence nuls ; suivant Fabricius, petiie et rétractile; suçoir consistant en une gaine univalve, et ne renfermant qu'une soie; palpes courts, filiforınes; vertex un peu plus bas que les yeux et recevant antérieurement la base des antennes, et immédiatement après, les yeux lisses. Antennes petites, verticales; premier article très-court, patelliforme ; deuxième fusiforme, ierminé par un long style.

Thorax nu. Abdomen presque sphérique. Nervures des ailes facilement distinctes; cellule marginale imparfaite; dcux sous-marginales terminales dont la première imparfaite; deux discoïdales; l'externe quelquefois confondue avec la première postérieure ; deux postérieures n'atteignant pas l'extrémité de l'aile ; anale et axillaire distinctes.

M. Meigen a donné le nom d'Acrocères aux insectes de cette famille qui ont les antennes insérées sur le vertex, par opposilion aux Hénops qui ont cette insertion près 
de la bouche. Cette considération l'avait conduit à comprendre dans le même genre des Vésiculeux à trompe longue et courte. Il les a séparés depuiss, en adoptant pour les premiers le genre Cyrte que M. Latreille avait formé du Syrphus gibbus de Fabricius.

1. ACrocìne orbicule; $A$. orbiculus, Meig.

Noir. Abdomen taché de blanc.

Henops orbiculus, Meig. Klass, x , 152, a. , Fab .Syst. antl. , $334,2$.

Ogcodes orbiculus, Lat. Gen. crust. ins., 4, 318. Syrphus orbiculus, Fab. Ent. syst., 4, 311 , 122.

Long. $x=1$.

Thorax à deux taches blanches, allongées, dé chaque côté; l'une à l'épaule, l'autre entre la base de l'aile et l'écusson. Abdomen d'un brun noirâtre; premier segment a large bande blanche interrompue ou échancrée antérieurement au milieu et n'atteignant pas le bord extérieur ; deuxième à bande semblable moins interrompue et s'étendant davantage sur les côtés; les suivans forts petits, entièrement blanchâtres; anus brunâtre. Pieds d'un blanc jaunâtre. Cuillerons fort convexes. Ailes hyalines, beaucoup plus longues que l'abdomen.

Fort rare.

OGCODE ; OGCODES.

Ogcodes, Lat. - Henops, Meig. , Fab. Syst. antl., Walck., Fall. - Syrphus, Fab. Ent. syst., Panz. - Nemotelus, Schœff. - Musca, Linn., Gmel.

Trompe et palpes comme dans le genre précédent. Antennes insérées sur le bord antérieur de la cavité de la bouche, très-petites, inclinées ; premier article très-court, patelliforme; deuxième ovalaire, à style allongé, un peu renflé à l'extrémité et terminé par deux petites soies.

Thorax pubescent. Abdomen presque sphérique, déprimé 


\section{$\left(9^{3}\right)$}

en-dessous. Nervures des ailes peu distinctes ; cellules marginale et sous-marginale confondues; deux discoïdales ; quatre postérieures; deuxième et troisième confondues à la base.

L'insertion des antennes au bord de la bouche distingue singulièrement les Ogcodes des Acrocères, et les rapproche un peu des Némotèles parmi lesquelles Schœffer les a rangés. Ces insectes ont un autre rapport avec ces dernières par la nullité apparente des palpes et les couleurs de l'abdomen. Ils offrent encore une certaine ressemblance avec les Stratiomydes en général par les nervures peu distinctes des ailes. Aussi Fallèn les a-t-il compris dans cette famille, avec les Acrocères, quoique la forme du corps les en éloigne entièrement.

M. Latreille a donné à ces insectes le nom d'Ogcodes ; M. Meigen a adopté celui d'Hénops, qui appartient à Illiger. Avec des droits à peu près égaux, l'un et l'autre réclament la préférence fondée sur la priorité (1). Comment pourrions-nous hésiter à choisir le nom donné par le grand entomologiste, émule de Fabricius, qui, s'éloignant d'une trop séduisante théorie, a posé la science sur ses véritables bases, lui a donné la plus belle ordonnance, une classification avouée par la nature, une hiérarchie indispensable l'ordre; dont les immensés travaux ont porté le plus grand jour, non-seulement dans la classe entière des insectes, mais encore dans celles des Crustacés et des Arachnides; qui compte parmi ses élèves la plupart des entomologistes actuels, et dont la retraite enfin,

(1) Ces deux noms qui n'expriment que des caractères communs à foute la famille, pourraient ètre remplacës par celui de Stomacère, qui indiquerait le caractère essentiel fondé sur l'insertion des antennes sur les bords de la bouche. 


\section{( 94 )}

toute récente et nécessitée par la fatigue de ses longs travaux, affligerait profondément la science si elle ne conservait l'espoir que, rendu à la santé par le repos, il pourra jouir paisiblement d'une célébrité si bien acquise.

I. Ogcode bossu ; O. gibbosus.

Thorax noil. Abdomen blanc à bandes noires. Pieds fauves; cuisses à base noire.

Ogcodes leucomelas, Lat. Encyc. tom. 8, p. 2, pag. 471. Henops gibbosus, Meig. tom. 3, 99, Walck. Ent. par.,

Fab. Syst. antl., 333, x.

Henops leucomelas, Meig. Klass., 1, 15 1 , 2, Fall., 3, 2. Syrphus gibbosus, Fab. Ent. syst., 4, 31 1 , 121 .

Musca gibbosa, Linn. Faun. suec. 18 15, Gmel., 5, 2874, 49 .

$$
\text { Long. 2, } 3 \div 1 \text {. }
$$

Tête noirâtre. Thorax d'un noir luisant, à poils jaunâtres antérieurement, gris postérieurement. Abdomen d'un blanc d'ivoire; une bande noire au bord postérieur des segmens, élargie au milieu; ventre blanc; base et bord postérieur des segmens noirs. Pieds d'un fauve pâle; cuisses noires, à extrémité fauve. Cuillerons blancs. Ailes hyalines.

Rare.

2. OGCODE bordé ; $O$. marginatus.

Thorax noir. Abdomen noirâtre; bord postérieur des segmens blanc. Pieds fauves.

Henops marginatus, Meig. tom. 3, 100.

- gibbosus, Meig. Klass, 1, 151, 1, Fall. Strat., 3 , 2 .

Syrphus gibbosus, Panz. Faun. germ., 44, 21.

Nemotelus, Schœff. Icon. ins. t. 200, 1.

Long. $2,31$.

Thorax d'un noir luisant à poils gris. Abdomen d'un brun noirâtre; bord postérieur des segmens blanc; ventre 


\section{( $\left.9^{5}\right)$}

blanc à bandes d'un brun noirâtre. Pieds entièrement d'un fauve pâle. Cuillerons blancs. Ailes hyalines à nervures costales d'un brun jaunâtre.

\section{Rare.}

3. Ogcode pallipède; O. pallipes, Lat. Enc.

Thorax noir. Abdomen noirâtre; bord postérieur des deuxième, troisième et quatrième segmens blanc.

$$
\text { Long. 2, } 3 \text { I. }
$$

Thorax d'un noir hisant, pubescent. Abdomen d'un brun noirâtre; bord postérieur des deuxième, troisième et quatrième segmens blanc en-dessus et en-dessous. Pieds d'uu jaune blanchâtre; hanches noires. Cuillerons blanchâtres, bordés de noir. Ailes hyalines à nervures jaunâtres.

\section{Rare.}

4. OgCode varié ; O. varius, Lat. Encyc.

Thorax noir à taches roussâtres. Abdomen brunâtre à taches noires et lord postérieur des segmens blanchâtre.

\section{Long. 21.}

Thorax d'un noir luisant, pubescent; extrémité du premier segment, bord postérieur des épaules, pointe de l'écusson et deux taches à la base de ce dernier, d'un roussâtre foncé. Abdomen d'un brun roussâtre; bord antérieur des segmens noirâtre et s'avançant au milieu en taches triangulaires; bord postérieur d'un blanc jantnâtre; ventre -blanchâtre; quelques points noirs sur les côtés. Pieds noirs; extrémité des cuisses et jambes jau-

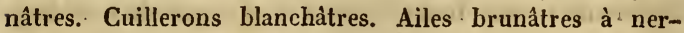
vures noires.

Rare.

STRATIOMYDES ; Stratiomydæ, Lat.; Meig.

Caractère essentiel : antennes de trois articles; troisième divisé."Abdomen de cinq segmens distincts. Tarses 


\section{$\left(9^{6}\right)$}

munis de trois pelottes. Ailes ordinairement à cinq cellules postérieures, souvent peu distinctes.

Corps oblong. Tête subhémisphérique, à la hauteur du Thorax. Front presque nul dans les mâles; large dans les femelles; hypostome ordinairement plat. Trompe peu saillante; lobes terminaux, épais, ovales, velus. Lèvre supérieure pointue ou échancrée; langue rarement distincte ; deux soies ( mâchoires) capillaires, quelquefois peu distinctes. Palpes ordinairement de trois articles; le troisième ordinairement renflé. Antennes rapprochées à la base, insérées ordinairement vers le bas de la tête,

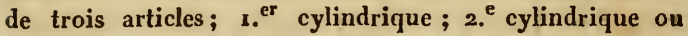
cyathiforme ; 3 . $^{\mathrm{e}}$ lenticulaire, conique ou fusiforme, à 3,4 ou 5 divisions, ordinairemènt terminé par un style. Yeux arrondis; trois yeux lisses.

Thorax ovale, marqué d'une suture sur les côtés; écusson tantôt mutique, tantôt armé de deux pointes au bord postérieur. Abdomen ordinairement court, déprimé, dépassant les ailes sur les côtés, de cinq segmens distincts. Pieds assez courts; jambes mutiques; tarses munis de trois pelottes. Balanciers allongés, découverts. Ailes couchées. Nervures postérieures, souvent peu distinctes ; point de cellule stigmatique ; marginale très-petite; deux sous-marginales petites, ordinairement éloignées du bord postérieur ; trois discoïdales; ordinairement cinq postérieurés n'atteignant pas ordinairement l'extrémité de l'aile; base de la quatrième appuyée sur la discoïdale inférieure; anale fermée, souvent éloignée du bord intérieur et arrondie vers l'extrémité ; nervure axillaire nulle. ( $P l .2$, fig. $6-8 ; p l .3$, fig. 1 - 3.)

Trois familles de Diptères, les Stratiomydes, les Xylophagites et les Tabaniens, qu'il nous reste à décrire jusqu'aux Tipulaires, offrent une modification singulière 


\section{( 97 )}

dans la conformation de leurs antennes. Les deux premiers articles n'ont rien de particulier ; mais ensuite on distingue, soit une suite d'autres articles plus ou moins serrés qui paraissent n'en former qu'un, soit réellement un seul qui, marqué d'incisions circulaires, semble subdivisé en plusieurs. C'est cette dernière définition qui a été généralement adoptée, excepté pour le genre Hexatome parmi les Tabaniens, dont les antennes sont réputées de six articles. Je pourrais appuyer l'opinion contraire en rapportant une observation que j'ai faite sur les antennes des Stratiomydes. J'en ai brisé quelquesunes en les pliant, et elles se sont toujours rompues a l'une des sections, ce qui semble prouver qu'il y a autant d'articles que d'incisions. Il est à remarquer aussi qu'un assez grand nombre d'autres insectes de divers ordres, tels que les Cynips, les Nitidules et plusieurs Tipulaires, ont également les antennes terminées par une masse composée de plusieurs articles plus ou moins serrés, et qui a la plus grande analogie avec le troisième article que nous examinons. Quoiqu'il en soit, M. Latreille, dans ses savans Mémoires sur l'organisation des insectes, considère les antennes comme composées de deux parties : la base, formée de deux articles, qui se modifie fort peu, et la tige, infiniment variable, dont nous retrouvons en quelque sorte le type dans le dernier article des antennes triarticulées des Diptères, et qui présente la modification la plus simple dans ceux qui ont ce troisième article incisé, comme les Stratiomydes, les Xylophagites et les Tabaniens. Cet organe paraît donc développé dans ce groupe plus que dans les familles précédentes, et il semble être une transilion pour arriver aux Tipulaires. Les autres parties de l'organisation montrent aussi plus ou moins un développement ascendant. Dans ces trois 
familles, les tarses sont munis de trois pelottes comme dans les Leptides et les Vésiculeux. Los Stratiomydes et les Xylophagites ont souvent les palpes de trois arlicles. Enfin les Tabaniens ont la trompe plus fortement organisée que dans aucun autre Diptère, à l'exception du genre Cousin.

Ces trois familles, par les caractères qui leur sont communs, constituent une tribu plus naturelle qu'elle ne le paraît d'après un examen superficiel. Rien de plus différent que les Stratiomydes et les Tabaniens, et cependant les Xylophagites viennent s'interposer entr'eux, et s'unissent tellement aux unes et aux autres, qu'il est impossible de méconnaître la série naturelle que ces familles forment entr'elles.

Les Stratiomydes, par lesquelles nous commencerons, à cause de leur organisation moins développée, montrent surtout cette infériorité dans la conformation de la Trompe. Non-seulement les soies écailleuses ne sont pas au nombre de six comme dans les Tabaniens, mais on en distingue difficilement quatre, et Latreille même n'en a reconnu que deux, la lèvre supérieure et la langue. Cependant les palpes ont souvent un article de plus que n'en ont ordinairement les Diptères, et le troisième est quelquefois remarquable par sa forme globuleuse.

Les nervures des aîles semblent également moins développées que dans les familles suivantes, et elles ont une disposition particulière. La cellule marginale fort petite, prend naissance vers l'extrémité de la médiastine, tandis que dans la généralité des Diptères, elle commence bien en deça. Leș deux sous-marginales, égalemeut petiles, n'atteignent pas l'extrémité de l'aile. Enfin les nervures qui forment les cellules postérieures sont incomplètes et affectent une disposition rayonnante autour" de la dis-" 


\section{( 99 )}

coïdale inférieure. On remarque aussi que la surface des ailes est ridée longitudinalement ( 1 ).

Les Stratiomydes diffèrent encore des Diptères suivans par la conformation de l'abdomen qui n'offre que cinq segmens distincts ; et telle est apparemment la raison qui a déterminé Meigen à les rapprocher des Syrphies et des Muscides, en accordant plus d'importance à ce earactère qu'à ceux qui les en éloignent; cependant si l'on considère que la différence observée dans le nombre des segmens de l'abdomen des Diptères n'est qu'apparente, et que ce nombre est toujours de sept dont les derniers, quelquefois fort petits et rétractiles, sont plus ou moins cachés dans le précédent; cette différence se réduira à quelques modifications dans la forme, et perdra beaucoup de l'importance que Meigen paraît y attacher.

Ces Diptères ainsi que les Xylophagites offrent encore un caractère distinctif dans les pointes qui terminent souvent l'écusson, et dont la destination est peut-être de faciliter la sortie de l'insecte hors de l'enveloppe de nymphe. Ces pointes leur ont fait donner, par Réaumur, le nom de Mouches armées, traduit en celui de Stratiomys par Geoffroy qui en a fondé le genre. Ensuite Meigen et Fabricius ont divisé ce genre en plusieurs autres, ..et Latreille l'a converti en famille. Enfin Meigen, , consi $\rightarrow$ dérant les principales modifications et particulièrement le nombre des segmens de l'abdomen, a établi, une seconde famille sous le nom de Xylophage.

L'organisation des Stratiomydes se modifie de diverses

(1) M. Latreille, trompé par la disposition singulière de la cellule marginale, l'a prise pour un stigmate; de sorte qu'il regarde les sousmarginales comme marginales, et la première postérieure comme sousmarginale. 
manières. La tête, ordinairement déprimée, se prolonge en pointe dans les némotèles. Le même genre offre une autre singularité dans l'insertion des antennes sur cette saillie de la tête. Plusieurs genres sont caractérisés par le nombre des divisions du troisième article des antennes qui varie de trois à cinq, et par la forme de cet article. Quelques-uns se distinguent par la forme de la lèvre supérieure et des palpes ; d'autres'par l'écusson armé ou mutique. Les nervures des ailes, quoique peu diversifiées, offrent encore des caractères génériques. Enfin une modification singulière affecte les yeux dont les facettes, dans quelques Stratiomes mâles, sont beaucoup plus grandes dans la partie supérieure que dans l'inférieure. Je n'ai fait la 'même observation que sur les Tabaniens.

Les Stratiomydes de l'Europe appartiennent généralement à la partie tempérée, et les espèces connues y sont nombreuses. Quelques-unes sont rares dans le nord de la France.

Ces insectes proviennent de larves ovales, allongées, aplaties, qui, pour la plupart, vivent dans l'eau. Le corps est formé de douze segmens recouverts d'une membrane assez-dure et peu flexible; les premiers sont larges et courts; les trois derniers ordinairement étroits et allongés en forme de tube. Dans les espèces aquatiques, la tête est petite, cornée. La bouche est accompagnée, tantôt de deux crochets, tantôt de six. On y distingue encore deux espèces de palpes garnis de cinq pointes arquées et de poils. Cette conformation et l'action rapide et habituelle des palpes qui met l'eau en mouvement, paraît indiquer que ces larves se nourrissent de petits animaux que l'agitation de l'eau amène à la portée de la houche. Les trois derniers segmens du corps sont munis 


\section{( 101$)$}

en-dessous de deux petits crochets. Le dernier est terminé par un stigmate entouré d'une touffe de poils barbus que la larve met en contact avec l'air pour respirer, en se tenant souvent à la surface de l'eau. Les poils s'épanouissent alors en entonnoir, et paraissent ne servir qu'à écarter l'eau de l'ouverture du stigmate. Quoiqu'ils ressemblent fort aux panaches qui, dans d'autres animaux aquatiques, sont l'organe même de la respiration.

Lorsque ces larves ont atteint le terme de leur développement, elles changent d'état sans aucun changement extérieur de forme, restant sans mouvement et flottant sur l'eau. Leur peau sert de coque aux nymphes qui, ovales et offrant déjà tous les organes de l'insecte ailé, ne remplissent qu'une partie de cette enveloppe. Cet état dure dix à douze jours, et la dernière métamorphose a lieu comme dans les autres Diptères.

Swammerdam a le premier fait connaître le jeune âge des Stratiomydes; Réaumur ensuite l'a observé et décrit avec son talent ordinaire. Le développement de ces Diptères a étế revu depuis par la plupart des entomologistes qui ont étudié les mœurs des insectes, et aucun doute ne semblait pouvoir s'élever sur la vérité de ces observations, lorsqu'un professeur distingué de l'Allemagne fit une remarque qui lui donna une opinion différente sur le premier état des Stratiomydes, et il la fit adopter par Meigen qui tient le premier rang parmi les naturalistes dont les travaux ont les Diptères pour objet. " Suivant " les observations, dit ce dernier, de feu le professeur "Knoch, de Brunswick, les larves (des Stratiomes) sont " des chenilles parasytes qui vivent dans les vers aqua"tiques que l'on a pris faussement jusqu'ici pour les "véritables larves; car un de ces vers qu'il avait placé " dans un vase, mit au jour plus de 300 petits qui lui 


\section{(102)}

)

)

" de ses observations. La différence totale de la figure de

" ces larves présumées avec celle des autres larves de

" mouches, s'explique maintenant, ainsi que la cause

" pour laquelle on réussit si rarement à élever ces Dip-

" tères, ces vers vivant souvent sans en nourrir les larves.

"Ainsi la demeure de ces larves est connue, mais leur

"propre conformation ne l'est pas encore."

Quel que soit mon respect pour des autorités aussi imposantes, je ne puis abandonner l'ancienne opinion pour la nouvelle. D'abord l'observation sur laquelle celle-ci est basée ne me paraît pas concluante. Knoch rapporte à la vérité qu'un de ces vers en mit au jour plus de 300 qui lui étaient semblables, mais il ne dit pas de quelle manière il en fit l'observation; s'il les vit sortir du corps de leur mère, ou si, les ayant trouvés dans le même vase rempli d'eau, sans les y avoir mis, il en conclut qu'ils y étaient nés de celui qu'il y avait déposé. Il y a de grandes raisons pour adopter cette dernière interprétation, et il me semble que la conséquence que Knoch en a tirée n'est rien moins qu'inattaquable, et qu'il est très-possible que ces 300 vers soient éclos dans le vase d'un pareil nombre d'œufs qui ont facilement pu s'y trouver sans que Knoch s'en soit aperçu, la plupart des œufs d'insectes déposés dans l'eau ayant une transparence qui les rend peu visibles. Cette conjecture est d'autant plus admissible que les Stratiomydes, paraissant dans l'état parfait à deux époques différentes, au printemps et en été, il doit $\mathrm{y}$ avoir deux générations par an, et

(r) Voyez Knochs neue beitrage zur insektenkunde, Leinsick, $180 \mathrm{I}$. Seite 193 . 
qu'on peut trouver leurs larves dans différens degrés de développement.

Une seconde raison qui me dissuade de partager l'opinion du professeur allemand, est la difficulté qu'il y aurait pour les Stratiomydes de loger leurs larves dans les vers qui, selon lui, les nourrissent de leur substance. On ne peut guères supposer que ces insectes puissent déposer leurs œufs dans le corps des vers aquatiques, comme les Ichneumons dans celui des chenilles. Il est vrai que la nécessité de respirer amène souvent ces prétendus vers à la surface de l'eau; mais ils se tiennent dans une position plus ou moins renversée, et il n'y a que le tube respiratoire en communication avec l'air. Si l'on prèfère' l'hypothèse que le Stratiome confie ses œufs à l'eau, et que les larves, à leur naissance, s'introduisent dans le corps de leurs vers nourriciers, il est encore bien difficile de leur supposer les moyens nécessaires pour cette opération.

Enfin une raison plus puissante eneore m'éloigne de l'opinion de Knoch. Le prétendu ver qui, selon lui, nourrit la larve inconnue du Stratiome, ne peut nullement, par son organisation, être considéré comme un ver proprement dit, et même il n'est possible de le comprendre dans aucun ordre connu d'animaux invertébrés, si ce n'esí parmi les insectes dans l'élat de larves. Tous les naturalistes sentiront la force de cette objection: Ils savent combien la nature, cet ensemble plein d'harmonie des lois du Gréateur, répugne aux exceptions discordantes, et combien nous devons être en' garde contre les apparences qui:nous en font apercevoir. D'ailleurs cet animal présente dans ses organes, quoiqu'en dise Meigen, plusieurs rapports avec les larves de plusieurs Diptères, tels que les Syrphies et quelques Tipulaires. 


\section{( 104 )}

Par toutes ces considérations, je persiste à croire que les larves de ces insectes sont telles que Swammerdam et Réaumur nous les ont fait connaitre.

Les Stratiomydes des genres Sargue et Pachygastre, qui s'écartent de la famille par plusieurs caractères, s'en éloignent aussi par le mode de leur développement. Nous le décrirons à leur article.

\section{TA B LEA U des genres.}

\section{3.e article des antennes lenticulaires}

à trois divisions.

SARGUE.

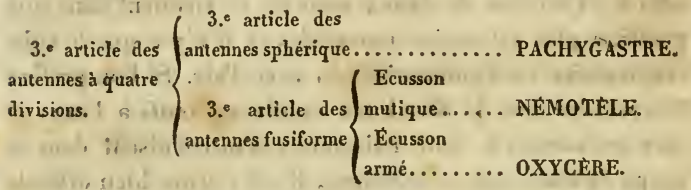

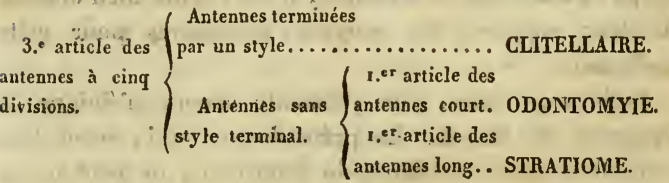

SARGUE; SARGUS.

Sargus, Meig., Lat., Fab. Syst. antl., Schell., Fall. Rhagio, Sch. Faun. boic. - Nemotelus, Deg. - Musca, Linn., Geoff., Gmel., Schr., Fab. Spec. ins., ent. syst. Lèvre supérieure très-courte, échancrée. Langue nullement distincte. Soies capillaires aussi courtes que la lèvre (nullement distinctes dans les espèces de la deuxième division ). Palpes nuls dans la première division, à troisième article fort renflé, ovale ét velu dans la deuxième. Premier article des antennes un peu renflé vers l'extrémité, légèrement velu ; deuxièmé cyathiforme, velu; troisième lenticulaire, plus ou moins ovale, à trois 


\section{( 105 )}

divisions; style capillaire. Yeux verts, quelquefois marqués d'un arc pourpre. Yeux lisses sur le front ou sur le vertex.

Thorax poli; écusson mutique. Abdomen souvent allongé. Nervures des ailes souvent fort distinctes; deuxième cellule sous-marginale atteignant le bord postérieur; anale atteignant à-peu-prèsle bord intérieur. $(P l .2, f g .6$.

Ces insectes se distinguent des autres Stratiomydes par le dernier article des antennes qui n'est divisé qu'en trois sections. On les reconnaît aussi au beau vert métallique qui les colore et les rend fort jolis. Les yeux, également verts, sont quelquefois ornés, comme dans les Stratiomes, d'une ligne pourpre courbée en arc, très-brillante pendant la vie.

Ce genre se divise en deux sections : dans la première les mâchoires, sous la forme de soies capillaires, sont distinctes; les palpes sont nuls; le troisième article des antennes est presque rond; les yeux dans les deux sexes sont séparés l'un de l'autre; les yeux lisses ont leur insertion ordinairement sur le front, et l'antérieur est éloigné des deux autres; l'abdomen est assez allongé; les ailes sont grandes et les nervures atteignent l'extrémité, à l'exception de la troisième postérieure. Dans la deuxième section, les soies ne sont pas distinctes et les palpes le sont; le troisième article des antennes est elliptique; les yeux sont contigus dans les mâles; l'abdomen est court et les nervures des ailes n'atteignent pas le bord postérieur.

Ces brillans insectes habitent les buissons et les haies depuis le mois de mai jusqu'au mois d'août. Comme on ne les voit pas sur les fleurs, et qu'ils ne.vivent pas de proie, il est probable qu'ils se nourrissent des sucs répandus sur le feuillage. Ils ont peu de vivacité, et leur vol est assez pesant. 
Leurs larves vivent dans les bouzes de vaches; elles ont la tête cornée, le corps ovale, allongé, déprimé. Leur peau sert de coque aux nymphes; et si elles avaient un tube respiratoire, elles différeraient bien peu des larves aquatiques des Stratiomydes.

1. Troisième article des antennes rond. Yeux séparés dans les deux sexes. Point de palpes distincts.

A yeux lisses sur le front; l'antérieur éloigné des autres. I. SARGUE cuivreux; $\mathcal{S}$. cuprarius, Fab. Ent. syst., supp. 566, 1, Syst. antl., 256, 3, Lat. 4, 278, Fall. 15, 2. Thorax d'un vert doré. Abdomen cuivreux, postérieurement violet. Yeux à bande pourpre. Ailes à tache obscure. Nemotelus cuprarius, Deg. 6, 81, 16 .

Rhagio politus, Schr. Faun. boic. 3, 2394 .

Musca cupraria, Linn. Faun. suec. 1853, Gmel. 5, 2849, $9^{2}$, Schr. Faun. aust. 944 . Musca, Geoff. 525, 6r.

\section{Long. $4 \frac{x}{2} 1$.}

Trompe d'un jaune blanchâtre. Hypostome d'un bleu foncé. Front velu, d'un vert cuivreux, antérieurement bronzé et convexe au-delà des yeux lisses. Yeux d'un vert changeant, foncé, dans l'état de vie, avec une ligne arquée et un angle pourpres. Thorax d'un vert doré, à poils roussâtres. Abdomen cuivreux à extrémité violette dans le mâle, violet à base cuivreuse dans la femelle; ventre noir: Pieds noirs, à poils roussâtres, courts ; base des jambes jaunâtre; dernier article des tarses un peu dilaté ; pelottes jaunâtres, garnies d'un rang de petites soies. Balanciers d'un jaune clair. Ailes hyalines à la base, brunâtres au milieu, légèrement obscures vers l'extrémité; tache stignatique brune.

Commun. Je n'ai pas vu, comme le dit Meigen, que 


\section{( 107 )}

les côtés et la poitrine soient noirâtres; mais le vert doré paraît noir vu dans un certain sens.

2. SARGU I obscur; S. infuscatus, Hoffm., Meig.

Thorax d'un vert doré. Abdomen cuivreux (mâle), violet (fem.). Yeux à bande pourpre. Pieds noirâtres. Ailes obscures.

Sargus auratus, Meig. Klass. 1, 143, 2.

cuprarius, Fem. Fall. strat. 15, 2.

\section{Long. 51.}

Fort ressemblant au précédent, excepté : abdomen violet seulement à la pointe, dans le mâle, entièrement violet dans la femelle. Ailes un peu plus obscures.

Assez commun. N'est-ce pas une simple variété?

3. SARgue cou bleu; $S$. carruleicollis, Meg., Meig.

Thorax bleu. Abdomen d'un vert doré. Pieds obscurs; genoux et tarses jaunes. Ailes à tache obscure.

Long. $3 \div 1$.

Semblable aux précédens; thorax d'un bleu obscur à reflets verts. Abdomen à dernier segment bleu. Genoux et tarses jaunes. Tache des aîles plus petite et contiguë à la tache stigmatique.

Fort rare.

4. Sargue luisant; $S$. nitidus, Meig.

Abdomen cuivreux (mâle), violet (fem.). Ailes obscures. Yeux sans bande.

Long. 31 .

Front et hypostome d'un bleu brillant foncé à reflet vert. Trompe d'un jaune pâle. Antennes noires. Deux points blancs derrière les antennes, au bord des yeux. Thorax d'un vert brillant, noir en-dessous. Abdomen cuivreux à extrémité violette (mâle), violet à base légèrement cuivreuse (fem.); ventre noir. Pieds noirs; genoux jaunes. 


\section{( 108 )}

Balanciers jaunes. Ailes obscures vers le milieu; tache stigmatique brune.

La drescription de Meigen diffère de la mienne par. les côtés du thorax noirs et par la tache stigmatique des ailes qui n'est pas marquée.

5. SaRgUe pieds jaunes; $S$. flavipes, Meig.

Abdomen cuivreux ( mâle), violet ( fem.). Pieds jaunes.

\section{Long. $3 \div 1$.}

Hypostome et front d'un noir luisant. Deux points blancs derrière les antennes. Antennes noirâtres. Thorax d'un vert doré ; côtés et poitrine noirs. Abdomen cuivreux (mâle), violet à base cuivreuse ( fem.); ventre noir. Pieds jaunes; cuisses quelquefois brunâtres. Balanciers d'un jaune pâle. Ailes brunâtres; tache stiginatique plus obscure.

Rare.

B. Yeux lisses sur le vertex, à égale distance.

6. SARGUe de Réaumur; $S$. reaumuri, Fab., Meig.

Abdomen cuivreux (mâle), bleu à tache latérale rouge à la base (fem.). Pieds jaunes.

Réaumur, Ins. 4 , tab. 22 , f. $5-8$.

$$
\text { Long. } 5,61 \text {. }
$$

Mâle : tête noire. Front élargi au-delà des antennes, avec deux points blancs. Antennes noires. Yeux verts sans bande. Thorax d'un vert doré, noir en-dessous; les deux couleurs séparées par une ligne blanche. Abdomen d'uu cuivreux clair, à poils d'un jaune pâle. Pieds jaunes ; extrémité des tarses brune. Balanciers d'un fauve pâle. Ailes brunâtres; tache stigmatique à peine plus obscure.

Femelle : semblable au mâle, excepté abdomen d'un bleu d'acier; les deux premiers segmens d'un rouge 


\section{( 109 )}

sanguin sur les côtés; ventre de même, mais les deux segmens entièrement rouges.

\section{Fort rare.}

1x. Troisième article des antennes elliptique. Yeux du mâle contigus. Yeux lisses sur le vertex. Palpes distincts. 7. Sargue superbe; $\mathcal{S}$. formosus, Meig.

Abdomen doré (mâle), violet (fem.). Ailes ferrugineuses. Yeux à bande pourpre.

Sargus auratus (Mas.), Fab. Syst. antl, 257, 4.

- xanthopterus (fem.), Fab. Syst. antl., 255, 1, Meig.

Klass. , 1, 144, 5, Lat. ; 4, 278 , Fall. , 14 , 3.

Nemotelus flavogeniculatus, Deg. , 6, 81 , 17 .

Rhagio formosus, Schr. Faun. boic.' 3 , 2395.

Musca formosa, Schr. aust., 89g.

aurata, Gmel. , 5, 285o, 218, Fab. Ent. syst., $4,335,9^{6}$.

\section{Long. 41 .}

Mâle : hypostome noir, velu. Antennes d'un brun noirâtre. Yeux velus, verts à bande pourpre arquée. Thorax d'un vert doré, à poils fauves, côtés et poitrine noirs. Abdomen doré à poils fauves; ventre noir. Pieds bruns; genoux fauves. Balanciers fauves. Ailes d'un brunâtre jaune à nervures brunes.

Femelle : front large, d'un noir luisant. Abdomen d'un violet luisant.

Commun.

8. Sargue poli ; S. politus, Meig., Fab. Syst. antl., Fall.

D'un vert doré. Antennes obscures. Yeux sans bandé. Ailes hyalines.

Sargus splendens ; Mèig. Klass., I, 144, 4. - cyaneus, Fab. Syst. antl. (fem. var.).

Nemotelus auratis, Deg., $6,81,18$. Musca polita, Linn., Gmel., Fab. Spec. ins., ent. syst. Long. 2 I. 


\section{( 110 )}

Mâle : antennes d'un brun noirâtre; le troisième article plus ovale que dans le précédent. Yeux nus, verts. Thorax vert doré. Abdomen légèrement cuivreux; ventre noir. Pieds jaunes; cuisses noires à extrémité jaune; jambes postérieures brunes. Balanciers d'un jaune vif. Ailes hyalines à nervures brunes.

Femelle : front d'un vert olivâtre, ou vert doré, ou bleu d'acier. Abdomen cuivreux à reflet bleu.

\section{Commun.}

9. Sargue flavicorne; S. Alavicornis, Meig.

D'un vert doré. Antennes jaunes. Ailes hyalines.

$$
\text { Long. } 21 .
$$

Mâle : hypostome d'un vert doré. Trompe et antennes jaunes. Yeux marqués d'une bande. Thorax d'un vert doré. Abdomen d'un vert doré à reflet doré. Pieds jaunes ; hanches postérieures noires à extrémité jaune; milieu des cuisses postérieures noirâtre ; dernier article des tarses noirâtre. Balanciers jaunes. Ailes hyalines; stigmate pâle.

Femelle : hypostome noir; front large, d'un vert doré., Thorax d'un vert doré, à reflet bleuâtre postérieurement.

Assez commun; ce n'est peut-être qu'une variété de l'espèce précédente.

PACHYGaSTRE; PAchygaster.

Pachygaster, Meig. - Vappo, Lat., Fab. Syst. antl. Sargus, Fall. - Nemotelus, Panz.

Tête hémisphérique, allongée; bord postérieur assez large et saillant. Lèvre supérieure petite, pointue. Langue distincte, pointue, une fois plus courte que la lèvre supérieure. Soies capillaires de la longueur de la lèvre supérieure, vers la base de laquelle elles sont un peu inclinées. Palpes coniques, légèrement velus, situés sur les côtés. Antennes insérées au milieu de la hauteur de la tête ; les deux premiers articles très-courts et cyathi- 


\section{(III)}

formes; le troisième sphérique, comprimé, à quatre divisions; style capillaire.

Écusson mutique. Abdomen beaucoup plus large que le thorax, convexe et incliné ; segmens peu distincts. Nervures des ailes assez distinctes et atteignant l'extrémité ; quatre cellules postérieures ( $\mathrm{I}$ ); discoïdale inférieure assez grande, presqu'en pointe à l'extrémité. ( $\mathrm{Pl} .2$, f. 7.)

Le petit insecte qui forme le genre Pachygastre est assez remarquable par la grandeur de l'abdomen, qui lui donne un peu de la figure des vésiculeux; mais l'ensemble de l'organisation me paraît fixer sa place entre les Sargues et les Némotèles, quoiqu'il se distingue des uns et des autres par de nombreuses différences. Nous le trouvons sur les fleurs, mais rarement, aux mois de juillet et d'août.

Le premier âge du Pachygastre a été récemment découvert par M. Carcel, jeune entomologiste très-distingué, de Paris, et je dois à son extrême obligeance l'avantage d'en donner la description d'après nature. Ayant reçu de lui des Larves vivantes dans l'intérieur d'une lettre contenant du detritus de bois, les petites voyageuses ont parfaitement supporté les incommodités de leur. position, sont arrivées sans accident à Lille, et ont repris de suite leurs habitudes naturelles dans un vase où elles sont parvenues au terme de leur développement.

Ces Larves, qui paraissent avoir toute la grandeur qu'elles doivent acquérir, ont deux lignes et demie de long. Elles sont allongées, un peu ovales, très-déprimées, assez luisantes, d'un gris roussâtre et marquées de trois

(1) Les troisième et quatrième cellules postérieures des autres Stratiomydes sont ici confondues. 
bandes longitudinales obscures. Le corps est composé de onze segmens distincts, arrondis sur les côtés, et dont le dernier est grand, semi-circulaire, noir, bordé de roussâtre. Chaque segment a sur le dos plusieurs poils, et de chaque côté une soie allongée et deux courtes. Le dernier $a$, vers l'extrémité, une petite ligne transversale enfoncée, et en-dessous, une ligne longitudinale à rebord légèrement relevé. Huit soies en munissent les bords. La tête est cornée, allongée, beaucoup plus étroite que le corps, conique, obtuse, un peu courbée en-dessous, d'un roux clair avec les côtés obscurs. On aperçoit de chaque côté un petit œil noir, luisant, saillant, accompagné de deux petites soies. A l'extrémité supérieure de la tête, on voit une très-petite pointe, et en-dessous, on croit découvrir la bouche entourée d'un rebord; mais je n'ai pu y reconnaître aucun organe, si ce n'est un petit corps blanc qui semble en occuper l'ouverture.

“ Ces larves, dit M. Carcel dans sa lettre d'envoi, se "trouvent dans le detritus du bois d'orme. Tant qu'elles " prennent de la nourriture, elles se tiennent dans la " partie basse et humide. Je suis sûr qu'elles ont besoin " de plus d'une année pour leur développement; mais w je ne sais si ce terme va au-delà de deux ans, ce que " je présume. Près de se transformer, la Larve s'élève " vers la surface, y reste immobile, sans changer de " peau, et passe à l'état de nymphe. Sa dépouille sert " de coque à celle-ci sans changer de figure. Si on l'ouvre „ on trouve cette nymphe sous la forme de l'insecte par" fait, nıais ayant tuutes, ses parties enveloppées d'une " mince pellicule, et n'occupant qu'une partie de son "domicile. Enfin la dernière transformation s'opère. " Pachygastre noir; $\boldsymbol{P}$. ater, Meig. Vappo ater, Lat., 4, 278 , Fab. Syst. antl., 254, 1. 


\section{(113)}

Sargus pachygaster, Fall. Strat., 13, 1.

Nemotelus ater, Panz. Faun. germ., 54, 5.

\section{Long. I $\frac{3}{4} 1$.}

D'un noir peu luisant. Trompe fauve. Front d'un noir luisant. Antennes fauves; style blanchâtre. Tarière de l'abdomen saillante, courte. Pieds d'un jaune pâle ; cuisses noires; antérieures à extrémité jaune. Balanciers jaunes à tête noirâtre. Moitié antérieure des ailes noirâtre ; la postérieure légérement jaunâtre.

Je l'ai trouvé à Ranchicourt, près de Béthune, sur les fleurs du Daucus vulgaris.

NÉMOTÉLE ; NEMOTELUS.

Nemotelus, Geoff., Fab. Ent. syst., Syst. antl., Panz., Meig., Schell., Fall. - Stratiomys, Fab. Spec. ins., Schr., Ross.

Tête presque sphérique. Hypostome plus ou moins prolongé en bec horizontal, conique, canaliculé endessous et renfermant la trompe. Trompe une fois plus longue que la tête, renflée vers la base, géniculée, ensuite menue, cylindrique, sans lobes distincts. Lèvre supérieure cylindrique, de la longueur du bec. Langue, soies et palpes peu ou point distincts (1). Antennes insérées ordinairement près de l'extrémité du bec, plus courtes que la tête; premier article cylindrique; deuxième renflé à l'extrémité; troisième fusiforme, à quatre divisions et terminé par un style biarliculé. Yeux séparés par un front très-large dans les femelles.

Thorax presque quadrangulaire, légèrement voùté ;

(1) Latreille décrit une langue ( seta infera) grêle, arquée, un peu plus courte que la lèvre supérieure, et des palpes très-petits insérés a la base latérale do la trompe. Meigen dit qu'il n'en a pas découvert. J'ai aussi cherché inutilement. 


\section{(114)}

écusson mutique. Nervures des âles fort peu distinctes; cellule marginale nullement distincte; deuxième sousmarginale quelquefois nulle. ( $P l .2, f i g .8$.

Les Némotèles présentent à la fois les principaux caractères des Stratiomydes et une grande anomalie dans leur conformation. L'espèce de bec qui prolonge la tête est non-seulement fort étranger à toute cette famille, il paraît encore coordonné à une organisation particulière de la trompe. Celle-ci, dirigée en arrière dans l'inaction, et cachée dans une rainure inférieure de ce bec, s'allonge fort en avant, lorsque l'insecte la met en mouvement; elle se termine par une pointe sans aucune apparence de lèvres terminales, et ne paraît accompagnée, ni de langue, ni de soies écailleuses, ni même de palpes. Outre cette singularité, et pour compenser, ce semble, la privation des palpes, les antennes sont le plus souvent placées presqu'à l'extrémité du bec, c'est-à-dire de la manière la plus étrange, en conservant fidèlement la conformation commune aux autres Stratiomydes. Ces petits insectes sont encore remarquables par la différence de couleurs entre les deux sexes et par le mélange agréable du noir et du blanc de leur abdomen.

Ils sont communs, surtout dans les cantons marécageux, et vivent du suc des fleurs. On ne connaît pas leur développement, qui probablement s'opère comme celui des Sargues et du Pachygastre.

1. NÉmotèLe uligineuse; $N$. uliginosus, Fab., Meig., Fall.

Thorax noir à bande latérale blanche. Abdomen blanc, à tache noire avant l'extrémité (mâle); noir, à bords et points blancs (femelle).

Nemolelus, Geoff. 2, 543, 2.

Stratiomys mutica, Fab. Spec. ins. 2, $419,14$.

Minsca uliginosa, Gmel. Syst. nat. 5, 2836, 22.

Long. $2 \frac{3}{4}$ l. 
Mâle : front noir; une tache blanche au-dessus des antennes. Thorax d'un noir luisant à poils gris; côtés à bande blanche qui s'étend depuis l'épaule jusqu'à la base de l'aîle. Abdomen blanc à base et tache noire près de l'extrémilé. Pieds blancs; cuisses noires à extrémité blanche; jambes postérieures noires à base et extrémité blanches. Balanciers blancs. Ailes hyalines à nervures costales jaunâtres.

Femelle. Tête à poils blanchâtres; une ligne blanche interrompue au-dessus des antennes. Thorax à poils blanchâtres soyeux; saillie de l'épaule et ligne s'étendant jusqu'à la base de l'aile, blanches. Abdomen bordé d'un blanc jaunâtre; trois rangs de tâches blancs triangulaires; les points latéraux contigus au bord.

Rare.

2. NÉmotèle panthérine; $N$. pantherinus, Meig.

Thorax noir. Abdomen blanc à tache noire avant l'extrémité (mâle); noir à bords et taches blanches. Nemotelus uliginosus (mas.), Lat. 4, 276, Panz. 46, 21, Meig. Klass. 1, 139 , 1 .

Nemotelus marginatus (femelle), Fab. Ent. syst. 4, $270,3$. Syst. antl. 88, 3, Lat. 4, 276, Panz. Faun: germ. '46, 22. Nemotelus marginellus, Fall. Strat. 5, 2.

$$
\text { Geoff. 2, 543, } 1 .
$$

Stratiomys mutica, Schr. Faun. boic. 3, $238 \mathrm{~g}$.

- marginata, Fab. Spec. ins. 2, 419; 13.

Musca pantherina, Linn. Faun. suec. 1783, Gmel. $2830,8$. - marginella, Gmel. 2836, 163.

Schellenb. g. de m., tab. 25 , f. x.

$$
\text { Long. } 2,2 \frac{7}{2} 1 \text {. }
$$

Comme la précédente, excepté : point de ligne blanché sur le front de la femelle: Thorax sans ligre blanche. Selilement un rang de taches blanches sur l'abdomen. 


\section{( 116 )}

Jambes blanches à extrémité brune; tarses blancs.

J'ai observé un point blanc de chaque côté du bord antérieur du thorax dont les auteurs cités ne font pas mention.

Fort commune.

NÉmotèle noire; N. nigrinus, Fall., Meig.

D'un noir luisant. Genoux et tarses jaunâtres.

Nemotelus nigritus, Panz. Faun. germ. 107, 17.

$$
\text { Long I } \frac{5}{2}, 21 .
$$

D'un noir à reflets verts ou bleus. Bec moins allongé que dans les précédentes. Antennes brunes, insérées à la base du bec. Un point jaunâtre à l'épaule et une ligne jusqu'à la base de l'aile. Cuisses noires à extrémité jaunâtre; jambes postérieures noires-à base et extrémité jaunâtres; les autres et tous les tarses jaunâtres. Balanciers blancs. Ailes hyalines; une seule cellule sous-marginale.

Assez commune.

\section{OXYCËRE; OXYCERA.}

Oxycera, Meig., Lat. - Stratiomys, Geoff., Fab., Schr.,

$$
\text { Panz., Fall. - Musca, Linn., Gmel. }
$$

Antennes plus courtes que la tête; les deux premiers articles courts, cylindriques, velus; le troisième fusiforme-ovalaire, à quatre divisions; style sétiforme de deux articles, inséré soit à l'extrémité, soit un peu sur le côté. Yeux légèrement velus dans les mâles.

Ecusson muni de deux pointes. ( $P l .3$, fig. ..)

Les genres Oxycère, Odontomyie et Stratiome dif̊èrent particulièrement des deux précédens par les pointes de l'écusson. Ils sont les vraies mouches armées de Réaumur et de Geoffroy, les seules Stratiomydes qui justifient leur nom.

Les Oxycères ont été détachés du genre primitif par Meigen d'après des caractères différentiels dans le troisième article des antennes qui est de quatre divisions 


\section{( 117 )}

et muni d'un slyle dans les Oxycères, et de cinq divisions sans style dans les Stratiomes. Mais ces différences sont bien légères, si l'on considère que la cinquième division de ce troisiène article paraît n'être qu'une modification du style des Oxycères, et même que dans plusicurs espèces, telles que Straitomys hydroleon, ornata, etc., elle en prend la forme, et n'en diffère que par la longueur.

Ces petits. Diptères ornés de couleurs agréables vivent sur les fleurs et le feuillage, dans le voisinage des eaux. On ne connaît pas leur premier état.

I. OxYcène hypoléon; O. hypoleon, Meig., Lat.

Noir. Abdomen à trois taches latéralcs et extrémité fauves.

Stratiomys hypoleon, Fab., Schr., Panz. , Fall.

Misca hypoleon, Gmel. Syst. uat. 2835, 7 .

$$
\text { Long. 3, } 41 .
$$

Front jaune à bande noire. Antennes fauves à base noire. Veux velus à bande pourpre. Thorax noir; d̀ l'épaule, une tache fauve qui descend en pointe sur les côtés; une autre tache jaune, triangulaire à la base de l'aile, divisée par une suture; une autre sous celle-ci, se prolongeant en ligne et se terminant par une autre encore; entre la base de l'aile et l'écusson, une tache triangulaire fauve; écusson et pointes fauves. Abdomen noir; une tache fauve, allongée, oblique, de chaque côté des deuxième, troisième et quatrième segmens; cinquième marqué d'une tache semi-circulaire, au milieu; les deuxième et troisième segmens du ventre jaunes au milieu, avec une petite tache jaune sur les côtés. Pieds fauves; cuisses noires ou brunes dan's leur partie supérieure; tarses antérieurs noirâtres; les autres jaunes à extrémité fauve.

Rare. 


\section{( 118 )}

2. OXYcène joli; O. pulchella, Meig.

Noir. Abdomen à deux taches latérales et extrémité jaunes.

Oxycera hypolean, Meig. Klass., tab. 8, f. 3, mas., Lat.

Encyc. tom. 8, p. 2, page 600.

Stratiomys, Geoff. $2,481,6$.

\section{Long. 31 .}

Mâle : hypostome noir, à poils d'un gris blanchâtre. Front à deux points argentés. Antennes noires. Yeux à bande pourpre. Thorax noir; une bande jaune depuis l'épaule jusqu'à la base de l'aile où elle se prolonge endessous; entre cettc base et l'écusson une tache jaune triangulaire; écusson jaune; pointes à extrémité noire. Abdomen noir; une tache d'un beau jaune, allongée, dirigée en avant, de chaque côté des troisième et quatrième segmens; cinquième à tache jaune, triangulaire, au milieu; ventre noir; deuxième et troisième segmens jaunes au milieu; le quatrième moins. Pieds jaunes; cuisses noires dans leur partie supérieure; les quatre derniers articles des tarses antérieurs d'un brun noirâtre; les trois derniers dans les autres. Balanciers jaunes. Ailes hyalines à nervures brunes.

Femelle : hypostome et front jaunes à bande noire; vertex noir. Bord postérieur des yeux jaune. Premier segment de l'abdomen à tache jaune sous l'écusson. Dans quelques individus, j'ai vu, outre les taches du thorax, deux lignes jaunes latérales qui ne s'étendent ni au bord antérieur, ni au postérieur.

Assez commun.

3. OXYCìne trois-lignes; O. trilineata, Meig., Lat.

Vert ou jaunâtre. Thorax à trois bandes noires. Abdomen noir à taches et bandes vertes. Antennes fauves. Pieds jaunes. 


\section{(119)}

Sirativnys trilinealn, Fab., Schr., Panz., Fall.

Geoff. 2, 482, 7.

Musca pantherina, Linn. Faun. suec. 1783.

- trlineala, Gmel. Syst. nat. $2835,6$.

\section{Long. $2 \frac{3}{4} 1$.}

Mâle : trompe verte. Hypostome jaune; front noir; une tache jaune derrière les yeux lisses. Antennes fauves; style inséré un peu sưr le côté. Thorax à trois bandes noires réunies aux deux extrémités; une petite tache noire, allongée, au-dessus de la base de l'aile; poitrine noire; une petite tache jaunâtre devant les pieds antérieurs; une grande bande sous les ailes, et une petite tache allongée, oblique, de chaque côté, entre les pieds antérieurs et intermédiaires; écusson vert; pointes à extrémité noire. Abdomen à fond noir; premier segment à tache triangulaire verte, au milieu; deuxième et troisième à tache semblable au milieu, et une autre, allongée, aux bords latéraux; quatrième à large bande verte, rétrécie au milieu; cinquième vert, à bord antérieur noir; ventre jaunâtre, à base noirâtre. Pieds fauves. Balanciers verts. Ailes hyalines; nfervures jaunâtres; une seule cellule sous-marginale.

Femelle : front jaunâtre, à trois bandes noires, réunies sur le vertex.

Peu commun.

4. OXYcìre nigricorne; O. nigricornis, Lat. Enc. tom. 8, p. 2, page 6or.

Noir. Thorax à quatre lignes interrompues. Bords de l'abdomen jaunes.

Long. $2 \frac{\div}{4} 1$.

Tête jaune; une ligne noire sur le front; vertex et antennes noirs. Thorax noir à quatre lignes jaunes', interrompues au milieu; écusson jaune; poitrine noire 


\section{(120)}

à tache jaune sur les còlés. Abdomen noir à bord fauve, festonné intérieurement; ventre noir bordé de jaune, ainsi que le bord postérieur des segmens. Pieds jaunes. Balanciers jaunes. Ailes hyalines; nervures jaunâtres.

Rave.

5. OXycère léonin; O. leonina, Meig.

D'un noir luisant. Thorax à ligne latérale et écusson jaunes. Abdomen à base et extrémité jaunes. Pieds jaunes; cuisses noires.

Stratiomys leonina, Panz. Faun. germ. 58, 21. Odontomyia leonina, Lat. Gen. crust. 4, 275 .

\section{Long. $2_{3}^{2} 1$.}

Mâle : d'un noir luisant à reflets verts. Hypostome noir bordé de blanc argenté. Antenues noires. Thorax à ligne latérale jaune, depuis l'épaule jusqu'à la base des ailes; un point jaune à cette base. Ecusson jaune; extrémité des pointes noire. Premier segment de l'abdomen marqué à sa base d'une tache jaune carrée postérieurement, et élargie en croissant; deruier jaune. Dessous du corps noir à reflets bleus. Cuisses noires à extrémité jaune; jambes à base et extrémité jaunes; tarses olscurs ; les deux premiers articles jaunes aux postérieures et aux intermédiaires. Balançiers blanchâtres. Ailes hyalines à nervures brunâtres.

Femelle : front noir; bord postérieur des yeux jaune, ensuite noir, et enfin argenté.

Meigen u'a vu que la femeile; je n'ai trouvé que le mâle, près de Lille.

Clitellaire; Chitellaria.

Clitellaria, Meig., Ill. - Ephippiuin, Lat. - Strationys, Geoff., 'Fa5. ‘, Panz. - Musca, Gmel., Schr., Herbst.

Téte derni-sphérique. Trompe nullement saillante, épajsse, cylindrique; lobes terminaux rayés transversa- 
lement; lèvre supérieure courte, plane, écliancrée antérieurement; langue et soies capillaires nullement distinctes. Palpes velus, en massue; troisième article ovale, renflé vers l'extrémité. Antennes presqu'aussi longues que la tête; troisième article conique, à cinq divisions; style terminal biarticulé, divergent.

Ecusson tantôt mutique, tantôt armé. Cellule anale des ailes atteignant à-peu-près le bord intérieur, comme dans les Sargues. ( $P l .2, f i g .6$.

Ce genre a été établi primitivement en faveur d'une Stratiomyde qui diffère des précédentes par le nombrie des segmens du troisième article des antennes, et 'des suivantes par le style qui les termine. Cet insecte offre de plus un caractère qui lui est particulier : c'est une pointe à la base des ailes, qui arme les côtés du thorax, comme celles de l'écusson en défendent l'extrémité. Il 'est surtout remarquable par le duvet d'un rouge brillant et satiné, qui couvre ce thorax comme une selle, d'où proviennent les noms de Clitellaria et d'Ephippium.

A cette espèce singulière, M. Meigen a joint le Némòtelus villosus, de Fabricius, et deux autres qui n'ont de pointes, ni à la base des ailes, ni même à l'écussón, et dont il conviendrait peut-être de former un genre nouveau.

M. Latreille soupçonne que la larve de l'Ephippium vit dans le detritus de bois. Cependant toutes les Stratiomydes armées dont on a jusqu'ici observé le premier âge se développant dans les eaux, et les autres, provenant de larves terrestres, il paraît plus probable que celle-ci est aquatique.

Cumpllaire ephippium ; $C$ : ephippium, Meig.

Noir. Thorax sanguin à pointe latérale. Ephippuim thoracicum, Lat. Gen. 4, 276 . 
Stratiomys ephippium, Fab. Syst. antl. 79, 4 .

- Geoff. 2, 480, 3.

Schœff. Icon. tab. 47 , f. 7 .

Panz. Faun. germ. 8, 23 .

Schellenb. g. de m., tab. 24, f. 1, 2.

Schr. Faun. boic. 3, 2379 .

Musca ephippium, Gmel. Syst. nat. 2834, 151, Herbst. gemeinn. natur. 8 , t. 339 , f. 3 .

\section{Long. 51.}

Hypostome et front noirs; dans la femelle, le front a deux taches formées de poils blancs. Antennes d'un brun noir. Tharax couvert d'un duvet soyeux d'un rouge sanguin; une pointe noire, velue, à la base des ailes; côtés et poịtrine, noirs; écusson noir ; deux pointes velues et relevées. Abdomen noir. Pieds noirs ; jambes postérieures un peu arquées. Balanciers jaunes. Ailes d'un brun roussậtre, plus foncées au bord extérieur. -. Rare,

ODONTOMYIE ; ODONTOMYIA.

Odontomyia, Meig. Kl., Lat. - Stratiomys, Geoff, , Fab., $\therefore$ Schr. Faun. boic., Panz., Meig. - Musca, Linn., Gmel., Schr, aust.

Hypostome plus ou moins saillant. Trompe menue, un peu allongée, à labiules marquées de lignes transversales, du côté intérieur. Lèvre supérieure échancrée à l'extrémité. Langue de la longueur de. la lèvre supérieure (suivant Fabricius); deux soies très-courtes et peu distinctes. Troisième article des palpes peu renflé. Les deux premiers artiçles des antennes à-pẹu-près également courts; troisième long, fusiforme, à cinq divisions. Yeux souvent ornés d'un arc pourpre et à facettes beaucoup plus grandes dans la partie supériẹre que dans l'inférieure, dans les mâles. 


\section{( 123 )}

Ecusson armé. Queiquefois une seule cellule sousmarginale aux ailes; quatre postérieures; nervures postérieures simueuses. ( $\mathrm{Pl} .3$, fig. 2.)

Les caractères essentiels des Odontomyies consistent dans la briéveté du premier article des autennes, dans la forme menue et un peu allongée de la trompe, dans la conformation des yeux dont les facettes supérieures sont plus grandes que les inférieures, et enfin dans la disposition des nervures des ailes qui ne présentent que quatre cellules du bord postérieur.

Ce genre a été iustitué par Meigen, comme celui des Oxycères, aux dépens des Stratiomes de Geoffroy et de Fabricius, et adopté par Latreille et Illiger. Depuis, Meigen l'a supprimé dans son grand ouvrage, en alléguant qu'il ne différait des Stratiomes que par un seul caractère, quelquefois douteux, la longueur du premier article des antennes. Cependant, par une espèce d'inadvertance, il reconnaît lui-nême ceux qu'offre la conformation de la trompe et des yeux. Quant à celui que je tire des nervures des ailes, je l'ai vérifié dans toutes les espèces que j'ai observées; et, en ajoutant ce caractère à ceux précédemment signalés, je crois devoir conserver un genre qui avait déjà reçu la sanction du temps et de notre célèbre Latreille.

Nous trouvons ces insectes sur les fleurs, dans le voisinage des eaux. Il paraît que c'est l'Odontomyie ornée dont Réaumur a observé particulièrement la métamorphose. 1. Odontomyie microléon; O. microleon.

Noire. Abdomen à lignes latérales blanches, pâle endessous.

Stratiomys microleon, Fab. Syst. antI: 8o, 8, Lat. 4, 274 . Musca microleon, Linn. Faun. suec. 178i, Gmel. Syst. nat. 5,2834 , Schr. Aust. 887 . 
Deg. 6, 64, 2, tab. 9, f. 1, 2.

Fall. Strat. 8, 3.

\section{Long. $4 \mathrm{I}$.}

Hypostome noir à poils d'un blanc jaunâtre et reflets métalliques. Front de la femelle noir à tache jaune, allongée, divisée par une ligne noire. Thorax noir à poils jaunâtres ; écusson noir à poiutes jaunes. Abdomen noir ; trois lignes latérales, d'un jaune obscur près du bord postérieur des segmens; une ligne semblable à l'extrémité du dernier ; ventre d'un jaunâtre pâle ; un point noirâtre de chaque côté des troisième et quatrième segmens. Pieds noirs à genoux jaunes.

Rare.

2. Odontomyie ar zentée; O. argentata, Lat., Meig., Klass. Abdonien noir à poils argentés et taches latérales jaunes ( mâle), à poils dorés (femelle).

Stratiomys argentata, Fab. Syst. antl. 82, 17, Meig. Fall. Strat. 9, 5 .

Panz. Faun. germ. $7^{\mathfrak{r}}, 20$ (mas.) 108, 10 (fem.).

\section{Long. 41.}

Mâle : tête d'un noir luisant. Hypostome convexe, à poils d'un jaune clair; une touffe de longs poils d'un brun noirâtre sous les autennes. Front à poils d'un blanc argenté. Antennes noires. Yeux verts à ligne arquée, pourpre. Thorax d'un brun noirâtre à poils d'un jaune obscur ; pointes de l'écusson très-petites. Abdomen noir, couvert d'un duvet argenté bleuâtre; deuxième et troisième segmens (et quelquefois le quatrième) à tache latérale jaune, triangulaire; extrémité du dernier jaune. Ventre verdâtre. Pieds bruns; jambes fauves à anneau brunâtre au milieu. Balanciers jaunes. Aileŝt hyalines, à nervures d'un jaune brun ; un point obscur au milieu du bord extérieur. 
Femelle : tête, thorax et abdomen noirs, couverts d'un duvet doré verdàtre. Segmens de l'abdomen bordés postérieurement d'une large bande de poils d'un gris roussâtre, rétrécie au milieu; ventre fauve, bordé extérieurement de noir; troisième et quatrième segmens marqués chacun de deux petites taches allongées au milieu. Pieds fauves; un large anneau noir aux cuisses vers l'extrémité. Une seule cellule sous-márginale aux ailes ; nervures formant la discoüdale inférieure, trèsmarquées et entourées de brun.

J'ai trouvé plusieurs femelles dans les fortifications de Lille. Cette espèce et la précédente ont le premier article des antennes un peu plus long que les suivantes.

3. Odontomyie ornée; $O$. ornata.

Abdomen noir, à taches latérales, triangulaires, fauves, pâle, sans taches en-dessous.

Odontomyia furcata, Meig. Klass. 1, 129, 1, Lat. gen. $4,27^{5}$, Encyc. tom. 8, p. 2 , pag. 432.

Réaum. 4, tab. 24, f. 4,7 . Roesel ins. 2, Musc. tab. 5.

\section{Long. 71 .}

Mâle : hypostome caréné, d'un brun obscur à poils jaunâtres. Antennes noirâtres. Yeux verts. Thorax noirâtre à poils fauves; écusson à large bord fauve; pointes à extrémité noire. Abdomen noir, luisant, à taches latérales triangulaires fauves, échancrées du côté intérieur; angles obtus; ventre d'un jaune pâle; un point latéral obscur aux troisième et quatrième segmens. Pieds fauves; moitié supérieure des cuisses noire ; jambes à tache brune, extrémité des tarses obscure. Balanciers. jaunes. Ailes hyalines à nervures jaunes.

Femelle : front noir ; deux taches en forme de $\mathbf{C}$ opposćes, séparćes par une ligne; deux autres taches 


\section{( 126$)$}

fauves, triangulaires de chaque côté du vertex. Bord postérieur des yeux fauve. Antennes en partie fauves endessous. Yeux lisses noirs. Taches de l'abdomen plus petites. Pieds entièrement fauves.

Assez commune, au printemps et en été.

4. Odontomyie tigrine; O. tigrina, Meig. Kl., Lat. Encyc.

Abdomen noir, fauve en-dessous.

Stratiomys tigrina, Fab. Syst. antl. 82, 18, Panz. Faun. germ. 58, 20, Meig.

Stratiomys nigrita, Fall. Strat. 9, 4, 4 .

Stratiomys, Geoff. 2, 481, 5.

Musca tigrma, Gmel. Syst. nat. 5, $2835,157$.

Schr. Faun. boic. 3, 238 r.

\section{Long. 41.}

Mâle : Noir. Hypostome et front à poils noirs. Antennes noires. Yeux verts à ligne pourpre arquée. Thorax à poils noils; écusson à pointes jaunes. Abdomen fauve endessous, bordé de noir. Pieds fauves; cuisses noires ; jambes à milieu noir. Balanciers blancs. Ailes hyalines à nervures antérieures et costales noires.

Femelle: lyypostome et front à poils blancs. Thorax à poils jaunes. Ventre fauve au milieu. Balanciers d'un vert pâle. Ailes à nervures brunâtres ; bord extérieur roussâtre.

Assez commune.

5. Odontomie hydropote; O. hydropota.

Abdomen vert à bande noire anguleuse. Antennes d base fauve.

Stratiomys. hydropota, Meig. 3, 147, 16.

\section{Long. 51.}

Mâle : hypostome noir depuis les antennes jusqu'à l'ouverture de la bouche, avec une petite carène brune; 
bords de la bouche fauves. Antennes d'un roux foncé. Thorax noir, couvert de petits poils roussâtres ; écusson noir à large bord postérieur d'un jaune verdâtre ; pointes fauves à extrémité noire. Abdomen d'un vert clair, transparent, à bande d'un noir opaque et anguleuse, un peu plus large à la base, arrondie à l'extrémité ; angles obtus. Pieds fauves. Balanciers blancs. Ailes hyalines.

Femelle : tête fauve. Hypostome à poils blanchâtres; front à ligne noire enfoncée; vertex noir; deux lignes arquées renfermant chacune une tache fauve; un point blanc à l'extrémité de ces lignes; deux autres taches fauves au-dessus du vertex; bord postérieur des yeux blanchâtre ; les deux premiers articles des antennes fauves; le troisième noir. Thorax à poils dorés; écusson fauve à base noire. Bande de l'abdomen plus large, à angles plus marqués.

Je l'ai trouvée rarement, dans les fortifications de Lille. 6. Odontomyie hydroléon ; 0 . hydroleon, Meig. Klass., Lat. , Encyc.

Abdomen vert, à bande noire anguleuse. Antennes noires.

Odontomyia angulata, Meig. Kl. 133, 4.

Stratiomys liydroleon, Fab. Syst. antl. 82, 19, Panz. Faun. germ. 7, 21, Meig.

Stratiomys angulata, Panz. $7^{8}, 19$, Encyc. tom. 8, p. 2, pag. 135.

Stratiomys, Geoff. 2, 481, 4.

Musca hydroleon, Linn. Faun. suec. 1762 , Gmel. Syst. nat. $5,2835,5$, Schr. Aust. 888 .

Deg. 6, 65, 3 .

Schell. g. de m. tab. 24 , f. 3.

Schr. Faun. boic. 3, 2382. 


\section{( 129 ) \\ Long. 4,51 .}

Mâle : hypostome noir à poils blancs. Antennes noirâtres. Yeux verts. Thorax noir à poils d'un gris jaunâtre. Ecusson noir à extrémité fauve ; pointes petites, fauves, à extrémité uoire. Abdomen vert à bande noire, anguleuse, n'alleignant ni les côtés, ni l'extrémité. Pieds fauves; jambes postérieures à anneau brun, peu distinct.

Femelle : tête fauve, à enfoncemens. Hypostome à point noir de chaque côté de la bouche; front marqué d'une ligne enfoncée, longitudinale; vertex à point noir. Bord des yeux jaune. Thorax noir à poils d'un vert doré; écusson à bord postérieur et pointes jaunes. Angles de la bande de l'abdomen tronqués et approchant davantage du bord extérieur.

Rare.

7. Odontomyin verle; O. viridula, Meig. KI., Lat.

Abdomen vert, à bande noire dilatée postérieurement. Odontomyia dentata, Meig. K1. 1, 13o, 2. - canina, ibid. I, 132, e., Encyc. tom. 8, p. 2 ,

pag. 435.

Strationy-s viridula, Fab. Syst. antl. 84, 25, Panz. 58, 18. - marginata, Fab. Syst. antl. 84, 27.

- canina, Panz. 58, 23.

Musca viridula, Gmel. Syst. nat. 5, 2835, 158.

Schr. Faun. boic. 3, 2383.

Schœff. icon. tab. 14 , f. 14 .

\section{Long. $3 \frac{r}{2} 1$.}

Mâle: hypostome noir, à poils d'un blanc jaunâtre. Antennes noirâtres. Yeux verts à ligne arquée, pourpre. Thorax noir à poils dorés; écusson à bord postérieur et pointes jaunes. Abdomen vert, à bande noire qui s'élargit au quatrième segment et atteint le bord antérieur du cinquiéme. Pieds jaunes. Balanciers blancs. Ailes à nervures jaunes; une seule cellule sous-marginale. 


\section{( 129 )}

Femelle : tête d'un noir luisant, à poils dorés souvent eflacés. Front à ligne enfoncée. Bande de l'abdomen élargie au troisième segment et plus large que dans le mâle.

Commune.

8. Odontomyie lunulée; O. lunulata, Encyc.

Noire. Thorax à poils bronzés. Abdomen à bord et tache latérale d'un vert jaunâtre.

\section{Lollg. $2 \frac{3}{4} 1$.}

Femelle : tête noire, à poils bronzés. Antenues noires. Thorax à poils bronzés; pointes de l'écusson très-petites. Abdomen noir à bord et tache latérale, à la base, d'un vert jaunâtre; ventre obscur. Pieds fauves. Balanciers jaunes. Ailes hyalines, à nervures costales jaunes.

M. de Brébisson l'a trouvée en Normandic.

STRATIOME; Stratiomys.

Stratiomys, Geoff. , Fab., Schr. Faun. boic., Panz. ,

Lat., Meig. - Musca, Linn., Gmel., Schr. Aust. Hirtea, Scop.

Hypostome plus on moins saillant. Ouverture de Ia bouche, tantôt ronde, tantôt allongée. Trompe courte et comprimée. Lobes terminaux marqués de ligues transversales du côté intérieur. Lèvre supérieure échancrée à l'extrémité. Langue de la longueur de la lèvre supérieure (suivant Fab.), deux soies très-courtes et peu distinctes. Troisième article des palpes peu renfté. Premier aricie des antennes long; troisième fort long, fusiforme à cinq divisions. Yeux souvent ornés d'un arc pourpre.

Thorax couvert de poils dans les mâles, d'un léger duvet dans les femelles ; écusson armé. Nervures postérieures des ailes sinueuses. ( $P l .3, f .3$.

Les Stratiomes se trouvent réduits par la formation des genres Oxycère et Odontomyie à un petit nombre 
d'espèces très-faciles à recounaître à la longueur des autennes, et aussi à la grandeur du corps. Elles diffèrent d'ailleurs des Oxycères par le nombre des divisions du troisième article des anteunes et par l'absence du style ; et des Odontomyies par la conformation de la trompe, des yeux et des nervures des ailes.

Ces insectes ne sont pas communs dans ce pays. Meigen dit que le Stratiome caméléon se trouve au mois de mai sur les fleurs de l'aubépine, de l'épine vinette et du populage d'eau, et en été sur les plantes aquatiques. 1. Stratione caméléon; $S$. chamaleon, Fab., Meig. , Lat.,

Panz., Fall.

Thorax brun. Abdomen noir à bandes jaunes interrompues, jaune en-dessous, à lignes noires. Ecusson jaune; une tache triangulaire noire à la base.

Stratiomys nigrodentata, Meig. K!. $127,5$.

\section{Geoff. 2, 479, I.}

Musca chamneleon, Linn. Faun. suec. 1780, Gmel. Syst. nat. $5,2833,3$.

Deg. $6,64,1$.

Schœeff. tab. 59 , f. 3 .

Schr. Faun. boic. 3,2376 .

Aust. 886.

Long. 71 .

Mâle : hypostome noir, à poils jaunes et tache triangulaire jaune au bord des yeux. Front noir à sillon longitudinal. Antennes noires. Thorax brun à poils d'un jaune brun; écusson jaune: une petite tache triangulaire à la base; pointes jaunes à extrémité souvent noire. Abdomen ovale noir, pubescent; deuxième segment à taches latérales jaunes, triangulaires; troisième à bande jaune, interrompue au milieu ; quatrième à bande semblable, oblique; cinquième à tache triangulaire; ventre d'un jaune sale; 


\section{(131)}

deuxième segment à petite tache noirâtre, allongée, pointue, oblique, de chaque côté ; troisième et quatrième à bande tranversale, interrompue; cinquième à bord antérieur noir. Pieds fauves; cuisses obscures, souvent jaunes à l'extrémité. Balanciers jaunes. Ailes brunâtres, à nervures d'un jaune obscur.

Femelle : hypostome jaune à bande noire. Front d'un noir luisant; bord postérieur des yeux jaune. Bàdés du ventre plus larges et plus distinetes que dans le mâle.

Peu commun.

2. Stratiome des fleuves; $S$. potamida, Meig.

Thorax brun. Abdomen noir ; deux taches latérales à la base et deux bandes étroites, jaunes; la première interrompue daus le mâle; jaune en-dessous, à bandes noires.

Strationys chamoeleon, mas., Meig. Kl. I, 126,4 .

$$
\text { Long. 6, } 7 \text { l. }
$$

Comme la précédente, excepté : écusson à bord antérieur noir et pointes entièrement jaunes. Deuxième segment de l'abdomen à taches jaunes, latérales, triangulaires; troisième à bande étroite au bord postéricur, interrompue au milieu dans le mâle; quatrième à bandes semblables, entière dans les deux sexes; cinquième à tache triangulaire au bord postérieur; ventre à quatre bandes noires dont les deux premières sont interrompues.

Rare.

3. Stratiome fourchue; S. furcata, Fab., Meig.

Thorax à poils gris. Abdomen noir; taches latérales inégales, quatre bandes jaunes, en-dessous.

Stratiomys panthaleon, Fall. Strat. 72 .

$$
\text { Long. } 7,81 \text {. }
$$

Hypostome noir, à poils blancs. Front de la femelle noir, luisant ; une ligne jaune, transversale, interrompue, 
au-dessus des antennes; une tache bifide sur le vertex. Antennes noires. Bord postérieur des yeux à poils blancs. Thorax brun, à poils gris ; écusson jaune, à tache triangulaire, noire à la base ; pointes jaunes. Abdomen noir, pulescent ; deuxième segment à taches latérales triangulaires qui avancent un peu sur le troisième; celui-ci à taches plus allongées qui avancent également sur le suivant; le quatrième à taches allongées; cinquième à petite tache triangulaire; ventre noir à quatre bandes jaunes inégales. Cuisses noirâtres ; jambes jaunes à extrémité obscure; tarses jaunes. Balanciers jaunâtres. Ailes à bord extérieur et nervures brunâtres.

Assez rare.

4. Stratrome striée; S. strigala, Fab., Meig., Schr.

Thorax à poils fauves. Abdomen noir, à bandes blanches en-dessous.

Stratiomys villosa, mas., Meig. KI. 1, 125, 1.

- nubeculosa, Fem. ibid. $1,125,3$.

\section{- thoracica, Fem. Fab. Syst. antl. 79, 7 .}

- Geoff., 2, 480, 2.

Hirtea longicornis, Scop. ent. carn. 999.

Panz. Faun. Germ. 12, 20.

Schœef. icon. 14, f. 10.

\section{Long. 6, 81 .}

Mâle : hypostome noir, à poils d'un roux vif. Yeux velus, verts, à ligne arquée, pourpre, au bord postérieur ; une autre ligne arquée devant celle-ci. Antennes noires. Thorax et écusson noirâtres, à poils roux; pointes de l'écusson petites, jaunes. Abdomen noir, à poils roux; ventre à bandes jaunâtres, pointues sur les côtés. Pieds jaunâtres; cuisses brunes; jambes à deux anneaux brunâtres, l'un au milieu, l'autre à l'extrémité ; tarses à extrémité brune. Balanciers blanchâtres. Ailes brunâtres à base et extrémité plus claires; nervures costales brunes. 


\section{( 133 )}

Femelle: hypostome et front à poils roussâtres; une tache triangulaire, jaune au bord des yeux. Une autre tache, quelquefois divisée, au vertex. Côtés de l'abdomen à poils d'un gris clair, surtout au deuxième segment.

Assez rare, à Lille. J'ai observé une femelle qui avait une petite tache jaune, allongée, au bord extérieur et à l'extrémité des deuxième et troisième segmens.

\section{XYlOPHAGITES ; Xrlophagr, Meig.}

Stratiomyde, Lat.

Caractère essentiel : trompe peu saillante. Antennes de trois articles; troisième divisé. Abdomen étroit, de sept. segmens distincts. Tarses munis de trois pelottes. Ailes à quatre ou cinq cellules postérieures.

Corps assez étroit, elliptique. Tête hémisphérique, trèsdéprimée dans les femelles. Front presque nul dan's les mâles, large daus les femelles. Trompe peu saillante; lobes terminaux épais, ovales. Lèvre supérieure, langue et deux soies (mâchoires) capillaires souvent distinctes ; palpes de deux ou trois articles. Antennes rapprochées à la base, de trois articles; le premier cylindrique, le second cyathiforme, le troisième allongé, conique, à huit divisions, sans style. Yeux arrondis. Trois yeux lisses.

Thorax ovale, à suture; écusson tantốt mutique, tantôt armé de pointes au bord posiérieur. Abdomen elliptique, allongé, déprimé, de sept segmens distincts. Pieds assez courts; jambes tantôt terminées par des pointes, tantôt. muliques; tarses munis de trois pelottes. Balanciers découverts. Ailes couchées; cellule marginale souvent allongée; deux sous-marginales; trois discoïdales ; quatre ou cinq postérieures; anale fermée. ( $\mathrm{Pl} .3, f .4,5$. )

Les Xylophagites sont un petit groupe récemment formé par M. Meigen, et composé de Diptères dont les uns ont des rapports avec les Stratiomydes, et les autres 


\section{( 134 )}

avec les Tabaniens; ne pouvant convenablement être compris dans ces fanilles, mais se plaçant très-bien entr'elles. Cependant, on ne peut nier qu'en servant de transition entre deux familles très-différentes, celle-ci ne présente également dans les genres dont elle se compose, des différences qui la rendent peu naturelle, d'autant plus qu'elle est en même-temps dénuée de caractère essentiel qui lui soit propre. La trompe, peu saillante, est plus ou moins fortement organisée; le troisième article des antennes est toujours subdivisé en huit segmens, et ce serait un caractère distinctif, si un genre de Tahaniens ne l'offrait également; l'écusson est souvent armé d'épines, et quelquefois nu; les jambes sont, dans les uns, terminées par des pointes; dans d'autres, il n'y en a point. Enfin les nervures des ailes présentent plusieurs modifications, et indiquent mieux qu'aucun autre organe, au moins dans le genre Béris, la nuance entre les deux familles.

Ces Diptères habitent particulièrement les bois. Les uns se posent sur le feuillage, d'autres sur le tronc des arbres. Baumhauer a découvert la larve d'un Xylophage dans le bois décomposé; c'est tout ce que l'on sait sur le développement de ces insectes, et ce qui leur a valu leur nom.

Des genres Béris, Xylophage et Cœnomyie, qui composent cette famille en Europe, le premier seul est commun dans cette partie de la France.

\section{TABLEAU DES GENRES.}

Écusson à plus de deux pointes........ BÉrIs.

Écusson sans pointes.............. XYlophage.

Écusson à deux pointes............ CEenomyix.

BÉRIS ; BERIS. 


\section{( 135 )}

Beris, Lat., Meig. - Actina, Meig. K1. - X Xlophagus, Lat. - Stratiomys, Geoff., Fab., Panz. , Fall. - MIusca, Gmel., Schr. aust.

Trompe peu saillante. Lèvre supérieure et langue peu distinctes; soies capillaires nullement distinctes. Palpes petits, de trois articles. Premier article des antennes court.

Écusson armé de quatre, six ou huit pointes velues au bord postérieur. Jambes mutiques; premier article des tarses postérieurs renflé et allongé dans les mâles. Cellule marginale des ailes courte; deux sous-marginales assez petites; quatre postérieures; quelquefois nurudiment de nervure dans la troisième; anale éloignée du bord intérieur. $(P l .3, f .4,5$.

L'affinité du genre Béris avec les Stratiomydes se manifeste par les épines de l'écusson, quoique le nombre en soit différent; par l'absence de pointes à l'extrémité des jambes, et par la disposition des nervures des ailes. Ces dernières offrent une cellule marginale et deux sous-marginales presqu'aussi petites que dans la famille précédente, mais sur la détermination desquelles on ne peut pas se méprendre, et qui m'ont fait reconnaître la véritable structure de celles des Stratiomydes.

L'organisation des Béris se modifie dans quelques-unes de ses parties : le nombre des pointes de l'écusson varie de quatre à huit; les palpes, ordinairement très-petits, s'allongent un peu dans le B. nitens, et l'ont fait comprendre dans le genre Xylophage par M. Latreille; les cellules des ailes présentent quelques différences dans la grandeur des sous-marginales et dans un rudiment de nervure qui commence quelquefois une cinquième postériẹure. Enfin les jambes postérieures sont renflées en massue dans quelques espèces, et le premier article des tarses est dilaté dans les mâles. 


\section{( 136 )}

Ces petits insectes paraissent plus communs dans cetle parlie de la France et en Angleterre qu'en Allcmagne.

1. Écusson à quatre pointes.

1. Béris luisant; B. nilens, Lat. Hist. des Crust., Meig.

Luisant. Thorax d'un bleu d'acier. Aldomen d'un bleu noirâtre. Pieds obscurs à base jaune.

Xylophagus nitens, Lat. Gen. crust., 4, 273.

Actina chaliboea, Meig. Kl., 1, 117, 1 .

$$
\text { Long. } 2 \frac{3}{2} 1 \text {. }
$$

Femelle : Palpes noirs. Hypostome d'un noir luisant, à poils blancs au bord des yeux. Front d'un bleu d'acier. Thorax bleu d'acier à reflets d'un vert doré; pointes de l'écussón noires. Abdomen d'un bleu noirâtre pcu luisant; ventre noir. Pieds obscurs; partie supérieure des cuisses et bases du premier article des tarses fauves.

Rare.

2. BÉrIs tibial; B. tiúvialis, Meig.

Thorax d'un vert cuivreux. Abdomen noir. Pointes de l'écusson et picds fauves. jambes postérieures obscures et renflées.

\section{Long. $2 \frac{1}{2}, 31$.}

Mâle : yeux bruns. Hypostome noir à ligne enfoncée au milieu; un point blanc au-dessus des antennes. Trompe d'un jaune clair. Antennes noires; deuxième article et premières divisions du troisième d'un brun clair endessous; dernière division plus longue. Abdomen noirâtre, à reflets bleus, et garni sur les côtés de poils jaunâtres; bord antérieur des troisième, quatrième et cinquième segmens marqué d'une tache transversale triangulaire, d'un roussâtre clair ; la dernière presque linéaire. Pieds jaunes ; hanches blanchâtres; tarses noirâtres; cuisses postéricures allongées, légèrement renflées vers l'extrémité qui est noirâtre; jambes postérieures plus 


\section{( 137 )}

renflées et noirâtres; premier article des tarses roussảtre vers la base. Balanciers jaunes. Ailes hyalines; cellule marginale ovale, noirâtre. La discoïdale inférieure émet le rudiment d'une nervure dans la troisième postérieure. (Pl. 3, f. 5.)

- Femelle : front assez étroit, d'un vert brillant plus foncé que le thorax. Une petite bande blanche au-dessus des anterines. Abdomen un peu plus large; deuxième, troisième, quatrième et cinquième segmens marqués chacun d'une grande tache rhomboïdale jaune qui comprend toute la longueur du segment; bord postérieur de ces segmens noir; ventre jaune. Base des jambes postérieures roussâtre.

M. Meigen ne fait pas mention des taches de l'abdomen; maịs il dit que le jaune du ventre paraît sur les troisième, quatrième et cinquième segmens en-dessus.

J'ai trouvé les deux sexes au mois de mai dans les bois de Ranchicourt, près de Béthune.

11. Écusson à six pointes.

3. BÉris métallique; B. chalybeata, Meig.

Thorax d'un vert cuivreux obscur. Abdomen noir soyeux. Ailes et balanciers obscurs. Actina atra, Meig. K1., I, I1 8, 3. Musca chalybeata, Gmel. Syst. nat., 5, 2837, 165.

\section{Long. $2 \div 1$.}

Mâle : hypostome et front d'un noir luisant. Antennes noirâtres, à peine aussi longues que la tête. Thorax à reflets d'un bleu obscur; côtés et ventre d'un noir luisant; pointes de l'écusson noires. Pieds fauves; tarses obscurs; premier article des postérieurs fauve, dilaté.

Rare.

4. BérIs clavipède; B. clavipes, Meig.

Thorax d'un noir luisant. Abdomen et pieds fauves. Tarses obscurs. Ailes fuligincuses dans les deux sexes. 
Strutiomys clavipes, Panz. Faun. germ., 9, 19 , Fall. Strat., $12,10$.

MIusca clavipes, Linn. Syst. nat., 12, 2, $9^{81}, 12$, Schr. aust., 894 .

\section{Long. 31 .}

Trompe jaune. Hypostome et front d'un noir luisant. Antennes obscures. Thorax d'un noir luisant. Abdomen fauve. Pieds fauves; extrémité des jambes et tarses obscurs; jambes postérieures fauves. Balanciers jaunes. Ailes brunes dans les deux sexes.

Assez commun.

5. BérIS armé; $B$. vallata, Meig.

Thorax d'un noir luisant. Abdomen et pieds fauves; extrémité des jambes et tarses obscurs. Ailes fuligineuses (mâle), hyalines à base jaune (fem.).

Beris nigritarsis, Lat. Gen., 4, 273.

- clavipes, Lat. consid., 442.

Actina clavipes, Meig., 1, $117,2$.

Stratiomys clavipes, Fab. Syst. antl., 86, 35, Geoff., 2, $483,8$.

Misca vallata, Gmel. Syst. nat., 2837, 166.

- clavipes, Gmel, 2836, 12.

$$
\text { Long. } 2 \frac{1}{2} 1 \text {. }
$$

Semblable au précédent, excepté deux taches noires à la base de l'abdomen et extrémité obscure dans le mâle; moitié inférieure des jambes et tarses obscurs. Balanciers bruns dans le mâle, jaunes dans la femelle. Ailes presqu'hyalines dans la femelle, jaunâtres à la base et au bord extérieurr; les deux nervures de la deuxième cellule postérieure se réunissent à la base,

Commun.

6. BÉRIS noir ; B. nigra, Meig.

D'un noir luisant. Pieds roussâtres ; extrémịté des cuisses et des tarses obscure. 


\section{$(139)$ \\ Long. 31.}

Hypostome et front larges. Antennes brunes un peu plus courtes que la tête. Thorax à reflets bleus; pointes de l'écusson noires. Extrémité des cuisses et les quatre derniers articles des tarses obscurs; jambes postérieures brunâtres à l'extrémité. Balanciers jaunes. Ailes légèrement obscures à base jaunâtre et stigmate noirâtre.

Rare.

I I. Écusson à huit pointes. 7. BÉrIs fuscipède; $\boldsymbol{B}$. fuscipes, Meig.

D'un noir luisant. Écusson d'un vert doré. Pieds obscurs; jambes à base jaune.

\section{Long. 31.}

Mâle : hypostome velu. Antennes noirâtres, un peu plus courtes que la tête. Thorax à reflets bleu d'acier; écusson d'un vert doré à pointes noires; pointes extérieures trèscourtes. Pieds obscurs; base des jambes jaune; premier article des tarses postérieurs allongé, renflé. Balanciers jaunes. Ailes brunâtres à stigmate noirâtre.

Rare.

8. BÉris flavipède; B. flavipes, Nob.

Thorax d'un noir cuivreux (mâle), d'un vert brillant (femelle). Abdomen noir. Pieds fauves; tarses noirâtres. Ailes fuligineuses (mâle) presqu'hyalines (fem.).

\section{Long. $2 \frac{2}{2} 1$.}

Mâle : Trompe fauve. Abdomen d'un noir velouté. Hanches noires; cuisses et jambes fauves. Balanciers obscurs.

Femelle : Front d'un noir brillant. Abdomen d'un brun noirâtre bronzé, brillant. Cuisses et jambes jaunes, ainsi que le premier article des tarses postérieurs, Balanciers jaunes. Stigmate des ailes noirâtre.

J'ai trouvé le mâle et la femelle dans les fortifications. de Lille. 
XYLOPHAGE ; XYLOPHAGUS.

Xylophagus, Meig., Fab., Fall. - Stratiomys, Fab. Ent. syst. - Empis, Rhagio, Panz. - Nemotelus, Deg. Asilus, Schell.

Trompe très-peu saillante. Lèvre supérieure épaisse, plus courte que la trompe, à extrémité obtuse; langue fine, pointue, plus longue que la lèvre supérieure; soies capillaires nullement distinctes. Palpes allongés, relevés, de deux articles; premier fort menu; deuxième épais, ovale, velu. Antennes à premier article, tantôt court, tantôt allongé.

Écusson mutique. Abdomen cylindrique dans les mâles, conique dans les femelles, à tarière articulée. Jambes terminées par deux pointes. Nervures des ailes comme dans les taons. ( $P l .3, f .6$.

En considérant la syuonymie des Xylophages, l'on voit à combien de genres ils ont été rapportés avant que Meigen n'en ait institué un pour eux, et quels rapports on leur a trouvés avec tant de Diptères différens. Mais cette conformation qui ressemble à tant d'autres, considérée partiellement, offre par cela même un ensemble original. On doit convenir d'ailleurs qu'il fallait les examiner bien superficiellement pour les réunir aux Empis, aux Rhagions, aux Asiles. Plusieurs organes, et particulièrement les antennes, par les subdivisions du troisième article, les en éloignent fort, et déterminent leur place naturelle entre les Stratiomydes et les Tabaniens, quoiqu'ils n'aient pas de rapports très-marqués avec les premiers, comme les Béris, ni avec les derniers, comme les Conomyies.

Ces Diptères sont d'assez grands insectes, rares partout, vivant dans les forêts, et se posant sur le tronc des arbres. Suivant M. Latreille, le Xylophage maculé se 


\section{(141)}

trouve sur les ulcères des ormes, et il est probable que la femelle y dépose ses œufs. La Larve du X. noir a été découverte par Baumhauer dans le bois décomposé ; mais ce naturaliste ne l'a pas décrite.

I. Premier article des antennes plus long que le second. 1. Xylophage noir ; $X$. ater, Meig., Lat., Fab., Fall. Noir. Thorax de la femelle à trois bandes grises. Pieds fauves.

Empis subulata (Mas), Panz. Faun. Germ., 54, 23.

$$
\text { Long. } 5,61 \text {. }
$$

Mâle : d'un noir luisant. Premier article des palpes jaune; second noir. Thorax sans bandes. Pieds antérieurs et intermédiaires d'un jaune pâle ; extrémité des tarses obscure; pieds postérieurs également jaunes, avec l'extrémité des cuisses, des jambes et des tarses obscure. Balanciers jaunes. Ailes hyalines; une bande vers le milieu, obscure, transversale, un peu anguleuse, plus claire vers le bord intérieur; les nervureŝ transversales vers l'extrémité de l'aile, ainsi que l'interno-médiaire bordées de bruu.

Femelle : Thorax à trois larges bandes grises; les latérales plus courtes antérieurement. Les taches des ailes jlus distinctes que dans le mâle.

Rare.

2. Xxlophage ceint; $X$. cinctus, Meig., Fab., Lat.

Noir ; abdomen à bande fauve. Xylophagus ater, Var., Fall., 13, 1. Nemotelus cinctus, Deg. , 6, 75, 6 . Rhagio syrphoides, Panz. Faun. Germ., 77, 19. Asilus, Schell. g. de m., tab. 3o, f. 2.

$$
\text { Long. } 5,6 \text { l. }
$$

Femelle : d'un noir luisant. Premier article des palpes jaune; second noir. Thorax à cinq lignes grises, peu 


\section{$(142)$}

distinctes. Abdomen à large bande fauve, qui s'étend sur les deuxième, troisième et quatrième segmens. Pieds fauves. Balanciers jaunes. Ailes comme dans l'espèce précédente.

Rare.

Ir. Les deux premiers articles des antennes d'égale longueur.

3. Xylophage tacheté; X. Maculatus, Meig., Fab., Lat. Fall.

Noir. Thorax tacheté de jaune. Bord postérieur des segmens de l'abdomen jaune.

$$
\text { Long. } 6 \text { I. }
$$

Extrémité de la trompe jaune. Premier article des palpes noir; second jaune. Hypostome noir. Front blanc audessus des antennes, ensuite d'un jaune obscur; vertex noir. Antennes noirâtres, fauves en-dessous depuis la base jusqu'au milieu de la longueur. Thorax noir ; saillie des épaules d'un jaune vif avec une tache d'un jaune clair, contiguë, du côté intérieur ; une bande transversale, interrompue au milieu, prenant naissance à la base des ailes où elle joint une ligne jaune qui s'étend șur les flancs depuis cette base jusqu'aux épaules; une tache jaune de chaque côté en avant de l'écusson; écusson jaune à base noire. Abdomen d'un noir luisant; une tache jaune de chaque côté sur le deuxième segment; bord postérieur des autres. Hanches noires; pieds antérieurs fauves à tarses obscurs; premiers articles des tarses intermédiaires à base jaune ; pieds postérieurs fauves; extrémité des cuisses et des jambes noire; les trois derniers articles des tarses obscurs. Balanciers fauves. Ailes légèrement brunâtres, jaunâtres au bord extérieur.

Rare.

4. Xylophage varié; $X$. varius, Meig.

Noir. Antennes plus longues que la tête. Bord postérieur des segmens de l'abdomen jaune. 


\section{( 143 ) \\ Long. $3 \frac{1}{2}$.}

Trompe et palpes jaunes. Hypostome et front d'un noir luisant ; bord des yeux blanc au-dessus des antennes. Antennes presqu'une fois plus longues que la tête, jaunies en-dessous, depuis le deuxième article jusqu'au quatrième segment du troisième article. Thorax d'un noir luisant, à poils blanchâtres qui forment quatre bandes peu distinctes, une bande jaune sur les côtés, de la base des ailes aux épaules; écusson jaune, noir sur les côtés. Abdomen d'un noir luisant, à poils blancs; bord postérieur des segmens jaune; un enfoncement elliptique fauve, à la base. Pieds jaunes à hanches noires et extrémité des tarses obscure. Balanciers jaunes. Ailes hyalines.

Rare.

CENOMYIE; Conomyia.

Conomyia, Lat. , Lat. - Sicus, Fab. Syst. antl. , Meig. Klass., Walck., Ill. , Schell., Fall. - Tabanus, Fab. Spec. ins. , Ent. syst., Gmel. - Strationys, Panz., Sclir., Schœff. - Musca, Herbst, Scop., Yill.

Tête un peu moins large que le Thorax. Trompe légèrement saillante; lobes terminaux grands, striés antérieurement. Lèvre supérieure pointue, presqu'aussi longue que la trompe; langue de la longueur de la lèvre, également pointue; soies capillaires de la même longueur. Palpes velus, à-peu-près cylindriques, légèrement arqqués, couchés sur la trompe, de deux ou trois articles peu distincts; premier fort court. Antennes presqu'aussi longues que la tête; premier article un peu allongé, velu; troisième allongé, conique ; premier et huitième segmens un peu plus longs que les autres.

Écusson petit, armé de deux petites pointes. Abdomen allongé. Pieds assez menus; jambes terminées par deux pointes. Nervures des ailes à-peu-près comme dans les 


\section{(144)}

Taons; deuxième cellule sous-marginale un peu plus longue; lase de la quatrième postérieure appuyée sur la discoïdale inférieure ; anale assez éloignée du bord intérieur ( 1 ).

Ce genre, comme les deux précédens, offre un assemblage de caractères communs à divers autres Diptères, et c'est peut-être ce qui a engagé $M$. Latreille à lui donner le nom de Cœnomyie. Les parties de la bouche sont à-peu-près semblables à celles des Leptides; les antennes, par la subdivision du troisième article en en huit segmens, offrent le caractère principal des Xylophagites; les pointes de l'écusson établissent un rapport avec les Stratiomydes; le port des ailes est couché comme dans ces dernières, et les nervures, quoique très-différentes, présentent également la base de la quatrième cellule postérieure appuyée sur la base de la discoïdale inférieure, modification que l'on ne retrouve point ailleurs. Elles ont cependant beaucoup plus de rapports avec celles des Tabaniens.

La classification des Conomyies a éprouvé des fluctuations analogues à ces divers rapprochemens. Elles ont été tour à tour comprises parmi les Stratiomes et les Taons; mais quelle que soit la place qui leur ait été assignée, elle n'a jamais paru satisfaisante. Celle qu'elles occupent maintenant, quoique très-naturelle, suivant nous, ne paraît pas l'être davantage, et voici sans doute quelle en est la raison: les Stratiomydes et les Tabaniens forment les deux extrémités de la série des Diptères dont les anteunes ont le troisième article subdivisé. L'intervalle qui sépare ces deux familles très-différentes n'est occupé, au moins en Europe, que par celle des

( 
Xylophagites, qui ne peuvent remplir tous les degrés intermédiaires, et dont les différens genres sont plus ou moins éloignés les uns des autres.

Les Conomyies sont rares dans le nord de la France. Leurs habitudes et leur mode de développement sont incounus. M. Meigen croit qu'elles n'ont pas, comme les Taons, la faculté de piquer. Il soupçonne que les larves vivent dans le détritus du bois.

Cønomyı ferrugineuse; $C$. ferruginea, Lat., Meig.

Abdomen à taches latérales blanches. Ailes jaunâtres. Sicus ferrugineus, Fab. Syst. antl. 72, 2, Meig. KI. r , 121, 1, Fall. Dipt. suec., 12, 1. Sicus bicolor, Fab. Syst. antl. 76, 3, Meig. KI. 122, 2 a. — aureus, Meig. Kl. 122, $2,6$.

\section{errans, Fab. Syst. an tl. 76,4 .}

Tabanus bidentatus, Fab. Ent. syst. 4, 372, 40, Gmel. $5,2885,33$.

Tabanus bispinoosus, Fab. Ent. syst. 4, 372, 41 , Gmel. 5, $2885,34$.

Stratiomys macroleon, Panz. Faun. germ. 9, 20.

grandis, Schr. Faun. boic. 3 ,
Musca olens, Herbst, Gem. nat. 8, 108.

$$
\text { Long. } 6,7 \text { I. }
$$

D'un brun ferrugineux. Thorax à deux bandes rapprochées, d'un blanc changeant, peu distinctes au-delà du milieu. Abdomen plus foncé antérieurement; une tache blanche de chaque côté du déuxième segment; une bande blanche rétrécie au milieu, sur les troisième et quatrième; ventre ferrugineux ; bord postérieur des segmens, excepté le premier, blanc. Pieds ferrugineux. Balanciers jaunes. Ailes d'un jaune brunâtre à nervures d'un jaune ferrugineux.

Rare. 


\section{( 146 )}

TABANIENS ; Tabanil.

Tabanï, Lat., Meig.

Caractères essentiels : trompe renfermant six soies dans les femelles. Antennes ordinairement de trois articles; troisième divisé. Abdomen de sept segmens distincts. Tarses munis de trois pelottes. Ailes à $\operatorname{cinq}$ cellules postérieures.

Corps élargi, déprimé. Tête hémisphérique, déprimée, légèrement concave postérieurement; front nul dans les mâles, plus ou moins large dans les femelles; hypostome ordinairement plat. Trompe submembraneuse, horizontale dans les mâles, perpendiculaire dans les femelles, subcylindrique, de la longueur de la tête; lobes terminaux épais, allongés; lèvre supérieure de la longueur de la trompe, assez large, sillonnée; langue étroite, pointue; deux soies supérieures (mandibules) en forme de lámes, lancéolées, dans les femelles seulement; deux soies inférieures (mâchoires) plus étroites; palpes épais, comprimés, velt:s, horizontaux dans les mâles, perpendiculaires dans les femelles; premier article court, cylindrique; deuxième ordinairement conique. Antennes rapprochées à la base; premier article ordinairement court, cylindrique; deuxième ordinairement très-court; troisième à quatre ou cinq divisions dont la première est beaucoup plus grande, quelquefois échancrée vers la base. Yeux arrondis, brillans; facettes supérieures plus grandes que les inférieures dans les mâles; yeux lisses souvent nuls.

Thorax muni de chaque côté d'un petit tubercule vers la base de l'aile, d'où part une ligne enfoncée oblique de chaque côté en avant de l'écusson. Abdomen large, déprimé, rétréci postérieurement. Pieds assez courts; postéricurs un peu plus longs que les autres; jambes intermédiaires ordinairement terminées par deux pointes; 


\section{(147)}

tarses assez courts, munis de trois pelottes. Balanciers en grande partie cachés sous une double écaille. Ailes ordinairement à demi-ouvertes; cellule stigmatique nulle ou peu distincte; marginale élargie vers l'extrémité; deux sous-marginales terminales; deuxième petite et souvent sinueuse; trois discoïdales; cinq postérieures; anale ordinairement fermée. ( $\mathrm{Pl} .3, \mathrm{fg} .6-8$.

Nous terminons la description de la longue série des Diptères à antennes triarticulées par la famille des Tabaniens dont l'organisation esi plus forte que dans aucun autre de ces insectes. Tous les organes paraissent avoir reçu le plus haut degré de développement dont ils étaient susceptibles. Le corps est grand; les ailes sont mues par des muscles puissans, et pourvues du plus giand nombre de nervures observées dans cet ordre. Les pieds sont robustes, et les tarses munis de trois pelottes. Les antennes ont le troisième article divisé en plusieurs segmens, comme dans les deux familles précédentes, et même, dans l'un des genres qui la composent, ces divisions ne peuvent plus être considérées que comme autant d'articles distincts; de sorte qu'en terminant leur série, les Tabaniens commencent en même temps celle des Diptères à antennes multiarticulées. Enfin la trompe, cet organe dont nous avons vu, depuis les Phthiromyies et les Muscides, les pièces intégrantes se multiplier progressivement, acquiert dans les Tabaniens un accroissement refusẻ à tout ce qui précède, et elle présente pour la première fois, au moins dans l'un des sexes, le même nombre de parties qui accompagnent la bouche dans les insectés' les plus 'développés, c'est-à-dire que l'on y distingue, de plus que dans les Diptères précédens, deux soies ou lames cornées qui par leur position sont analogues aux mandibules des insectes masticateurs. M. Savigny, dans ses excellens 


\section{(148)}

mémoires sur les animaux invertébrés, qui nous ont révélé l'identité de composition dans la bouche de tous les insectes, décrit et figure ces mandibules, et il les distingue des deux autres soies qui sont les mâchoires, et que l'on reconnaît comme telles à leur adhérence aux palpes. M. Meigen, qui méconnaît cette analogie, et qui nomme mandibules dans tous les Diptères les parties que nous nommons mâchoires, les considère seulement comme doubles dans les Tabaniens, sans expliquer davantage la nature des deux soies insolites qu'on y découvre. Au surplus, c'est ce grand entomologiste qui a fait connaitre que les femelles seules de ces Diptères possédaient ces parties supplémentaires.

L'un des organes les plus remarquables des Tabaniens sont les yeux. J'ai observé que dans les mâles, les faceltes supérieures sont plus grandes que les inférieures, comme dans une partie des Stratiomydes. Ils sont quelquefois admirables par leurs couleurs brillantes et la variété des figures qui y sont dessinées. Dans les uns, ils sont d'un beau vert Céladon tacheté de brun; dans d'autres, d'un vert obscur orné d'un ou de plusieurs Iris nuancés; tantôt la surface en est grisâtre et traversée par des lignes onduleuses; tantôt elle est éblouissante d'or et émaillée de pourpre. Cet éclat relève singulièrement les couleurs souvent ternes du corps; mais c'est l'éclat chatoyant des yeux du Tigre, du Léopard, l'indice de la cruauté et de la perfidie; et en effet, l'instinct des Tabaniens ne s'accorde que trop avec les moyens de nuire que leur donne la conformation de leur trompe. Leur avidité pour le sang est extrême, et ils partagent avec les Asiles, les Stomoxes, les Cousins, l'odieux privilège de nous faire la guerre, et de s'abreuver de notre fluide nourricier; mais ils se rendent bien plus redoutables encore aux animaux qui 


\section{(149)}

ne peuvent se défendre avec autant d'avantage que nous, et que le cuir le plus épais ne met pas à l'abri de leurs douloureuses piqûres. Les chevaux et les bœufs en sont souvent tourmentés au point d'entrer en fureur. Ces bestiaux et plusieurs autres en ont chacun une espèce qui s'attache plus particulièrement à leurs pas, et qui portent leur nom. Le Renne, si précieux aux Lapons, a aussi son parasyte ailé ; et si l'histoire de ces formidables insectes était mieux connue, on pourrait peut-être en nommer le plus grand nombre du nom de leurs victimes. Cependant les femelles seules, excitées par le besoin d'une nourriture plus substantielle, ont cette soif de sang. J'ai fait arrêter bien des fois des chevaux dans les bois pour observer les Taons qui venaient à l'instant les assaillir en grand nombre. Je tuais tous ceux de ces insectes qui parvenaient à se fixer, malgré les obstacles qu'y mettait le mouvement adroitement dirigé de la crinière et de la queue. Je n'ai jamais observé de mâles parmi les assaillans. Ceux-ci vivent du suc des fleurs. Leur trompe, quoique moins fortement organisée que celle de l'autre sexe, paraît bien propre encore à percer la peau des animaux, et l'on ne peut guères attribuer cette différence de l'appétit qu'au besoin moins impérieux de nourriture qu'éprouvent tous les insectes mâles. L'on trouve aussi quelques femelles sur les fleurs.

Les Tabaniens fréquentent particulièrement les bois et les prairies humides, comme les Asiles, les terrains secs. C'est pendant l'été et aux heures les plus chaudes de la journée qu'ils se rendent le plus redoutables. Leur vol est rapide et accompagné d'un bourdonnement. Leur développement n'est connu que par les observations de Degeer sur le Taon des bœufs. La femelle confie ses œufs à la terre. Les larves sont grises, longues, cylindriques, 


\section{( 150$)$}

rétrécies aux extrémités et sans pieds. Elles ont le corps composé de douze segmens; la tête est cornée, étroite, allongée et munie de deux crochets, de palpes et d'antennes. Les nynuphes sont nues. Le front porte deux tubercules, et l'extrémité du corps six pointes. Les segmens de l'abdomen sont bordés de petites pointes. Elles passent un mois sous cette forme.

Cette famille se diversifie en plusieurs genres institués pour la plupart par Meigen, et distingués entr'eux par la conformation des antennes, par la présence ou l'absence des yeux lisses, et par quelques autres caractères moins importans. Parmi les genres dont elle se compose en Europe, nous ne connaissons dans le nord de la France, ni les Pangonies, ni les Sylvius, qui sont propres au midi.

\section{TABLEAU DES GENES.}

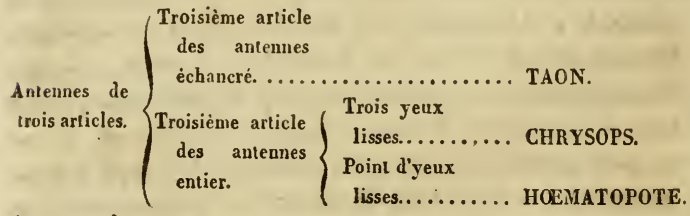

Antennes de six articles........................ HEXATOME.

\section{TAON; Tabanus.}

Tabanus, Linn., Gmel., Geoff., Schœff., Schr., Herbst, Fab., Deg., Panz., Meig., Fall.

Hypostome marqué de quatre impressions longitudinales; les deux intermédiaires étroites; les latérales plus larges et plus profondes. Front des femelles assez étroit; une callosité noire, un peu saillante, à la partie inférieure, souvent prolongée par une ligne noire; quelquefois 


\section{( 151$)$}

une seconde plus petite. Lèvre supérieure tronquée dans les mâles, obtusément pointue dans les femelles. Palpes fort courts, à deuxième article presque rond, dans les mâles; allongés, à deuxième article conique et subulé, dans les femelles. Antennes insérées vers le bas de la tête, sous les yeux, de la longueur de la tête; troisième article allongé, comprimé, à cinq divisions; la première large vers la base, fortement échancrée à la face supérieure, paraissant quelquefois bifide; la cinquième pointue. Yeux d'un vert foncé, marqués de lignes arquées, pourpres; point d'yeux lisses.

Jambes intermédiaires terminées par deux pointes:? Cellule anale des ailes n'atteignant pas le bord intérieur. (Pl. 3, fig. 7.)

Les Taons se reconnaissent d'abord à leur grande taille et à la forme du troisième article des antennes qui est fortement échancrée vers sa base, et dont le bord supérieur se prolonge en pointe. Ils diffèrent encore des autres genres par la lèvre supérieure qui est tronquée dans les mâles; mais si le genre est facile à déterminer, il n'en est pas de même des espèces qui le composent. Nonseulement elles n'offrent presque point de modifications dans la conformation, mais les caractères tirés des couleurs sont souvent très-vagues et variables. Aussi Meigen, malgré les nombreuses recherches auxquelles il s'est livré pour la détermination des espèces, la regarde- $t-i l$ comme trèsimparfaite encore.

Les légères modifications dans la conformation consistent dans la pointe plus ou moins saillante des antennes; dans la forme et le nombre des petites callosités du front des femelles. On croit voir aussi quelquefois des yeux lisses, mais dans. l'état rudimentaire.

Les Taons commencent à paraître au mois de juin. 


\section{( 152$)$}

Ils infestent dès-lors les bois et les prairies, en poursuivant les bestiaux. Ils sont surtout les ennemis les plus redoutables des chevaux qui succomberaient souvent à la fureur qu'ils leur causent, sans le secours de leurs crinières, ou, à leur défaut, des housses dont nous les couvrons. Connus dans tous les temps comme dans tous les lieux, leur nom est encore le même que l'on retrouve

- dans Varron, seulement altéré par l'usage et par le génie des langues.

1. TAON atre ; $T$. ater, Ross. Faun. etr., Meig.

D'un noir brillant. Antennes fourchues, noires. Thorax gris; anus blanc, velu. Ailes obscures.

Tabainus morio, Fab. Ent. syst. 363, 6 , Syst. antl. 94, 4, Meig. KI. 1, $167,4$.

Tabanus nigrita, Fab. Ent. syst. 367,21 , Syst. antl. $9^{8}$, 23 ; Meig. KI. 172, d.

Tabanus niger, etc. Geoff. 2, 46r, 4.

$$
\text { Long. 8, } 91 \text {. }
$$

Front de la femelle blanchâtre à ligne noire qui se termine en tache noire au-dessus des antennes; bord des yeux blanchâtre. Thorax à poils gris. Deuxième segment de l'abdomen avec une tache de poils blancs de chaque côté ; anus à poils blancs. Ailes obscures; le centre de la plupart des cellules à-peu-près diaphane.

Assez rare.

2. TAON obscur; T. fuscatus, Nob.

D'un noir brillant. Antennes fourchues, à première division du troisième article lestacé. Thorax gris. Anus blanc. Ailes obscures.

\section{Long. 71 .}

Mâle : hypostome velu. Première division du troisième article des antennes d'un testacé obscur. Thorax à poils gris. Deuxième segment de l'abdomen à poils blancs sur 


\section{( 153 )}

les bords latéraux; anus à poils blancs. Ailes obsoures; centre de plusieurs cellules postérieures assez clair.

Femelle : hypostome nu. Première division du troisième article des antennes d'un testacé rouge. Les poils blancs de l'anus moins apparens que dans le mâle. Ailes d'un brun uniforme peu foncé.

Je crois devoir distinguer cette espèce de la précédente par les caractères que je lui assigne. Elle ne peut se rapporter d'avantage, ni au T. nigrita de Fab., ni aux T. carbonarius et aterrima de Meigen.

J'ai pris le mâle et la femelle à Lestrem.

3. TAON brillant; T. micans, Meig.

Noir. Abdomen à trois rangs de taches blanchâtres; tarses antérieurs des mâles fasciculés.

Tabanus austriacus, Fab. Syst. antl. $9^{6}, 17$.

\section{Long. 7 1.}

Mâle : hypostome à poils gris. Palpes et antennes d'un noir de poix. Thorax noirâtre, légèrement pubescent, à bandes peu distinctes; abdomen noir à reflets bleuâtres; côtés du premier segment à tache de poils blanchâtres; côtés des suivans à tache d'un blanc bleuâtre; point triangulaire blanc sur le dos; et bord postérieur blanc. Ventre d'un noir bleuâtre. Pieds noirs; tarses antérieurs à fascicules de poils au côté extérieur. Balanciers noirs. Ailes d'un brun grisâtre pâle; bord extérieur et bords des nervures transversales plus foncés; stigmate brun.

Femelle : yeux verts avec trois lignes pourpres. Front gris; base et vertex à taches noires unies par une ligne. Côtés du thorax à poils gris. Tarses sans fascicules.

Rare.

4. TAON autumnal; T. autumnalis, Linn., Gmel., Fab., Meig., Fall.

Noir. Thorax à lignes cendrées. Abdomen blanchâtre, à quatre rangs de taches noires, obliqués. 
Tabanus, Geoff. $2,460,2$.

\section{Long. 8, 9 l.}

Mâle : hypostome et palpes d'un gris clair. Yeux clairs en-dessus, obscurs en-dessous, à ligne noire au milieu. Thorax d'un gris brunâtre, velu, à quatre lignes noirâtres. Abdomen d'un blanc grisâtre, changeant en brun rougeâtre, à quatre rangs de taches noirâtres, obliques, presque carrées; premier segment brun; ventre d'un gris clair rougeâtre, à large bande noirâtre, et bord postérieur des segmens blanc. Cuisses noirâtres; jambes brunes à base blanchâtre; tarses noirâtres. Balanciers brnns à tête blanche. Ailes grisâtres; nervures noirâtres.

Femelles : front blanchâtre; ligne à base saillante, d'un noir luisant. Abdomen d'un blanc grisâtre; ventre grisâtre. Jambes d'un blanc jaunâtre à extrémité noirâtre. Assez commun.

5. TAON poils dorés; T. auripilus, Meig.

Noir. Bord postérieur des segmens de l'abdomen à poils fauves.

\section{Long. 7,81 .}

Femelle : palpes noirs. Hypostome cendré ; front gris ; une ligne noire, élargie à l'extrémité supérieure, et une saillie d'un noir luisant à la base et sur le vertex. Thorax à poils noirs; deux bandes grises, peu distinctes, à sa base; côtés à poils jaunâtres. Abdomen à poils dorés sur les côtés et au bord postérieur des segmens ; un rang de taches dorsales jaunes, peu distinctes; ventre à poils dorés au bord postérieur des segmens. Pieds noirs à poils jaunes. Balanciers bruns. Ailes légèrement obscures ; bord extérieur jaunâtre; nervures transversales bordées de brunâtre.

Rare. Cette espèce paraît s'étendre depuis la Norwège jusqu'à Paris. 
6. Taon des boufs ; T. bovinus, Linn., Gmel., Schoff., Schr., Herbst, Fab. , Lat., Deg. , Panz., Fall., Meig.

Noirâtre. Abdomen à bandes jaunes et taches dorsales, triangulaires, blanchâtres. Jambes pâles.

Tabanus, Geoff. 2, 459, $x$.

\section{Long. 10, 121.}

Trompe noire. Palpes, hypostome et front d'un gris jaunâtre pâle. Front de la femelle à ligne noire qui s'élargit vers la base où elle se termine en une saillie semi-elliptique, d'un noir luisant. Antennes noires; premier et deuxième articles d'un brun noirâtre. Yeux d'un vert bronzé. Thorax d'un brun noirâtre, à poils jaunâtres, quelquefois ardoisé, à bandes noirâtres. Abdomen d'un brun noirâtre ; premier segment à bord postérieur fauve; second à bande fauve interrompue au milieu, de la largeur du segment; troisième et suivans à bande fauve, également interrompue, et de plus en plus étroite, au bord postérieur; une lache triangulaire d'un blanc jaunâtre au bord postérieur de chaque segment, excepté le premier et le dernier; ventre d'un gris jaunâtre; une large bande obscure au milieu ; bord postérieur des segmens jaunâtre. Cuisses et tarses d'un brun noirâtre; jambes d'un jaune pâle à extrémité obscure. Balanciers bruns. Ailes faiblement obscures; bord extérieur jaune.

Commun. Cette espèce varie beaucoup par les bandes fauves plus ou moins larges de l'abdomen. J'en ai un individu dont les trois premiers segmens sont entièrement fauves, à l'exception d'une bande noire et de la tache blanche au milieu.

7. TAON albipède; T. albipes, Fab., Lat., Meig.

Noir. Thorax et base de l'abdomen à poils gris. Jambes. blanches.

Tabanus, Geoff. 2, 460, 3. 
Tabanus gigas, Herbst gem. nat. 8, 112.

Schœff. icon. tab. $182,2,3$.

Ross. Faun. etr. 2, $320,1546$.

\section{Long. 10, 12 l:}

Palpes d'un brun noirâtre. Hypostome et front noirs. Yeux bronzés. Thorax à poils gris dans le mâle, jaunâtres dans la femelle; bandes noires peu distinctes; une petite tache de poils noirs à la base des ailes; poitrine noire. Abdomen d'un noir luisant; les deux premiers segmens à poils gris (mâle), jaunâtres (fem.); bord postérieur du dernier à poils fauves; ventre noir: bord postérieur du deuxième segment à poils blanchâtres. Pieds noirs; jambes ciliées, d'un blanc jaunâtre, à extrémité obscure, plus large dans les antérieures. Balanciers obscurs à tête blanche. Ailes à moitié antérieure jaunâtre; ensuite le bord des nervures brun.

Rare.

8. TAON cordigère; T. cordiger, Wiedem., Gmel., Meig.

D'un gris ardoisé. Abdomen noirâtre, à trois rangs de taches jaunâtres. Front de la femelle à callosité inférieure carrée et supérieure cordiforme.

\section{Long. 6,7 l.}

Hypostome blanchâtre. Front de la femelle marqué a la base d'une petite callosité carrée, surmontée d'une autre cordiforme; vertex marqué d'une tache noire où l'on aperçoit des points luisans qui semblent être des yeux lisses. Antennes d'un fauve obscur à extrémité noire. Thorax à cinq lignes blanchâtres; une élévation jaunâtre près de la base des ailes; taches latérales de l'abdomen obliques, composées d'une partie fauve et d'une partie grisâtre qui atteint le bord postérieur d'un gris jaunâtre; ventre noirâtre; bord postérieur des segmens jaunâtre; deux taches rougeâtres sur chaque segment. Jambes fauves; 


\section{$(157)$}

cuịsses et tarses obscures. Balanciers noiràtres. Ailes à nervures obscures.

La description de Meigen diffère de celle-ci par le ventre entièrement d'un gris jaunâtre et par les antennes noires. La couleur fauve des antennes m'aurait persuadé que c'était le T. bromius; mais la tache cordiforme du front et plusieurs autres différences m'ont déterminé à rapporter au Cordiger les individus d'après lesquels j'ai fait cette description.

Assez rare.

9. TAON glaucopis; $T$. glaucopis, Meig.

Thorax noirâtre à lignes cendrées. Abdomen noirâtre à trois rangs de taches fauves. Antennes testacées. Une callosité au front du mâle, trois à celui de la femelle. Tabanus ferrugineus, Meig. Kl. 1, 169, 10.

\section{Long. 81.}

Mâle : trompe noire. Palpes, hypostome et front d'un blanc grisâtre; ce dernier à callosité d'un noir luisant, divisée par une ligne enfoncée. Antennes testacées à extrémité obscure. Yeux gris ; partie inférieure verdâtre à deux lignes arquées et bord pourpres. Thorax noir à poils cendrés en-dessus; d'un gris jaunâtre sur les côtés et la poitrine. Abdomen conique, d'un brun noirâtre à trois rangs de taches fauves; le rang intermédiaire peu distinct et à reflets gris; les taches latérales allongées, obliques et contiguës au bord postérieur fauve des segmens; ventre jaune; bord postérieur des segmens pâle et anus brunâtre. Cuisses cendrées; jambes jaunes à extrémité obscure; tarses bruns. Balanciers bruns à extrémité blanchâtre. Ailes légèrement grisâtres.

Femelle : front à trois callosités d'un noir luisant ; l'inférieure demi-circulaire, à deux petites taches allongées, en-dessous ; l'intermédiaire allongée; la supérieure cor- 
diforme; vertex à deux petits traits noirs. Yeux verts à trois lignes arquées pourpres. Thorax à bandes d'un gris clair.

Rare.

10. TAON quatre-taches; T. 4 notatus, Meig.

Noirâtre. Abdomen à trois rangs de taches jaunâtres; taches intermédiaires peu distinctes. Antennes noires. Front de la femelle à quatre callosités.

\section{Long. $8 \mathrm{l}$.}

Femelle : palpes jaunâtres. Hypostome et front d'un blanc grisâtre; ce dernier à quatre callosités d'un noir luisant; l'inférieure demi - circulaire; les deux intermédiaires carrées, allongées; la supérieure sur le vertex, demi-circulaire et divisée par une ligne peu distincte. Thorax noirâtre à poils cendrés ; côtés cendrés. Abdomen peu convexe, à trois rangs de taches jaunâtres; taches intermédiaires triangulaires, peu distinctes; latérales ovales, obliques et isolées ; bord postérieur des segmens jaunâtres. Balanciers obscurs à extrémité blanche. Cuisses cendrées; antérieures plus foncées; jambes fauves à extrémité obscure; tarses noirâtres. Ailes légèrement obscures; deuxième cellule sous-marginale à extrémité tronquée.

Rare.

1. TAon bruyant; T.bromius, Linn., Fab., Lat., Meig. Noirâtre. Thorax à lignes blanchâtres. Abdomen à trois rangs de taches jaunâtres. Antenues testacées. Front de la femelle à callosité carrée et ligne noires.

Tabanus maculatus, Deg. $6,83,3$.

Herbst gem. nat. 8, 112.

$$
\text { Long. } 6,71 \text {. }
$$

Palpes, hypostome et front blanchâtres; ce dernier à callosité carrée à la base et ligne d'un noir luisant 


\section{( 159 )}

dans la femelle; vertex noirâtre. Antennes testacées à extrémité noire. Yeux verdâtres à ligne arquée pourpre. Thorax noirâtre à poils gris et lignes blanchâtres; côtés cendrés à poils jaunâtres. Abdomen noirâtre à trois rangs de taches jaunâtres ou grises, et bord postérieur des segmens blanchâtre; les taches dorsales triangulaires; les latérales rhomboïdales ou arrondies et contiguës au bord postérieur des segmens; ventre d'un gris jaunâtre à large bande noirâtre; bord postérieur des segmens d'un jaune pâle. Cuisses grises; jambes testacées à extrémité obscure; tar'ses noirâtres. Balanciers noirâtres à extrémité blanche. Ailes grisâtres.

Assez rare.

12. TAON grec; $T$. grcecus, Fab., Meig.

Abdomen ferrugineux à reflets blanchâtres ; bande dorsale et anus noirâtres. Antennes fauves à extrémité noire.

\section{Long. 71.}

Mâle : palpes, hypostome et front d'un gris jaunâtre clair. Anteunes fauves ; premier article en-dessus et moitié postérieure du troisième noirs. Thorax noirâtre à poils cendrés et bandes peu distinctes ; côtés légèrement ardoisés à poils jaunâtres. Abdomen fauve à reflets d'un gris blanchâtre ; premier segment noirâtre à côtés ferrugineux; les trois suivans à bande dorsale d'un brun noirâtre; quelquefois une tache grise triangulaire, sur chacun; les derniers noirâtres; bord postérieur de tous d'un jaune clair; les quatre premiers segmens du ventre fauves, les autres noirâtres; bord postérieur jaune. Pieds antérieurs noirs; jambes à moitié autérieure fauve et postérieure brune; pieds postérieurs à cuisses grises; jambes fauves à extrémité brune et à franges noires du côté extérieur; tarses noirâtres. Balanciers bruns à extrémité 
blanchâtre. Ailes presque hyalines à nervures costales d'un fauve brun.

Femelle : palpes jaunâtres. Hypostome et front d'un gris pâle; une ligne arquée jaunâtre, au-dessus des antennes ; une callosité carrée, d'un noir luisant et une petite ligne noire au-dessus. Bande dorsale de l'abdomen plus large que dans le mâle.

Rare.

13. TaON livide; T. luridus, Fall., Meig.

Abdomen noir; les trois premiers segmens à bords latéraux fauves changeant en blanc. Antennes noires; troisième article fauve à extrémité noire.

\section{Long. 6,71 .}

Màle : palpes et hypostome d'un gris brunâtre. Yeux verts à trois lignes arquées pourpres. Thorax d'un noir luisant à poils noirs; côtés bruns. Abdomen d'un noir luisant; une tache demi-ovalaire fauve à reflets blanchâtres et bordée extérieurement de poils noirs, de chaque côté des trois premiers segmens; des vestiges de tache triangulaire blanchâtre sur les deuxième et troisième ; bord postérieur des suivans blanc; ventre fauve à base et extrémité noirâtres. Cuisses noires, velues; jambes testacées à extrémité obscure ; postérieures, frangées extérieurement; tarses noirs. Balanciers obscurs à extrémité blanchâtre. Ailes d'un gris brunâtre pâle ; bord extérieur jaunâtre; nervures légèrément bordées de brun.

Femelle : palpes et hypostome jaunâtres. Front d'un blanc grisâtre; une petite callosité d'un noir luisant à la base, une autre au vertex et une ligne noire.

Peu commun.

14. Thon tropical ; T. tropicus, Linn. , Gmel., Lat., Fab., Panz., Fall.

Abdomen noirâtre; les quatre premiers segmens à 


\section{$(16$,}

tache ferrugineuse de chaque côté (à reflets blanchâtres dans le mâle ). Antennes ferrugineuses à extrémité noire.

Schœeff. icon. tab. 131, f. $4-6$.

Schell. g. d. m. tab. 27 , f. 2.

Herbst naturg. 8, 11 3 , tab. 342 , f. 4 .

Schr. Faun. boic. 3, 2533.

- Ins. aust. 975 .

\section{Long. 7,8 l.}

Mâle : palpes et hypostome d'un gris obscur. Yeux verts à trois lignes arquées pourpres. Thorax d'un noir luisant à poils noirs sur le dos, brunâtres sur les côtés. Abdomen noir ; une large bande fauve à reflets blanchâtres de chaque côté des quatre premiers segimens; quelquefois des vestiges de la tache triangulaire blanche sur ces segmens; bord postérieur jaunâtre ; ventre fauve à extrémité noire ; côtés à poils noirs. Cuisses brunes ; jambes fauves; antérieures à moitié inférieure brune ; intermédiaires frangées ; tarses noirs. Balanciers obscurs à extrémité blanchâtres. Ailes d'un gris brunâtre pâle; bord extérieur d'un jaune brunâtre à nervures brunes.

Femelle : palpes et hypostome d'un gris jaunâtre; front jaunâtre; une callosité d'un noir luisant à la base; une ligne noire au milieu; un point brillant sur le vertex. Thorax à poils ferrugineux. Les bandes fauves de l'abdomen sans reflets; côtés du ventre à poils jaunes. Jambes intermédiaires sans poils.

Rare.

15. TaON rustique ; T. rusticus, Linn., Gmel., Fab., Meig., Panz., Fall.

Noirâtre à poils d'un gris jaunâtre. Abdomen sans tache (mâle), à quatre rangs de taches obscures (fem.). Antennes fauves à extrémité brune.

Schr. Faun. boic. 3, 2532.

- Austr. 976 . 
Tabanus, Geoff. 2, 462,7 .

$$
\text { Long. } 6,71 \text {. }
$$

Mâle : palpes et hypostome d'un gris jaunâtre clair. Yeux d'un vert clair sans lignes arquées. Corps d'un gris noirâtre à poils denses d'un gris jaunâtre pâle. Poitrine d'un gris ardoisé clair. Ventre gris antérieurement, jaunâtre postérieurement. Pieds jaunes; cuisses grises, à extrémité noirâtre ; tarses antérieurs noirs; postérieurs jaunes à extrémité noire. Balanciers d'un jaune clair à extrémité blanche. Ailes hyalines; bord extérieur jaunâtre; deuxième cellule sous-marginale à base tronquée.

Femelle : front à deux paints d'un noir luisant dont le supérieur est au milieu du front, et se prolonge quelquefois en une petite ligne. Un vestige de ligne arquée au côté intérieur des yeux. Abdomen à quatre rangs de taches d'un brun noirâtre. Cuisses entièrement grises.

Rare.

16. Thon fauve; T. fulvus, Meig.

Obscur, à poils d'un jaune doré. Antennes fauves. Tabanus alpinus, Schr. Faun. boic. 3, 2534.

\section{Long. 71.}

Mâle : tête hémispluérique. Palpes jaunâtres. Hypostome d'un gris jaunâtre. Antennes fauves. Yeux d'un vert clair, plus obscur inférieurement; corps noirâtre à poils denses d'un jaune doré. Abdomen à tache ferrugineuse de chaque côté, s'étendant depuis le bord postérieur du premier segment jusqu'à celui du troisième. Ventre d'un gris jaunâtre. Pieds fauves; hanches cendrées; tarses antérieurs noirs. Balanciers jaunes à extrémité blanche. Ailes hyalines; base et bord extérieur fauves; deuxième cellule sousmarginale à base tronquée.

Femelle : tête déprimée. Front d'un gris jaunâtre. Petite callosité d'un noir luisant souvent peu distincte.

Rare. 
17. TAON bimaculé; T. bimaculatus, Nob.

Abdomen noir. Une tache fauve sur les côtés des premier et second segmens. Antennes noires; troisième article fauve à extrémité noire.

\section{Long. $6 \frac{7}{2} \mathrm{l}$.}

Femelle : hypostome gris; front à callosité et lignes d'un noir luisant. Thorax noir à lignes peu distinctes. Abdomen à tache fauve sur les côtés des premier et second segmens ; la deuxième n'atteignant pas le bord postérieur; point de vestiges de taches dorsales; ventre noir à deux petites taches fauves au bord antérieur du troisième segment; bord postérieur des segmens blanchâtre. Cuisses noires; jambes testacées ; tarses noirs. Balanciers obscurs à extrémité blanchâtre. Ailes légèrement brunâtres; bord extérieur jaunâtre.

Rare.

CHRYSOPS ; Chrysops.

Chrysops, Meig., Lat., Fab. Syst. antl. Fall. - Tabanus,

Linn., Gmel., Geoff., Fab. Spec. ins., ent. syst., Deg., Schell.

Hypostome et front de la femelle munis chacun de deux callosités d'un noir luisant. Trompe assez menue; lobes terminaux allongés. Palpes horizontaux dans les mâles, verticaux dans les femelles, plus courts que la trompe. Antennes insérées au milieu de la face antérieure de la tête, plus longues qu'elle, dirigées en avant, et légèrement relevées vers l'extrémité ; les deux premiers articles allongés, d'égale longueur, cylindriques, velus; le troisième à cinq divisions dont la première un peu plus épaisse et plus longue que les quatre autres réunies, paraissant elle-même divisée en plusieur's segmens. Yeux d'un beau vert doré, marqués de taches et de lignes pourpres. Trois yeux lisses. 


\section{( 164 )}

Jambes terminées par deux très-petites pointes. Ailes à demi-ouvertes, obscurément colorées; cellule anale eulr'ouverte. ( $\mathrm{Pl} .3$, fig. 6.)

Les caractères qui sont propres à ces Tabaniens consistent dans la couleur éclatante des yeux, qui a donné lieu au nom de Chrysops; dans la conformation du troisième article des antennes dont la première division, vue à la loupe, paraît elle-même divisée en nombreux segmens; dans celle des jambes qui sont toutes munies de trois petites pointes à l'extrémité. Enfin, dans les' ailes dont les couleurs ténébreuses ne sont égayées que par quelques taches transparentes; de là les noms de Viduatus, de Funebris, de Sepulcralis, donnés aux différentes espèces. D'autres caractères ne distinguent les Chrysops que d'une partie des Tabaniens; tels sont les yeux lisses que l'on ne retrouve que dans les Pangonies et les Sylvius, du midi de l'Europe; les palpes à deuxième article conique dans les deux sexes semblables à ceux des Hœmatopotes; et les ailes à demi-ouvertes comme dans les Taons.

Ces insectes nous attaquent avec acharnement dans les bois; mais nous en éprouvons plus d'importunité que de mal. Comme ils ne cherchent à se fixer que sur les parties découvertes de notre corps, nous les voyons et évitons leurs piqùres plus facilement que celles du Cousin, et ces piqùres, d'ailleurs, ne sont pas envenimées comme celles de ce malfaisant animal.

La nomenclature des Chrysops a été long-temps erronée surtout par les différences qui existent entre les sexes, et qui étaient considérées comme spécifiques. Meigen en décrit onze dont plusieurs sont du midi.

f I. Chrysops aveuglant; C. caicutiens, 'Meig., Lat.; Fab. Syst. antl., Fall.

Abdomen noir; base à tache latérale rousse (mâle), 
ou base jaune à deux lignes obliques noires (femelle). Antennes et pieds noirs.

Chrysops viduatus, Fab. Syst. antl. 113, 10. lugubris, ibid. 113, 9 .

Tabanus coecutiens, Linn. Faun. suec. 1888, Gmel. 'Syst. nat. 5, 2885, 17, Deg. 6, 9o, 6, Fab. Spec. ins. 2, 459,27 (femelle), ent. syst. $4,372,42$.

Tabanus lugubris, Linn. 1889, Fab. Spec. ins. 2, 46o, 28 (mas), ent. syst. $4,375,46$.

Tabanus viduatus, Fab. Ent. syst. 4, 374, 47 (var. maris) Schell. g. de m., tab. 28, f. 1, 2.

\section{Long. 41.}

Mâle : noir. Hypostome jaune, velu, à deux grandes taches d'un noir luisant. Yenx à deux lignes trausversales d'un pourpre noirâtre. Côtés et dessous du thorax à poils fauves. Deuxième segment de l'abdomen à tache latérale fauve; le reste entièrement noir, avec quelques poils fauves; ventre noirâtre ; les deux premiers segmens jaunes avec une bande intermédiaire obscure. Ailes noires; une petite tache hyaline vers l'extrémité de la cellule discoïdale externe; partie postérieure du bord interne presqu'hyaline, avec une pointe vers le bord externe; un point allongé blanc près de la base.

Femelle : hypostome d'un gris jaunâtre à trois taches d'un noir luisant. Front cendré avec deux taches noires. Premier article des antennes d'un fauve obscur à la base. Thorax d'un noir luisant à deux bandes grises antérieurement, et à poils fauves sur les côtés; poitrine grise. Premier segment de l'abdomen noir à tache latérale jaune; deuxième jaune avec deux lignes noires, divergentes, au milieu; les autres noirs avec quelques poils jaunes; les deux premiers segmens du ventre jaunes à bande intermédiaire noire. Base du premier article des tarses fauve. 
Ailes noirâtres; une grande tache hyaline vers le milieu, n'atteignant pas le bord externe; une autre presqu'hyaline, à l'extrémité, comme dans le mâle.

Fort commun.

2. Chrysops négligé ; $C$. relictus, Meig.

Abdomen jaune; deuxième segment à tache double, et les autres à bande sinuée, noirs. Jambes fauves. Chrysops viduatus, Meig. KI. 1, 158, 2, Fall. Dipt. suec. 10, 2.

Tabanus coecutiens, Panz. Faun. germ. 13, 24.

Geoff. 2, 463, 8 .

\section{Long. 41.}

Palpes testacés. Hypostome et front jaunâtres avec les taches ordinaires. Antennes à base fauve. Thorax gris à trois bandes noires; côtés jaunes; écusson gris. Premier segment de l'abdomen jaune; milieu noir ; deuxième jaune avec deux taches $n$ oires triangulaires, conniventes; les antres noirs à bord postérieur jaune, élargi au milieu et sur les côtés; ventre d'un jaune sale; base des segmens brunâtre. Jambes fauves; antérieures à moitié postérieure obscure; tarses fauves à l'extrémité des articles obscurs; antérieurs noirâtres. Ailes comme dans l'espèce précédente.

Commun.

3. Chrysors peint; C. pictus, Meig.

Abdomen jaune; deuxième segment à point triangulaire et les autres à bandes, sinuées, noires. Palpes, base des antennés et pieds testacés.

Chrysops viduatus, var., Meig. KI. 1, 158, 2.

\section{Long. $4: 1$.}

Fémelle : semblable au précédent : premier, deuxième et base du troisième article des antennes testacés. Côtés du thorả fauves à taches noirâtres; écusson noir. Deuxième segment de l'abdomen à petite tache triangulaire noire; 


\section{( 167 )}

les deux premiers segmens du ventre fauves; les autres obscurs à bord postérieur jaune. Pieds fauves; cuisses noires.

Assez rare.

4. Chrysops carré; C. quadratus, Meig.

Abdomen jaune; deuxième segment à tache carrée, et les autres à bande sinuée, noirs. Palpes, antennes et pieds' noirs.

\section{Long. $4 \div 1$.}

Mâle : il ne diffère de celui de la première espèce que par le bord sinué fauve des derniers segmens de l'abdomen.

Asșez rare.

5. Cunysops rufipède; C. rufipes, Meig.

Abdomen noir; trois rangs de taches triangulaires et bord postérieur des segmens fauves. Pieds fauves, à genoux noirs.

\section{Long. 41.}

Cette espèce diffère des précédentes par l'abdomen. Premier segment à ligne fauve de chaque côté; les autres à taches fauves triangulaires sur le dos et sur les côtés, contiguës au bord postérieur de même couleur. Jambes fauves à genoux noirs. Parties hyalines des ailes un peu obscures.

\section{Rare.}

6. Chrysors marbré; C. marmoralus, Meig.

D'un jaune pâle. Thorax à deux bandes et abdomen à taches noires. Antennes allongées.

Tabanus marmoralus, Ross. faun. etrusc, 2, 1552. - flavipes, Meig. KI. KI, $159,3$. Geoff. 2,464 , 1 I.

\section{Long. 41.}

Femelle: palpes fauves à extrémité obscure. Hypostome d'un gris jaunâtré ; la tache noire intermédiaire divisée en deux. Front cendré. Antennés à premier et deuxième 


\section{( 168 )}

articles plus longs que dans les autres espèces; premier arlicle roussâtre à extrémité obscure. Thorax d'un gris clair; deux bandes d'un noir luisant, et une troisième dorsale moins distincte; écusson noir. Abdomen d'un jaune pâle; premier segment à deux taches noires triangulaires, conniventes; deuxième à deux taches séparées; suivans à bord antérieur noir, interrompu; ventre jaune. Pieds d'un fauve clair à genoux noirs; extrémité des jambes antérieures obscure; tarses noirs; premier article des postérieurs et intermédiaires fauves. Áiles à bord extérieur et bande transversale brune; une petite tache hyaline au milieu de cette dernière dans la cellule discoïdale postérieure.

Rare.

\section{HEMATOPOTE ; HøMATOPOTA.}

Hoematopota, Meig., Lat., Fab., Fall. - Tabanus, Linn.,

Gmel., Geoff., Schoff., Schr., Deg., Panz.

Hypostome à ligne enfoncée descendant de la base de chaque antenne jusqu'à un point noir enfoncé. Front de la femelle très-large. Trompe épaisse, convexe en-dessous. Antennes allongées, insérées vers le bas de la tête, légèrement arquées; premier article épais, allongé, velu, elliptique dans les mâles, cylindrique dans les femelles; deuxième velu; troisième nu, à quatre divisions dónt la première un peu plus épaisse et aussi longue que les antres réunis. Yeux lisses nuls.

Jambes intermédiaires terminées par deux petites pointes. Ailes côuchéés, tachetées; un 'rudiment de nervure à la base de la deuxième cellule sous-marginale; anale atteignant le bord intérieur. ( $P l .{ }^{1} 3 ; f g .8$. )

Les Hormatopotes ne diffèrent de tous les Tabaniens que par une légère modification dans les nervures des ailes.' Ils se distinguent particulièrement des genres pré- 


\section{( 169 )}

cédens par les quatre divisions du troisième article des antennes, et ce caractère les rapproche du genre suivant dont les antennes présentent le même nombre de parties, si l'on fait abstraction de la différence de dénomination à laquelle le plus ou moins d'adhérence de ces parties entr'elles a donné lieu. Cette affinité s'observe encore dans l'absence des yeux lisses, dans les pointes des jambes intermédiaires, et surtout dans le port des ailes.

Ces insectes nous attaquent autant que les animaux. Leur soif pour le sang, d'où dérive leur nom, s'accroît dans les temps orageux, et ils nous poursuivent alors avec un acharnement extrême. Les mâles, qui cherchent leur subsistance sur les fleurs, fréquentent les prairies.

Suivant Fabricius, ils se développent dans le fumier. 1. Hematopote pluvial; $\boldsymbol{H}$. pluvialis, Meig., Lat., Fab. Syst. antl., Fall.

Noirâtre. Thorax à lignes blanchâtres. Abdomen à bord postérieur des segmens blanchâtre, une bande dorsale et deux rangs de taches grises. Ailes cendrées à lignes onduleuses blanches.

Tabanus pluvialis, Linn., Gmel., Deg., Schr. Faun. boic., Fab. Spec. ins., ent. syst., Panz.

Tabanus hyemantis, mas, Schr. Faun. boic.

Réaum. 4, tab. 18 , f. I.

Schoff. tab. 85 , f. 89 .

Long. $4,4 \frac{7}{2} 1$.

Mâle : palpes et hypostome d'un gris clair, à poils blanchâtres; ce dernier ponctué de noir. Front consistant en un petit espace triangulaire occupé par une callosité noire et une pointe grise. Première division du troisième article des antennes d'un fauve olscur. Yeux d'un vert grisâtre; partie inférieure d'un brun pourpre à lignes 
transversales, sinuées, d'un vert jaunâtre. Thorax noiràtre avec trois lignes blanchâtres; les deux latérales à petite tache blanche vers le milieu ; côtés et poitrine gris, velus. Abdomen noirâtre; les trois premiers segmens bordés latéralement de fauve; une bande dorsale, un rang de taches de chaque côté et bord postérieur des segmens gris. Ventre gris; côtés des trois premiers segmens fauves. Pieds noirs; base des jambes antérieures fauve; intermédiaires et postérieures à deux anneaux fauves; base du premier article des tarses fauve; antérieurs entièrement noirs. Balanciers jaunâtres à extrémité obscure. Ailes d'un gris brunâtre; un grand nombre de taches d'un roussâtre pâle; plusieurs en forme de cercle; une petite ligne transversale près de l'extrémité; tache stigmatique noirâtre.

Femelle : front gris, à bande transversale d'un noir luisant, au-dessus des antennes; deux taches rondes d'un noir mat, an-dessus de cette bande, et une troisième plus petite, quelquefois nulle, au milieu. Abdomen sans bord fauve; taches moins distinctes que dans le mâle.

Fort commun. Les antennes varient pour la longueur et la forme du premier article.

Je considère l'H. equorum de Fab. comme identique avec celui-ci. Non-seulement la phrase spécifique de cet auteur ne donne d'autre caractère différentiel que les côtés fauves de l'abdomen, que présentent tous les mâles de l'espèce commune, mais M. Meigen nous en donne une seconde preuve en rapportant une note de Wiedemann qui nous apprend que les deux individus de cette prétendue espèce qui se trouvaient dans la collection de Fabricius éiaient des mâles.

HEXATOME; HeXatoma.

Hexatoma, Meig. - Heptatoma, Meig. Kl., Lat. , Fab. Syst. antl. - Tabanus, Gmel., Schr., Schœeff., Schell., Fab. Spec. ins., ent. syst. 


\section{(17:)}

Hypostome marqué de deux lignes enfoncées, perpendiculaires. Trompe épaisse. Palpes à deuxième article ovale dans les mâles, conique, allongé, dans les femelles. Antennes insérées au milieu de la hauteur de la tête, beaucoup plus longues qu'elle, de six articles; premier allongé; troisième plus long, quatrième et cinquième courts et ovales; sixième un peu plus long. Point d'yeux lisses.

Jambes intermédiaires terminées par deux petites pointes. Ailes couchées; nervures comme dans le g. Taon. ( $P l .3$, fig. 7.)

Voici un genre composé d'une seule espèce qui, selon la manière dont on le considère, offre dans son organisation la plus grande anomalie ou la plus légère différence ave $c$ le genre précédent. Appartenant par tous ses organes à la famille des Tabaniens, et généralement à la grande tribu des Diptères à antennes triarticulées, c'est-à-dire à tous les insectes de cet ordre, à l'exception des Tipulaires, ses antennes sont de six articles, et s'écartent ainsi de la manière la plus étrange du caractère en apparence le plus invariable de cette tribu. D'un autre côté, si l'on compare l'hexatome aux hœmatopotes, l'on ne voit plus au contraire qu'une, très-grande ressemblance dans les antennes, comme dans les autres organes. Les divisions du troisième article dans ces derniers réprésentent entièrement le nombre et même les dimensions respectives des quatre derniers articles de celles des Hexatomes, et elles n'en diffèrent qu'en ce qu'elles sont moins distinctes l'une de l'autre. Enfin il est difficile de méconnaître l'identité de conformation dans ces organes; et, comme il n'est pas possible de considérer les quatre derniers articles des antennes de l'hexatome comme $n$ 'en formant qu'un seul, marqué d'incisions annulaires, il 


\section{( 172 )}

s'en suit que dans les Homatopotes, l'on devrait regarder les quatre divisions du troisième comme autant d'articles; et l'on ne pourrait refuser de considérer de même les autres Tabaniens, les Xylophagites et les Stratiomydes, dont les antennes ont été regardées jusqu'ici comme formées de trois articles dont le troisième est également plus ou moins subdivisé.

Ce développement de l'organisation, plus sensible dans l'Hexatome, joint à celui de la trompe, semblable à celle des autres Tabaniens, nous détermine à placer ce genre à l'extrémité de cette première série des Diptères qui précède celle des Tipulaires. A la vérité, parmi les familles précédemment décrites, les Xylophagites ont quelquefois des rapports avec des Tipulaires (le genre rhyphe), et l'on forme, en les rapprochant, comme l'a fait Meigen, une sorte de série continue de la classe entière des Diptères; mais en employant cette transition, il faut renoncer à l'ordre progressif fondé sur le développement des organes, les Xylophagites ayant l'organisation moins développée que les Tabaniens, les Rhyphes plus que les Scathopses, les Bibions et plusieurs autres Tipulaires; et il nous semble que cette considération est d'un ordre supérieur à ces espèces de transitions plus ingénieuses que naturelles dont on se sert pour unir entr'elles les diverses párties de la chaîne des êtres.

$\therefore$ L'Hexatome n'a rien offert dans ses habitudes qui le distingue des autres Tabaniens.

Hexatome bimaculé; $\boldsymbol{H}$. bimaculata, Meig.

- Noir. Les deux premiers segmens de l'abdomen velus; une tache d'un blanc bleuâtre sur les côtés du deuxième dans la femelle; anus velu.

Heptatoma bimaculata, Meig. KI. 1, 156 , 1, Fab. Syst. antl. $105,1$. 


\section{$(173)$}

Tabanus pellucens, Gmel. 5, 2883, 23, Fab. Ent. syst. 4, 365, 15, Spec. ins. 2, 457, 12.

Tabanus albipes, Schr. Faun. boic. 3, 2531 .

Schœff. Icon. tab. 72, f. 6-8.

\section{Long. 61 .}

Mâle : hypostome d'un noir luisant, à poils jaunâtres. Yeux d'un brun pourpre, avec deux lignes arquées bleues, bordées de vert. Thorax noirâtre à poils fauves. Abdomen noir; les deux premiers segmens à poils d'un jaune brunâtre en-dessus; en-dessous, les côtés de ces deux segmens sont d'un blanc bleuâtre; les autres à trois lignes de même couleur, de chaque côté, en-dessous; anus à poils fauves. Pieds d'un brun noirâtre; jambes blanches à extrémité brune; antérieures brunes à ligne blanche à la base. Balanciers noirâtres. Ailes presqu'hyalines.

Femelle : hypostome d'un gris clair en-dessus, jaune clair en-dessous. Front noir, d'un brun rougeâtre endessus. Base de l'abdomen à poils d'un jaune brunâtre; deuxième segment à tache latérale d'un blanc bleuâtre.

J'en ai trouvé plusieurs individus. 


\section{TABLE ALPHABÉTIQUE}

DES

\section{GENRES ET DES ESPECES.}

ACrocère.

Anthrax.

orbicule... $9^{2}$

à fenêtre.... 6

bordé...... 58

jaune....... 57

pandore.... 61

- semi-atre... 58

-

- 1 varié...... 60

—— velouté...... 59

AsILE.

- à ceinture..... 33

albiceps....... 3o

annelé........ 36

à tenailles..... 3o

- barbe rousse.. 29

- bordé....... 35

chrysitis...... 29

cothurne...... 32

- crabroniforme. 28

- émule....... 33

$\longrightarrow$ estival....... 3 I

- germanique... 32
Pages

Asıle nigripède.... 35

- opaque...... 3 it

- punctipenne... 34 strié ........ 35

ATHÉRIX.

—— bordé..... 85

-

—— nébuleux.... 87 -sans tache.,. 88

BÉRIs.

— armé......... 138 $\begin{array}{lll}\text { clavipède..... } & 137\end{array}$

flavipède...... 139

fuscipède..... 139

luisant....... 136

$\begin{array}{llll} & - \\ \end{array}$ métallique .... 137

- noir......... 138 tibial........ 136

BoMbYLE.

anguleux... 5 r croisé...... 48 étincelant... 5 5 t luisant..... 5o 
Bonexle majeur.... 47

- mineur.... 49

moyen..... 47

postérieur.. 49 sulfuré..... 50

\section{Chrysopile.}

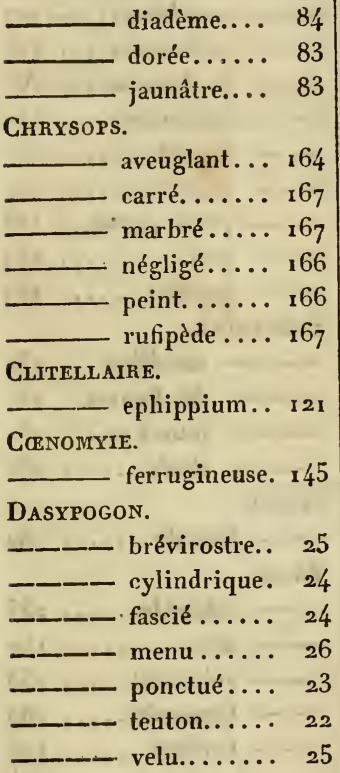

DIOCTRIE:

- - àdeuxceintures. 20

—— annelée...... 20

$\longrightarrow$ anomale..... 17
Dioctrie à poils noirs. $2 \mathrm{I}$

- de Baumhauer. 16 de Reinhard... 17 flavipède...... 15

$\begin{array}{lll}\text { - frontale....... } & 17\end{array}$

grêle......... 18

- hœmorrhoïdale $\quad$ 99

- - latérale....... 18

- - longicorne.... 19

_-

—_— rufipède...... 15

—— varipède...... 16

Hegmatopote.

HeXatome.

pluvial. .... 169 bimaculé.... 172

LAPHRIE.

- - atre........ 4r

—— bordée ....... 39

- - bossue ...... $33_{7}$

changeante... 4a

dorsale...... 39

- - fauve......... 40

—— fémorée...... 41

—— jaune.......... 38

LEPTIS.

- _ antennes jaunes. $8 \mathrm{x}$

- — bécasse....... $7^{8}$

- - chevalier..... 79 distinguée .... 79

- — linéole ....... 8r sans tache.... 8x 


\section{( $1_{7} 6$ )}

\begin{tabular}{|c|c|}
\hline ges. & \\
\hline … 77 & Phthyore. \\
\hline e... 80 & - — fauve....... \\
\hline EPTOGAST & ——— pulicaire.... 53 \\
\hline que. Ix & Ploas. \\
\hline a. 12 & - verdâtre. \\
\hline$\ldots 12$ & Sargue. \\
\hline MOTËLE & leu...... 107 \\
\hline$\cdots x$ & $\ldots \ldots 106$ \\
\hline e. $1 \times 5$ & — de \\
\hline .. 114 & ne..... 110 \\
\hline .... 1 & $\begin{array}{cc}\text { luisant........ } & 107 \\
\text { olsscur. ....... } & 107\end{array}$ \\
\hline . 127 & $\begin{array}{l} \\
\end{array}$ \\
\hline - 126 & —— poli......... sog \\
\hline .. 129 & e...... 109 \\
\hline 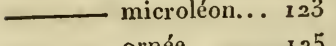 & TRATION \\
\hline . 1 & 3o \\
\hline 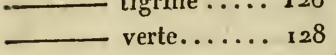 & $\begin{array}{ll}\text { euves.. } & 13 \mathbf{r} \\
\text { aue.... } & 13 \mathbf{r}\end{array}$ \\
\hline & - striée...... $3_{2}$ \\
\hline - 94 & TYGIE. \\
\hline ․ 94 & - lat \\
\hline - $9^{5}$ & Lon. \\
\hline $9^{5}$ & ..... 155 \\
\hline $1=$ & .152 \\
\hline$\cdots \times 17$ & .... 553 \\
\hline … 118 & a...... 163 \\
\hline …120 120 & t....... 53 \\
\hline e.... & t. . . . 158 \\
\hline$=$ & $\begin{array}{ll}\text { erre...... } & 156 \\
\text { eufs..... } & 155\end{array}$ \\
\hline & ....... \\
\hline
\end{tabular}




\section{( 17.7 )}

Pages.

TAon glaucopis..... 159

grec........ $\times 59$

Thérève biponctuée. 68

livide ....... 160

obscur ...... 152

pieds dorés.... 154

quatre-taches.. 158 rustique..... $16 \mathbf{r}$

tropical....... 16o

Thérève.

albipenne.... 68 annelée...... $7^{\circ}$ ceinte...... 66

— flavilabre.... 69

- noble....... 65

— plébéienne.... 66

- voisine...... 69

XYlophage.

- ceint........ $14 \mathrm{r}$

noir ........ $14 \mathrm{x}$

— tacheté. ..... 142

- varié....... 142

argentée..... 69 


\section{EXPLICATION DES FIGURES.}

\section{PLANCHE I. $^{\text {re }}$}

Figure I. Aile du LEPTOGASTRE cylindrique; L. cylindricus.
2.
Dioctrie rufipède;
D. rufipes.

3.

anomale;

D. anomala.

4. DasYrogon ponctué; $D$. punctatus.

5. AsILE frêlon;

A. crabroniformis.

6. LAPHRIE changeante; $L$. gilva. Bonibyre moyen; B. medius. 8. Phthyrie pulicaire; $P$. pulicaria.

$$
\text { PLANCHE }{ }_{2 .}^{\mathrm{e}}
$$

Figure x. Aile de l'Anthrax sinué; $A$. sinuata.

2. Théreve plébéienne; $T$. plebeia.

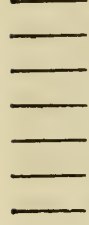

3. LEPTIS bécasse;

L. scolopacea.

4. Chrysopile doré;

C. auratus.

5. Atuénix bordé; A. marginata.

6. SARGUe cuivreux; S. cuprarius.

7. Pachygastre noir; $P$. aler. 8. —— NÉnotèLE panthérine; $N$. pantherinus.

PLANCHE $3 .^{\mathrm{e}}$

Figure I. Aile de l'OXYcìre joli ;

O. pulchella.

2. Stratiome caméléon; $S$. chamoeleon.

3. Odontomyie argentée; $\boldsymbol{O}$. argentata.

- 4. - BERIS clavipède;

B. clavipes. 5. — tibial ;

B. tibialis.

6. Chrysors aveuglant;

C. coecutiens.

- 7 . TAON de bœufs; T. bovinus, et HeXатомe bimaculé; $\boldsymbol{H}$. bimaculala.

- 8. Hematorote pluvial; $H$. pluvialis. 


\section{pl. 1 .}
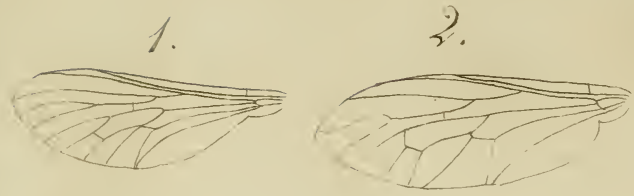

3.
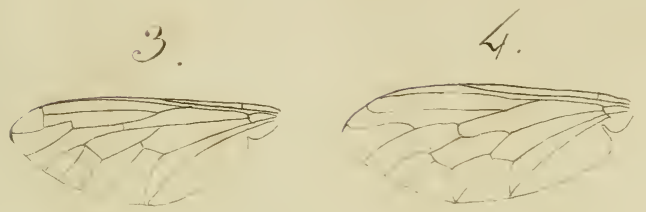

c)

63
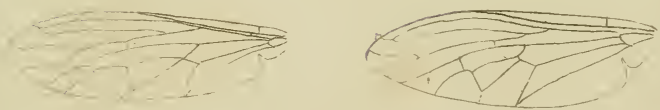

工

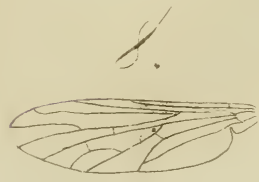





$$
\text { pl. }
$$

/.

2.

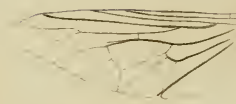

.”.

Ls.

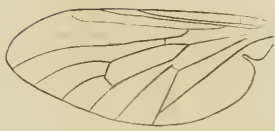

(i)

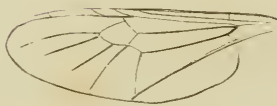

$\sim$

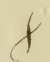







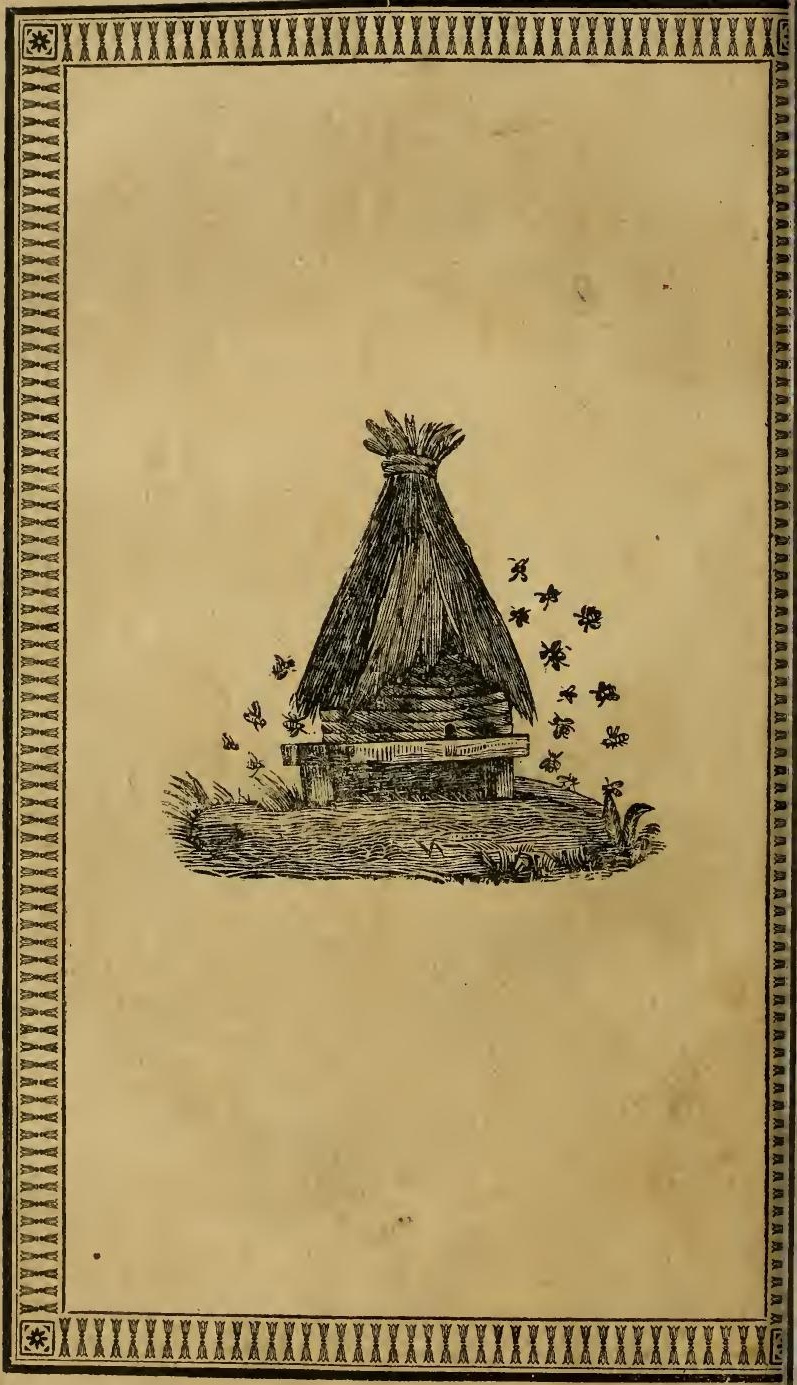





$1 I I S N I$

NVINOSHLIWS

S $\exists 18 \forall y 817^{-}$

LIBRARIES SMITHSONIAP

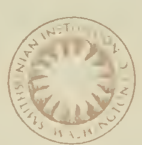

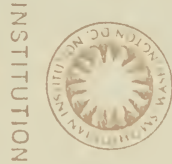

$z$
0
-1
-1
$c$
$=-1$
0
$z$

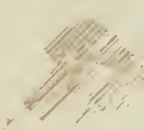

$A R I E S$

SMITHSONIAN
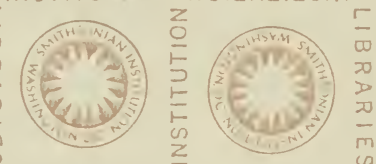

NYINOSHIIWS
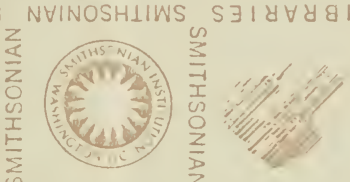

$z$
$\vdots$
$z$
0
0
$x$
$\vdots$
$\sum$

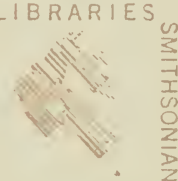

SMITHSONIAN INSTITUTION

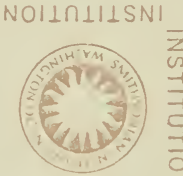

NVINOSHIIWS
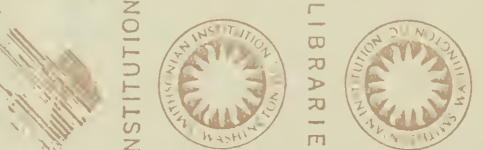

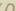

SMITHSONIAN

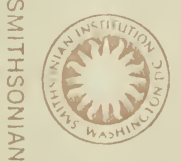

NHINOSHIIWS

A I S SNH
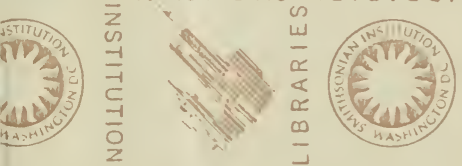

0
3
$\exists$
1
4
0
$\frac{1}{2}$
$\frac{1}{2}$

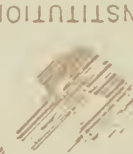

$z_{1}$
2
0
$\frac{1}{1}$
$\frac{5}{n}$

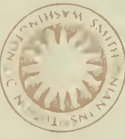

NHINOSHLIW

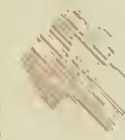

SMITHSONIA
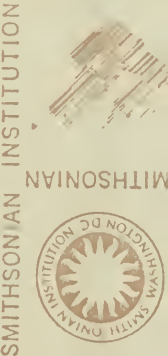

$\bar{z}$
w
$=$
$\overline{1}$
$\overline{1}$
$\overline{0}$
$z$

RARIES SMITHSONIAN

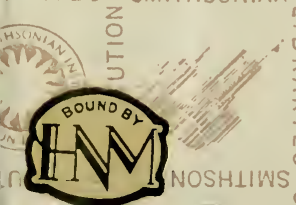

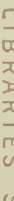
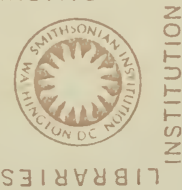
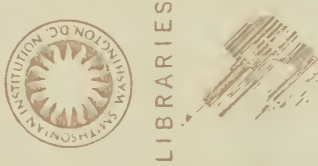

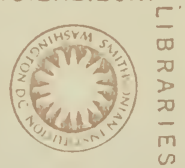

LIBRARIES
NVINOSHIIW

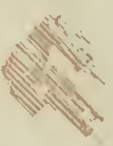


SMITHSONIAN INSTITUTION LIBRARIES

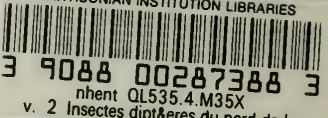

insectes dipt\&eres du nord de la 